\title{
Magnetic resonance imaging for evaluation of gastric motor function.
}

Citation for published version (APA):

Haans, J. J. (2012). Magnetic resonance imaging for evaluation of gastric motor function. [Doctoral Thesis, Maastricht University]. Universiteit Maastricht. https://doi.org/10.26481/dis.20120622jh

Document status and date:

Published: 01/01/2012

DOI:

10.26481/dis.20120622jh

Document Version:

Publisher's PDF, also known as Version of record

\section{Please check the document version of this publication:}

- A submitted manuscript is the version of the article upon submission and before peer-review. There can be important differences between the submitted version and the official published version of record.

People interested in the research are advised to contact the author for the final version of the publication, or visit the DOI to the publisher's website.

- The final author version and the galley proof are versions of the publication after peer review.

- The final published version features the final layout of the paper including the volume, issue and page numbers.

Link to publication

\footnotetext{
General rights rights.

- You may freely distribute the URL identifying the publication in the public portal. please follow below link for the End User Agreement:

www.umlib.nl/taverne-license

Take down policy

If you believe that this document breaches copyright please contact us at:

repository@maastrichtuniversity.nl

providing details and we will investigate your claim.
}

Copyright and moral rights for the publications made accessible in the public portal are retained by the authors and/or other copyright owners and it is a condition of accessing publications that users recognise and abide by the legal requirements associated with these

- Users may download and print one copy of any publication from the public portal for the purpose of private study or research.

- You may not further distribute the material or use it for any profit-making activity or commercial gain

If the publication is distributed under the terms of Article $25 \mathrm{fa}$ of the Dutch Copyright Act, indicated by the "Taverne" license above, 


\section{Magnetic Resonance Imaging for Evaluation of Gastric Motor Function}


(C) 2012 Jeoffrey Haans, Maastricht

Layout: Tiny Wouters

Production: Ridderprint B.V.

ISBN: 978-90-5335-554-1

Printing of this thesis was financially supported by Philips Healthcare, Medical Measurement Systems B.V., Laboratorium voor Klinische en Experimentele Beeldverwerking, Merck Sharp \& Dohme B.V., ABBOTT immunology, Ipsen Farmaceutica B.V., Tramedico B.V., Guerbet Nederland B.V., Nederlandse Vereniging voor Gastroenterologie. 


\title{
Magnetic Resonance Imaging for Evaluation of Gastric Motor Function
}

\author{
PROEFSCHRIFT
}

ter verkrijging van de graad van doctor aan de Universiteit Maastricht, op gezag van de Rector Magnificus, prof. mr. G.P.M.F. Mols,

volgens het besluit van het College van Decanen,

in het openbaar te verdedigen

op vrijdag 22 juni 2012 om 14.00 uur

door

Jeoffrey Josephus Leonardus Haans 


\section{Promotores:}

Prof. dr. A.A.M. Masclee

Prof. dr. A. de Roos, Universiteit Leiden

\section{Beoordelingscommissie:}

Prof. dr. R.G.H. Beets-Tan, voorzitter

Em. prof. dr. L.M.A. Akkermans, Universiteit Utrecht

Prof. dr. C.H.C. Dejong

Prof. dr. A.M.W.J. Schols 



\section{Contents}

Chapter 1 Introduction 9

Chapter 2 Review article: diagnosis and management of gastroparesis 21

Chapter 3 Gastric accommodation and motility are influenced by the 35 barostat device: assessment with Magnetic Resonance Imaging

Chapter 4 Gastric volume changes in response to a meal: validation of Magnetic Resonance Imaging versus the barostat

Chapter 5 Effect of sildenafil on gastric motor function measured with Magnetic Resonance Imaging

Chapter 6 Non-invasive measurement of early postprandial volume changes in functional dyspepsia using Magnetic Resonance Imaging

Chapter 7 Comparison of gastric emptying determined by stable isotope breath test and Magnetic Resonance Imaging during simultaneous recording

Chapter 8 Effect of somatostatin on gastric motility and emptying in health and functional dyspepsia, assessed with Magnetic Resonance Imaging

Chapter 9 Intragastric acidification inhibits motilin-induced phase III activity in humans

Chapter 10 Summary and General discussion

Dankwoord

Curriculum vitae 



\section{Chapter 1}

Introduction

J.J.L. Haans A.A.M. Masclee 


\section{Introduction}

The function of the stomach in the digestive phase consists of storage of a meal, secretion of acid and enzymes, mixing of nutrients and gastric contents, degradation to smaller particles and subsequent transport to the more distal duodenum. The motor function of the stomach consists of several aspects. Gastric accommodation is the response of the proximal stomach to a volume load, mostly food. Contractions are peristaltic waves, either propagating or non-propagating that grind and transport intragastric contents from proximal to distal in the stomach and eventually in well controlled smaller portions towards the duodenum. Gastric emptying is the transport of intragastric contents, i.e. food and secretory products, from stomach to duodenum.

All these aspects of gastric motility are relevant for the motor and transport function and can be studied separately using different techniques, both invasive and noninvasive.

\section{Gastric emptying}

Gastric emptying can be measured directly using scintigraphy or other imaging modalities (Magnetic Resonance Imaging, Single-Photon Emission Computed Tomography, ultrasonography) or indirectly using tests that detect oral ingested markers that are absorbed and detected in blood or exhaled air (i.e. stable isotopes, acetaminophen) or tests that require gastrointestinal intubation and aspiration of gastric contents ${ }^{1-5}$. These techniques are used to assess gastric emptying for liquids and solids in both research and clinical settings. Each of these techniques has its advantages and disadvantages. Disadvantages include radiation exposure during scintigraphy, technical difficulties in measuring proximal stomach regions by ultrasonography and interference with normal physiology during gastrointestinal intubation among others ${ }^{6}$. Conditions associated with delayed gastric emptying result in decreased nutrient intake, malnutrition and weight loss. In addition, gastric stasis leads to symptoms of dyspepsia, fullness, prolonged satiation, nausea and vomiting. On the other hand, accelerated or too rapid gastric emptying may also cause symptoms, especially dumping like symptoms. For clinical purposes, techniques that measure gastric emptying in a reliable and reproducible way may help facilitate a more precise diagnosis and more optimal management of many upper gastrointestinal symptoms and disorders. In the past decades attention has been drawn towards Magnetic Resonance Imaging (MRI). Feinle et al. ${ }^{6}$ have shown that it is feasible to utilize MRI for the evaluation of gastric emptying not only for liquid, but also for solid and mixed solid/liquid meals. Measurement of gastric emptying with MRI has been validated against scintigraphy for liquid and solid meals $s^{6-8}$. Scintigraphy is still considered the gold standard for evaluation of gastric emptying, but one should keep in mind its methodological limitations including 
count attenuation, Compton scatter, down scatter and imaging overlap ${ }^{9}$. Due to costs and radiation exposure other, non-invasive, techniques are urgently needed.

\section{Gastric accommodation}

The stomach can be divided into two functional parts: the proximal stomach (corpus and fundus) and distal stomach (antrum). The proximal stomach has a reservoir function regulated by tonic contractions. This means that the proximal stomach is capable of increasing its volume while maintaining the same intragastric pressure. The distal stomach grinds the meal and empties the stomach.

Gastric accommodation, a vagally mediated reflex that occurs postprandial in the proximal stomach, results in reduction of gastric tone and provides a reservoir for the meal. This allows ingestion of a considerable meal volume without an increase in intragastric pressure or gastric wall tension. Gastric accommodation is thought to consist of two parts: receptive and adaptive relaxation. Receptive relaxation is a vagally mediated reflex, known to dilate the corpus-fundus region of the stomach in response to swallowing or esophageal stimulation ${ }^{10}$. Adaptive relaxation is an intrinsic vagovagal reflex resulting in a reduction in gastric tone and an increase in compliance, allowing solid or liquid meals to be consumed and stored ${ }^{10,11}$.

In the past, dyspeptic symptoms, such as early satiety, have been associated with an impaired gastric accommodation response of the proximal stomach ${ }^{12-16}$. Moragas et al. ${ }^{17}$ were the first to describe the process of gastric accommodation using the barostat device. Ever since the introduction of this device numerous papers have been published concerning gastric accommodation in health and disease, and in response to pharmacological interventions ${ }^{12,18-21}$. The barostat technique is currently considered the gold standard to quantify meal or otherwise induced gastric accommodation. Apart from the barostat, the MRI technique hast the potential to correctly measure volume changes and an accommodation (or relaxation) response of the (proximal) stomach ${ }^{22}$. In a previous study an excellent correlation for proximal gastric motility was shown through simultaneous comparison of MRI and the barostat technique ${ }^{23}$. Measurement of accommodation of the stomach is important to increase our knowledge of gastric physiology and to better diagnose conditions with disturbed accommodation.

\section{Gastric contractions}

Contractions can be measured using invasive water-perfused or solid-state catheters or by non-invasive imaging techniques ${ }^{24-28}$. Water-perfused manometry has been used for several decades to measure proximal gastrointestinal motility, especially esophageal motility, and is nowadays also used to measure antropyloroduodenal motility $^{24,25}$. However, phasic and lumen-occlusive contractions mostly occur in the distal part of the stomach. The wall of the proximal human stomach is considered to produce mainly tonic, non-occlusive and slow wave fundic contractions that might 
contribute to transfer of gastric contents from the proximal to the distal stomach, but do not have a major contribution to propulsion of gastric contents ${ }^{29,30}$. Assessment of gastrointestinal motility is relevant in order to diagnose specific motility disorders, such as chronic intestinal pseudo-obstruction syndromes, gastroparesis and functional dyspepsia. Water-perfused or solid-state manometry is a time consuming technique, solely employed in tertiary referral centers with specialized motility units. Moreover, manometry is an invasive procedure that may cause certain discomfort ${ }^{24,25}$ and several investigators have suggested that the use of an intestinal tube may influence motility and thereby interfere with physiological function ${ }^{31,32}$.

Boulby et al..$^{33}$ were the first to use MRI for measurement of antral contractions and antropyloric flow. They managed to successfully measure flow events, flow direction and peak flow velocity, but only in very short periods (5 minutes) and with a large sampling interval of 10 seconds. The development of MRI techniques is still in progress. Due to technical improvements in both hardware and software the time needed to produce "good quality" images has been markedly reduced. Recent studies have shown that MRI enables assessment of both proximal and distal gastric contractions simultaneously ${ }^{23,27}$. The non-invasive character of MRI, the absence of an intragastric balloon and the possibility to measure different parameters simultaneously in both the proximal and distal stomach are important advantages of MRI. Therefore MRI holds the potential and the promise for a complete and noninvasive evaluation of gastric motor function, including proximal and distal contractions.

\section{Functional dyspepsia}

Functional dyspepsia (FD) is defined by the new Rome III criteria as the presence of symptoms thought to originate in the gastroduodenal region, in the absence of any organic, systemic, or metabolic disease that is likely to explain the symptoms ${ }^{34}$. Symptoms that are frequently present include bothersome postprandial fullness, early satiation, epigastric pain and/or epigastric burning. Nowadays FD is subdivided in two main categories: postprandial distress syndrome and epigastric pain syndrome. The pathophysiology of FD is not well understood and seems to include a variety of abnormalities in both motor and viscerosensory functions. Motor disturbances in a subgroup of FD patients include delayed gastric emptying, unsuppressed phasic contractile activity, impaired accommodation and small intestinal dysmotility. Viscerosensory disturbances include hypersensitivity to distension and altered duodenal sensitivity to acid and/or lipids ${ }^{35}$. Postprandial proximal gastric accommodation is impaired in $40 \%$ of FD patients and related to symptoms of early satiety ${ }^{12,36,37}$. The gastric barostat is considered the reference method for quantifying gastric accommodation in response to a meal. However, the technique is invasive, uncomfortable and stressful to many subjects ${ }^{38}$. More recently Single Photon Emission Computed Tomography (SPECT) has been introduced and 
applied as a technique to determine impaired accommodation in FD patients ${ }^{39,40}$. SPECT is an imaging technique that uses radioactive isotopes to visualize the gastric mucosa. The need for radioactive isotopes and the poor temporal resolution are the largest disadvantages and drawbacks of the SPECT technique. Functional dyspepsia is often treated with prokinetic drugs or acid suppression. Controlled studies have failed to demonstrate a substantial beneficial effect in patients with FD. Since FD is common in the general population and barostat studies have revealed new concepts for therapy (hypersensitivity, impaired accommodation), research in pharmacology is focusing on development of new drugs for treatment of dyspepsia. In the past Mearadji et al. ${ }^{41}$ have pointed to a potentially beneficial effect of somatostatin on visceral sensitivity. Indeed, in open studies an effect of somatostatin or its longacting analogue octreotide in functional dyspepsia has been suggested ${ }^{42}$. Nevertheless, the mechanism of action of somatostatin in FD remains unclear.

In the past decade, MRI has become an attractive, non-invasive alternative to investigate not only gastric emptying, but also accommodation and motility $6,23,27,43-46$. A previous study has validated $\mathrm{MRI}$ as a technique to measure proximal gastric motility and volume changes, comparing MRI and the barostat technique simultaneously ${ }^{23}$. 


\section{Aims and outline of the thesis}

The chapters in this thesis deal with several aspects of gastric motor function. Special attention will be given to the application of Magnetic Resonance Imaging (MRI) to explore in detail the different aspects of gastric motility, such as gastric relaxation/accommodation, gastric emptying and contractions.

In Chapter 2 an overview is provided on diagnosis and management of gastroparesis. Gastroparesis is a disorder characterized by a delay in gastric emptying of a meal in the absence of a mechanical gastric outlet obstruction. Prior to exploring gastric motility in detail we reviewed the current literature with respect to diagnosis and treatment of gastroparesis. A PubMed search was performed using search terms as gastroparesis, gastric retention, gastric emptying, accommodation, manometry, prokinetics, antiemetics, metoclopramide, domperidone, erythromycin, botulinum toxin, gastric pacing. Relevant studies were identified and original articles and reviews were collected. References in these articles were examined for relevance and included where appropriate.

Chapters 3 to 6 deal with several aspects of gastric accommodation. The barostat is considered the gold standard for evaluation of proximal gastric motility, especially for the accommodation response to a meal. The procedure is invasive because it requires oral intubation and positioning of a catheter and bag into the stomach and is not always well tolerated. Moreover, the barostat itself may influence proximal gastric motility.

A previous study ${ }^{23}$ compared gastric volumes determined by MRI in the presence of a barostat bag to barostat-determined volumes during fasting. In addition, the effect of pharmacological interventions known to relax (glucagon) and contract (erythromycin) the stomach was studied. However the volume response to a meal has not been evaluated ${ }^{38}$. Aim of Chapter 3 was to study whether the postprandial accommodation response of the stomach, observed with the barostat technique, is present in the absence of a barostat bag and whether the barostat technique interferes with gastric physiology. Direct and simultaneous comparison of barostat to MRI has enabled this study.

In order to further validate MRI as a tool to study the different aspects of gastric motility, in Chapter 4, we have compared in vivo barostat determined volumes against MRI determined volumes in response to a meal.

In Chapter 5 the effect of sildenafil on gastric emptying and relaxation has been evaluated with MRI. With respect to accommodation of the proximal stomach, at a cellular and molecular level, nitric oxide (NO) and nitrinergic neurons are involved. NO induced smooth muscle relaxation involves cyclic guanosine monophosphate (cGMP) production that is degraded by phosphodiesterase type 5 (PDE-5). Sildenafil, a PDE-5 inhibitor may affect fasting and postprandial motor function. Indeed, using a barostat, sildenafil significantly increases proximal gastric volume and delays gastric emptying of liquids, confirming that meal induced postprandial gastric 
accommodation involves the activation of a nitrenergic pathway ${ }^{47}$. We studied the effect of the PDE-5 inhibitor sildenafil on gastric motility using MRI, focusing on gastic volume responses, gastric emptying and intragastric meal distribution.

Impaired gastric accommodation is one of the pathophysiological mechanisms in functional dyspepsia (FD). Several studies using the barostat technique found impaired gastric accommodation in subgroups of patients with FD ${ }^{12,48}$. Chapter 6 explores whether $\mathrm{MRI}$ is an alternative, non-invasive technique to measure early postprandial volume changes of the stomach in health and disease (FD).

In the past decade an increasing number of studies has been performed using the stable isotope breath test method. Most commonly employed are the ${ }^{13} \mathrm{C}$-octanoic acid and ${ }^{13} \mathrm{C}$-acetate breath test for solid and liquid gastric emptying respectively ${ }^{49}$. In these tests the stable ${ }^{13} \mathrm{C}$-isotope is mixed and incorporated into either a solid or liquid meal. The meal is ingested and approximately $90 \%$ of the active compound is absorbed in the duodenum. Thereafter ${ }^{13} \mathrm{CO}_{2}$ is formed in the liver when the active compound is disintegrated. This ${ }^{13} \mathrm{CO}_{2}$ is exhaled in breath. From the exhaled breath the ratio of ${ }^{13} \mathrm{CO}_{2}$ and ${ }^{12} \mathrm{CO}_{2}$ is determined and parameters for gastric emptying are determined. Since the ${ }^{13} \mathrm{C}$-breath test is an indirect test, it needs validation against direct gastric emptying tests, preferably during simultaneous comparison, because gastric emptying may vary on a day-to-day basis. Data on the accuracy of the ${ }^{13} \mathrm{C}$-breath test for measurement of gastric emptying compared to scintigraphy are conflicting ${ }^{4,9,50-58}$. Various mathematical models have been employed to increase the accuracy of the ${ }^{13} \mathrm{C}$-breath test in determining parameters of gastric emptying, such as half-emptying time, compared to direct measurement of gastric emptying. These models have been applied to correct for distribution and elimination of the isotope through the ${ }^{13} \mathrm{CO}_{2}$ excretion process.

Recent studies indicate that MRI is possibly the most physiological and valid method for investigation of gastric function, especially gastric motility and emptying ${ }^{59}$. Up to now, evaluation of gastric emptying by MRI has been limited to research settings. This may change in the near future because MRI allows accurate evaluation of not only volume changes and emptying of gastric contents but also allows contraction analyses. When MRI is considered the most valid method, non-invasive techniques like the stable isotope breath test should preferably be compared with MRI. Aim of the study presented in Chapter 7 was to compare the indirect stable isotope breath test technique with the direct MRI technique for both solid and liquid gastric emptying during simultaneous recording. In addition different mathematical models currently used to determine gastric emptying parameters in stable isotope breath test analysis were compared to MRI.

Delayed gastric emptying has been identified as a possible pathophysiological mechanism in Functional Dyspepsia (FD). The cyclic tetradecapeptide somatostatin has numerous effects on the gastrointestinal tract $^{60}$. Controlled data on the effect of somatostatin on gastric emptying are conflicting and data on the effect of somatostatin on postprandial symptoms in FD are lacking ${ }^{41,42,61-65}$. In Chapter 8 we 
have investigated the effect of somatostatin on gastric volumes, gastric emptying, motility and symptoms in health and patients with FD using a single technique, i.e. MRI.

In Chapter 9 antropyloroduodenal motility was studied by water-perfused manometry. Gastrointestinal motility can be divided in a digestive and interdigestive part. The interdigestive part is characterized by the migrating motor complex (MMC) with onset of phases III in the stomach or duodenum. These phases III are relevant as intestinal housekeeper, extracting debris and nutritional remnants from stomach and small intestine ${ }^{66}$. In this chapter we have evaluated the interdigestive conditions under which phases III are generated. The variables we tested were intragastric $\mathrm{pH}$ and infusion of motilin, a gastrointestinal peptide regulating the MMC pattern ${ }^{67,68}$. We used a randomized, placebo-controlled crossover design to study the effect of gastric acidification on motilin-induced interdigestive antropyloroduodenal motility. Each experiment started after a spontaneous occurring phase III and consisted of intragastric infusion of either saline or acid and intravenous infusion of either saline or motilin.

In the studies performed in the Chapters 3-8 we have employed MRI to study gastric motor function. Different MRI protocols have been used to measure the various aspects of gastric motor function. Each protocol consists of different scanning modules. For volume measurement we have used two-dimensional volume scans, enabling us to calculate volumes. For motility measurement we have used twodimensional dynamic scan sequences, enabling us to visualize motility.

Finally, the results of the studies described in this thesis are summarized and discussed in Chapter 10. 


\section{References}

1. Camilleri M. New imaging in neurogastroenterology: an overview. NeurogastroenterolMotil 2006; 18:805-12.

2. Kondo T. Routine gastric emptying tests. J Gastroenterol 2000;35:476-8.

3. Kim DY, Myung SJ, Camilleri M. Novel testing of human gastric motor and sensory functions: rationale, methods, and potential applications in clinical practice. Am J Gastroenterol 2000;95: 3365-73.

4. Ghoos YF, Maes BD, Geypens BJ, Mys G, Hiele MI, Rutgeerts PJ, Vantrappen G. Measurement of gastric emptying rate of solids by means of a carbon-labeled octanoic acid breath test. Gastroenterology 1993;104:1640-7.

5. Braden B, Adams S, Duan LP, Orth KH, Maul FD, Lembcke B, Hor G, Caspary WF. The [13C]acetate breath test accurately reflects gastric emptying of liquids in both liquid and semisolid test meals. Gastroenterology 1995;108:1048-55.

6. Feinle $C$, Kunz P, Boesiger P, Fried M, Schwizer W. Scintigraphic validation of a magnetic resonance imaging method to study gastric emptying of a solid meal in humans. Gut 1999;44:106-11.

7. Kunz P, Crelier GR, Schwizer W, Borovicka J, Kreiss C, Fried M, Boesiger P. Gastric emptying and motility: assessment with MR imaging--preliminary observations. Radiology 1998;207:33-40.

8. Kunz P, Feinle C, Schwizer W, Fried M, Boesiger P. Assessment of gastric motor function during the emptying of solid and liquid meals in humans by MRI. J Magn Reson Imaging 1999;9:75-80.

9. Perri F, Clemente R, Festa V, Andriulli A. 13C-Octanoic acid breath test: valueless test for gastric emptying? Gastroenterology 1998;114:857-9.

10. Gilja OH, Lunding J, Hausken T, Gregersen H. Gastric accommodation assessed by ultrasonography. World JGastroenterol 2006;12:2825-9.

11. Mundt MW, Hausken T, Samsom M. Effect of intragastric barostat bag on proximal and distal gastric accommodation in response to liquid meal. AmJPhysiol GastrointestLiver Physiol 2002;283:G681-G6.

12. Tack J, Piessevaux H, Coulie B, Caenepeel P, Janssens J. Role of impaired gastric accommodation to a meal in functional dyspepsia. Gastroenterology 1998;115:1346-52.

13. Lee KJ, Kindt S, Tack J. Pathophysiology of functional dyspepsia. Best Pract Res Clin Gastroenterol 2004;18:707-16.

14. Van Oudenhove L, Vandenberghe J, Geeraerts B, Vos R, Persoons P, Fischler B, Demyttenaere K, Tack $J$. Determinants of symptoms in functional dyspepsia: gastric sensorimotor function, psychosocial factors or somatisation? Gut 2008;57:1666-73.

15. Bisschops R, Tack J. Dysaccommodation of the stomach: therapeutic nirvana? Neurogastro-enterol Motil 2007;19: 85-93.

16. Karamanolis G, Caenepeel P, Arts J, Tack J. Association of the predominant symptom with clinical characteristics and pathophysiological mechanisms in functional dyspepsia. Gastroenterology 2006; 130:296-303.

17. Moragas G, Azpiroz F, Pavia J, Malagelada JR. Relations among intragastric pressure, postcibal perception, and gastric emptying. Am J Physiol 1993;264:G1112-G7.

18. Mearin F, Cucala M, Azpiroz F, Malagelada JR. The origin of symptoms on the brain-gut axis in functional dyspepsia. Gastroenterology 1991;101:999-1006.

19. Klatt S, Bock W, Rentschler J, Beckh K, Adler G. Effects of tropisetron, a 5-HT3 receptor antagonist, on proximal gastric motor and sensory function in nonulcer dyspepsia. Digestion 1999;60:147-52.

20. van der Schaar PJ, Bremer Y, Lamers CB, Masclee AA. Role of cholecystokinin in relaxation of the proximal stomach. Scand J Gastroenterol 2001;36:361-6.

21. Kuiken SD, Vergeer M, Heisterkamp SH, Tytgat GN, Boeckxstaens GE. Role of nitric oxide in gastric motor and sensory functions in healthy subjects. Gut 2002;51:212-8.

22. Schwizer W, Steingotter A, Fox M, Zur T, Thumshirn M, Bosiger P, Fried M. Non-invasive measurement of gastric accommodation in humans. Gut 2002;51(Suppl 1):i59-i62.

23. de Zwart IM, Mearadji B, Lamb HJ, Eilers PH, Masclee AA, de Roos A, Kunz P. Gastric motility: comparison of assessment with real-time MR imaging or barostat measurement initial experience. Radiology 2002;224:592-7. 
24. Verhagen MA, Samsom M, Jebbink RJ, Smout AJ. Clinical relevance of antroduodenal manometry. Eur J Gastroenterol Hepatol 1999;11:523-8.

25. Byrne KG, Quigley EM. Antroduodenal manometry: an evaluation of an emerging methodology. Dig Dis 1997; 15 Suppl 1:53-63.

26. Marciani L, Young P, Wright J, Moore R, Coleman N, Gowland PA, Spiller RC. Antral motility measurements by magnetic resonance imaging. Neurogastroenterol Motil 2001;13:511-8.

27. Wright J, Evans D, Gowland P, Mansfield P. Validation of antroduodenal motility measurements made by echo-planar magnetic resonance imaging. Neurogastroenterol Motil 1999;11:19-25.

28. Kwiatek MA, Fox MR, Steingoetter A, Menne D, Pal A, Fruehauf H, Kaufman E, Forras-Kaufman Z, Brasseur JG, Goetze O, Hebbard GS, Boesiger P, Thumshirn M, Fried M, Schwizer W. Effects of clonidine and sumatriptan on postprandial gastric volume response, antral contraction waves and emptying: an MRI study. Neurogastroenterol Motil 2009;21:928-e71.

29. Nguyen NQ, Fraser RJ, Bryant LK, Holloway RH. Functional association between proximal and distal gastric motility during fasting and duodenal nutrient stimulation in humans. Neurogastroenterol Motil 2007;19:638-45.

30. Kelly KA. Gastric emptying of liquids and solids: roles of proximal and distal stomach. Am J Physiol 1980;239:G71-6.

31. Read NW, Al Janabi MN, Bates TE, Barber DC. Effect of gastrointestinal intubation on the passage of a solid meal through the stomach and small intestine in humans. Gastroenterology 1983;84:1568-72.

32. Medhus AW, Sandstad O, Bredesen J, Husebye E. Delay of gastric emptying by duodenal intubation: sensitive measurement of gastric emptying by the paracetamol absorption test. Aliment Pharmacol Ther 1999;13:609-20.

33. Boulby P, Moore R, Gowland P, Spiller RC. Fat delays emptying but increases forward and backward antral flow as assessed by flow-sensitive magnetic resonance imaging. Neurogastroenterol Motil 1999;11:27-36.

34. Tack J, Talley NJ, Camilleri M, Holtmann G, Hu P, Malagelada JR, Stanghellini V. Functional gastroduodenal disorders. Gastroenterology 2006;130:1466-79.

35. Tack J, Bisschops R, Sarnelli G. Pathophysiology and treatment of functional dyspepsia. Gastroenterology 2004;127:1239-55.

36. Coffin B, Azpiroz F, Guarner F, Malagelada JR. Selective gastric hypersensitivity and reflex hyporeactivity in functional dyspepsia. Gastroenterology 1994;107:1345-51.

37. Mittal RK, Hebbard G. An attempt to define the pathophysiological abnormality in patients with nonulcer dyspepsia using a gastric barostat. Gastroenterology 1994;107:596-7.

38. De Schepper HU, Cremonini F, Chitkara D, Camilleri M. Assessment of gastric accommodation: overview and evaluation of current methods. Neurogastroenterol Motil 2004;16:275-85.

39. Kim DY, gado-Aros S, Camilleri M, Samsom M, Murray JA, O'Connor MK, Brinkmann BH, Stephens DA, Lighvani SS, Burton DD. Noninvasive measurement of gastric accommodation in patients with idiopathic nonulcer dyspepsia. Am J Gastroenterol 2001;96:3099-105.

40. Bredenoord AJ, Chial HJ, Camilleri M, Mullan BP, Murray JA. Gastric accommodation and emptying in evaluation of patients with upper gastrointestinal symptoms. Clin Gastroenterol Hepatol 2003;1: 264-72.

41. Mearadji B, Straathof JW, Biemond I, Lamers CB, Masclee AA. Effects of somatostatin on proximal gastric motor function and visceral perception. Aliment Pharmacol Ther 1998;12:1163-9.

42. Ducrotte P, Maillot C, Leroi AM, Lalaude O, Colin R, Denis P. Octreotide in refractory functional epigastric pain with nutritional impairment--an open study. Aliment Pharmacol Ther 1999;13:969-75.

43. de Zwart IM, Haans JJ, Verbeek P, Eilers PH, de Roos A, Masclee AA. Gastric accommodation and motility are influenced by the barostat device: Assessment with magnetic resonance imaging. Am J Physiol Gastrointest Liver Physiol 2007;292:G208-G14.

44. Fraser R, Schwizer W, Borovicka J, Asal K, Fried M. Gastric motility measurement by MRI. Dig Dis Sci 1994;39:20S-3S.

45. Marciani L, Gowland PA, Fillery-Travis A, Manoj P, Wright J, Smith A, Young P, Moore R, Spiller RC. Assessment of antral grinding of a model solid meal with echo-planar imaging. Am J Physiol Gastrointest Liver Physiol 2001;280:G844-G9.

46. Schwizer W, Maecke H, Fried M. Measurement of gastric emptying by magnetic resonance imaging in humans. Gastroenterology 1992;103:369-76. 
47. Sarnelli G, Sifrim D, Janssens J, Tack J. Influence of sildenafil on gastric sensorimotor function in humans. Am J Physiol Gastrointest Liver Physiol 2004;287:G988-G92.

48. Boeckxstaens GE, Hirsch DP, Kuiken SD, Heisterkamp SH, Tytgat GN. The proximal stomach and postprandial symptoms in functional dyspeptics. Am J Gastroenterol 2002;97:40-8.

49. Braden B. Methods and functions: Breath tests. Best Pract Res Clin Gastroenterol 2009;23:337-52.

50. Bromer MQ, Kantor SB, Wagner DA, Knight LC, Maurer AH, Parkman HP. Simultaneous measurement of gastric emptying with a simple muffin meal using [13C]octanoate breath test and scintigraphy in normal subjects and patients with dyspeptic symptoms. Dig Dis Sci 2002;47:1657-63.

51. Punkkinen J, Konkka I, Punkkinen O, Korppi-Tommola T, Farkkila M, Koskenpato J. Measuring gastric emptying: comparison of 13C-octanoic acid breath test and scintigraphy. Dig Dis Sci 2006;51:262-7.

52. Chen CP, Chen CY, Lu CL, Chang FY, Lee SD, Chu LS, Liu RS, Wu HC. Infrared spectrometry based 13Coctanoic acid breath test in measuring human solid gastric emptying. J Gastroenterol Hepatol 2003;18:41-6.

53. Chey WD, Shapiro B, Zawadski A, Goodman K. Gastric emptying characteristics of a novel (13)Coctanoate-labeled muffin meal. J Clin Gastroenterol 2001;32:394-9.

54. Choi MG, Camilleri M, Burton DD, Zinsmeister AR, Forstrom LA, Nair KS. [13C]octanoic acid breath test for gastric emptying of solids: accuracy, reproducibility, and comparison with scintigraphy. Gastroenterology 1997;112:1155-62.

55. Choi MG, Camilleri M, Burton DD, Zinsmeister AR, Forstrom LA, Nair KS. Reproducibility and simplification of $13 \mathrm{C}$-octanoic acid breath test for gastric emptying of solids. Am J Gastroenterol 1998;93:92-8.

56. Maes BD, Ghoos YF, Geypens BJ, Mys G, Hiele MI, Rutgeerts PJ, Vantrappen G. Combined carbon-13glycine/carbon-14-octanoic acid breath test to monitor gastric emptying rates of liquids and solids. J Nucl Med 1994;35:824-31.

57. Maes BD, Mys G, Geypens BJ, Evenepoel P, Ghoos YF, Rutgeerts PJ. Gastric emptying flow curves separated from carbon-labeled octanoic acid breath test results. Am J Physiol 1998;275:G169-G75.

58. Dickman R, Steinmetz A, Bernnstine H, Groshar D, Niv Y. A novel continuous breath test versus scintigraphy for gastric emptying rate measurement. J Clin Gastroenterol 2011;45:22-5.

59. Fruehauf $H$, Steingoetter A, Fox MR, Kwiatek MA, Boesiger P, Schwizer W, Fried M, Thumshirn M, Goetze $O$. Characterization of gastric volume responses and liquid emptying in functional dyspepsia and health by MRI or barostat and simultaneous C-acetate breath test. Neurogastroenterol Motil 2009;21:697-e37.

60. Harris AG. Somatostatin and somatostatin analogues: pharmacokinetics and pharmacodynamic effects. Gut 1994;35:S1-S4.

61. van Berge Henegouwen MI, van Gulik TM, Akkermans LM, Jansen JB, Gouma DJ. The effect of octreotide on gastric emptying at a dosage used to prevent complications after pancreatic surgery: a randomised, placebo controlled study in volunteers. Gut 1997;41:758-62.

62. von der Ohe MR, Camilleri M, Thomforde GM, Klee GG. Differential regional effects of octreotide on human gastrointestinal motor function. Gut 1995;36:743-8.

63. Foxx-Orenstein A, Camilleri M, Stephens D, Burton D. Effect of a somatostatin analogue on gastric motor and sensory functions in healthy humans. Gut 2003;52:1555-61.

64. Maes BD, Ghoos YF, Geypens BJ, Hiele MI, Rutgeerts PJ. Influence of octreotide on the gastric emptying of solids and liquids in normal healthy subjects. Aliment Pharmacol Ther 1995;9:11-8.

65. Okamoto E, Haruma K, Hata J, Tani H, Sumii K, Kajiyama G. Effects of octreotide, a somatostatin analogue, on gastric function evaluated by real-time ultrasonography. Aliment Pharmacol Ther 1997;11:177-84.

66. Vantrappen G, Janssens J, Hellemans J, Ghoos Y. The interdigestive motor complex of normal subjects and patients with bacterial overgrowth of the small intestine. J Clin Invest 1977;59:1158-66.

67. Luiking YC, Akkermans LM, Peeters TL, Cnossen PJ, Nieuwenhuijs VB, Vanberge -Henegouwen GP. Effects of motilin on human interdigestive gastrointestinal and gallbladder motility, and involvement of 5 HT3 receptors. Neurogastroenterol Motil 2002;14:151-9.

68. Kamerling IM, Van Haarst AD, Burggraaf J, Schoemaker HC, Biemond I, Jones R, Cohen AF, Masclee AA. Dose-related effects of motilin on proximal gastrointestinal motility. Aliment Pharmacol Ther 2002;16:129-35. 


\section{Chapter 2}

Review article: diagnosis and management of gastroparesis

J.J.L. Haans

A.A.M. Masclee

Alimentary Pharmacology \& Therapeutics 2007;26 Suppl 2:37-46. 


\section{Abstract}

\section{Aims}

To provide an evidence-based overview on diagnosis and management of gastroparesis, i.e. delayed gastric emptying in the absence of a gastric outlet obstruction.

\section{Materials and Methods}

A PubMed search was performed using search terms including gastroparesis, gastric retention, gastric emptying, accommodation, manometry, prokinetics, antiemetics, metoclopramide, domperidone, erythromycin, botulinum toxin, gastric pacing. Relevant studies were identified and original articles and reviews were collected. References in these articles were examined for relevance and included where appropriate.

\section{Results}

Diagnosis of gastroparesis is based on the presence of symptoms such as nausea, vomiting and postprandial abdominal fullness and on an objectively determined delay in gastric emptying. The true prevalence of gastroparesis is unknown. Gastric emptying can be assessed by scintigraphy and stable isotope breath tests. Management of gastroparesis consists of dietary and lifestyle measures and/or pharmacological interventions (prokinetics, antiemetics, intrapyloric botulinum toxin injection) or other interventions that focus on adequate nutrient intake either through a nasoduodenal tube, percutaneous gastrostomy or jejunostomy.

\section{Conclusions}

Accurate diagnosis of gastroparesis requires an adequate protocol to measure gastric emptying. Treatment options in gastroparesis remain limited despite the disabling nature of the disorder. 


\section{Introduction}

Several mechanisms are involved in the process of gastric emptying. Gastric accommodation enables adaptation of the proximal stomach to a liquid or solid volume load, i.e. a meal. Antral contractions are required for grinding and transport of the meal toward the pyloric sphincter. Pyloric relaxation enables the titration of the grinded meal (chyme) into the duodenum and requires coordination of propulsive contractions in the stomach and duodenum. These actions are highly dependent on adequate neuronal and hormonal feedback mechanisms. The rate of gastric emptying is influenced by the composition of the ingested meal. Nonnutrient liquids are emptied almost immediately, whereas nutrient liquids and solids empty after a period of retention (lag phase) in a non-linear manner and linear manner respectively. Especially fat rich meals show a more prolonged emptying pattern, resulting from duodenal feedback mechanisms, in particular cholecystokinin. Gastroparesis is a disorder characterized by a delay in gastric emptying of a meal in the absence of a mechanical gastric outlet obstruction'.

\section{Prevalence}

The true prevalence of gastroparesis is unknown. It is assumed that up to $4 \%$ of the general population experiences symptoms of gastroparesis ${ }^{2}$.

In diabetes mellitus $5-12 \%$ of patients present with symptoms associated with delayed gastric emptying. However, when objectively determined with a gastric emptying test $30-50 \%$ of diabetics presented with delayed gastric emptying ${ }^{3}$. In functional dyspepsia $24-40 \%$ of patients have delayed gastric emptying ${ }^{4-7}$.

\section{Etiology}

The etiology of gastroparesis is diverse ${ }^{8}$. In approximately one third of cases gastroparesis is related to the presence of diabetes mellitus type I or II. Other causes include post-surgical conditions ${ }^{9-11}$, neurological disorders ${ }^{12,13}$, metabolic and systemic disorders (SLE, systemic sclerosis, amyloidosis, hypothyroidism, HIV) ${ }^{14,15}$ and inflammatory disorders of the gastrointestinal tract $^{16}$. The remaining one third of cases is of unknown cause, i.e. idiopathic.

\section{Diagnosis}

The diagnosis of gastroparesis is based on the presence of symptoms or typical signs combined with a delay in gastric emptying proven by objective methods. Mechanical outlet obstruction and other (extra) luminal pathology should be excluded preferably by gastrointestinal endoscopy. The presence of retained food in the stomach while fasted overnight or the presence of a bezoar in the stomach during endoscopy is highly suggestive for delayed gastric emptying. However, objective 
determination of delayed gastric emptying is required to establish a definite diagnosis of gastroparesis.

\section{Symptoms and signs}

Gastroparesis is associated with upper gastrointestinal symptoms such as nausea, vomiting and postprandial fullness ${ }^{17}$. Repeated vomiting several hours after eating is highly suggestive for gastroparesis ${ }^{1}$. Symptoms of idiopathic gastroparesis overlap with those of functional dyspepsia. Abdominal pain and discomfort predominates in functional dyspepsia, whereas nausea, vomiting, bloating, postprandial fullness and early satiety predominate in idiopathic gastroparesis ${ }^{18}$. Although symptoms of nausea, vomiting and postprandial fullness are associated with delayed gastric emptying, the correlation between the presence and intensity of symptoms and the degree of delayed gastric emptying, usually presented as half emptying time or percentage of gastric retention, is poor ${ }^{19,20}$.

Various systemic or local disorders may give rise to a delay in gastric emptying. Physicians should be aware that patients with gastroparesis might present at various departments such as the departments of gastroenterology, endocrinology (patients with diabetes mellitus) and surgery, but also at the departments of nephrology (chronic renal failure), neurology (Parkinson's disease, multiple sclerosis, cerebrovascular accidents) and rheumatology (SLE, systemic sclerosis, amyloidosis).

\section{Gastric emptying testing}

Scintigraphy is the gold standard for determining gastric emptying. As emptying is not only influenced by the mechanical properties of the gastrointestinal tract, but also depends on the composition of the meal, standardized measurement of gastric emptying is required to compare data between patients and institutions. Measurement of gastric emptying should be focused on the solid phase as emptying of the liquid phase is often preserved in gastroparesis. Adequate determination of delayed gastric emptying is obtained when the protocol is extended to at least 4 hours after meal ingestion. Shorter protocols tend to under detect patients with delayed gastric emptying ${ }^{21}$. Moreover, dynamic imaging, up to $90 \mathrm{~min}$ after consumption of the meal, provides half emptying times that are derived from mathematical extrapolation and could provide erroneous data, when the actual time point for half-emptying has not been reached. A useful protocol has been proposed, that consists of a low-fat meal and extents for 4 hours ${ }^{22}$. Control values for this protocol have been obtained in an international multi-center study in 123 healthy volunteers, where gastric retention $>60 \%$ at 2 hours and $>10 \%$ at 4 hours is abnormal. Control values depend on both the duration of the test and the composition of the meal, and when different between institutions or different from published data need to be determined for each gastric emptying measurement protocol separately. 


\section{Stable isotope breath test}

The non-invasive isotope breath test has been proposed as a valid test to measure gastric emptying of a solid meal in health and disease. Solid gastric emptying requires the use of ${ }^{13} \mathrm{C}$-octanoic acid or ${ }^{13} \mathrm{C}$-sodium octanoate as a substrate, whereas liquid gastric emptying requires ${ }^{13} \mathrm{C}$-sodium acetate as a substrate. The substrate is rapidly absorbed in the duodenum, transported to the liver and oxidized to ${ }^{13} \mathrm{CO}_{2}$ and exhaled. The ratio of ${ }^{13} \mathrm{CO}_{2} /{ }^{12} \mathrm{CO}_{2}$ in breath is used to determine the gastric emptying function ${ }^{23,24}$. Breath tests using the non-radioactive stable isotope ${ }^{13} \mathrm{C}$ have been validated against scintigraphy for measuring gastric emptying in health ${ }^{23,25}$ and disease ${ }^{26,27}$ and shows a good reproducibility ${ }^{28-30}$. However, it should be noted that the parameters (half-emptying and lag time) derived from scintigraphy and the ${ }^{13} \mathrm{C}$ isotope breath test are not interchangeable.

\section{Other techniques}

Several authors have pointed to Magnetic Resonance Imaging (MRI) ${ }^{31-33}$ and ultrasonography ${ }^{34,35}$ as techniques that allow the measurement of gastric emptying. Few data are available. MRI seems a promising technique to simultaneously measure not only gastric emptying but also motility and intragastric meal distribution. Results obtained with ultrasonography are particularly dependent on expertise and skills of the person performing the examination. Both techniques have been used only in research setting and need further validation in health and disease. MRI and ultrasonography provide the opportunity to non-invasively measure, not only gastric emptying, but also the mechanisms involved in gastric emptying; accommodation $33,36,37$, antral contractions $s^{38-40}$ and meal distribution ${ }^{41-44}$.

\section{Antropyloroduodenal manometry}

Antro(pyloro)duodenal manometry provides an objectively determined antral, duodenal and pyloric motor function. In gastroparesis several motor patterns are distinguished, including postprandial antral hypomotility due to infrequent contractions and/or low amplitudes, abnormal propagation of antroduodenal contractions, increased pyloric spasms, characterized by an increased tonic and phasic activity, and abnormal migrating motor complexes (MMC), originating less frequently from the stomach ${ }^{45}$.

Antroduodenal manometry requires a water-perfused or solid-state catheter that measures intraluminal pressures in the stomach and small intestine. In order to determine pyloric function a challenging method is required, a so-called pyloric sleeve is included in a water-perfused catheter assembly and transmucosal potential difference measurement is used to determine adequate positioning of the sleeve across the pyloric sphincter ${ }^{46}$. Current development in high resolution manometry 
systems and the possibility to present data as contour plots might simplify measurement of pyloric function ${ }^{47}$.

\section{Management}

The goals of treatment in gastroparesis are to reduce symptoms, to maintain a sufficient nutritional state and an optimal weight.

\section{Diet and lifestyle}

Dietary measures are important in the management of gastroparesis. Little or no evidence is available that dietary measures work since they have not been studied in a controlled manner ${ }^{2,48}$. Advice should be targeted at individual intolerances or difficulties with specific food products. Especially fat rich items and late evening meals should be avoided. Referral to a dietitian may prove helpful. Dietary and lifestyle advice should at least include the following recommendations: (1) reduce the number of fatty food products, (2) eat smaller proportions more frequently during the day, (3) remain in an upright position during and after the course of a meal, (4) limit the intake of insoluble fibers, (5) stop smoking, although it should be noted that smoking itself triggers the gastrocolonic reflex and accelerates intestinal transit, (6) screen for deficiencies especially in patients with weight loss and malnutrition and use multivitamin and/or vitamin supplementation when needed $^{48-51}$.

\section{Prokinetics}

\section{Metoclopramide and domperidone}

Metoclopramide, a dopamine $D_{2}$ receptor antagonist has been applied in the treatment of gastroparesis since the early 1970 ' $\mathrm{s}^{52}$. Metoclopramide has both antiemetic and prokinetic properties. The antiemetic effect of metoclopramide is based on the blockade of dopamine $D_{2}$ receptors in the area postrema, located outside the blood-brain barrier, and the vomiting center.

The prokinetic effect of metoclopramide is based on the blockade of dopamine $D_{2}$ receptors in the gastrointestinal tract. Dopamine is known to cause inhibition of motility throughout the gastrointestinal tract. It reduces gastric tone and intragastric pressure and decreases antroduodenal coordination through activation of dopamine $D_{2}$ receptors. Metoclopramide not only shows dopamine $D_{2}$ receptor antagonist properties but also shows moderate 5-hydroxytryptamine-4 (5- $\left.\mathrm{HT}_{4}\right)$ agonist and $5-\mathrm{HT}_{3}$ antagonist properties ${ }^{53}$. 
Domperidone, structurally related to butyrophenones is also a dopamine $D_{2}$ receptor antagonist ${ }^{54}$. It has similar effects as metoclopramide, however does not cross the blood-brain barrier and thus has a slightly less antiemetic effect.

Both metoclopramide and domperidone induce hyperprolactinaemia. Metoclopramide induces central nervous system effects (drowsiness, restlessness and fatigue) and extrapyramidal reactions, like Parkinsonism, acute dystonia, akathisia and tardive dyskenisia ${ }^{55}$. These side effects are believed to be more prevalent after long-term use, although data are conflicting and incomplete ${ }^{56-60}$.

Despite the widespread and increasing ${ }^{53}$ use of dopamine $D_{2}$ receptor antagonists, in part due to the withdrawal of the $5-\mathrm{HT}_{4}$-agonist cisapride, most of the available trials (Table 2.1) have limitations. In two studies the effects of domperidone and metoclopramide on gastric emptying and symptoms were similar, however showing a less favorable side effects profile for metoclopramide ${ }^{55,61}$.

Table 2.1 Overview of studies on the effect of metoclopramide on symptoms and gastric emptying in gastroparesis.

\begin{tabular}{|c|c|c|c|c|c|c|}
\hline Author & Etiology & $\mathrm{N}$ & Design & Dose & Follow up & Outcome \\
\hline Perkel et al. ${ }^{62}$ & Mixed & 28 & RDBP & $10 \mathrm{mg}$ TID & 3 weeks & Symptom reduction \\
\hline Snape et al. ${ }^{63}$ & Diabetic & 10 & RDBP & $10 \mathrm{mg}$ & & $\begin{array}{l}\text { Symptom reduction } \\
\text { GE improvement }\end{array}$ \\
\hline McCallum et al. ${ }^{64}$ & Diabetic & 40 & DBP & $10 \mathrm{mg}$ QID & 3 weeks & $\begin{array}{l}\text { Symptom reduction } \\
\text { GE improvement }\end{array}$ \\
\hline Schade et al. ${ }^{65}$ & Diabetic & 12 & $\mathrm{OL}$ & 10 mg TID & 1 month & No effect \\
\hline Ricci et al. ${ }^{66}$ & Diabetic & 13 & RDBP & $10 \mathrm{mg}$ QID & 3 weeks & $\begin{array}{l}\text { Symptom reduction of } 53 \% \\
\text { GE improvement }\end{array}$ \\
\hline De Caestecker et al. ${ }^{67}$ & Diabetic & 19 & DBP & $10 \mathrm{mg}$ & 8 weeks & No effect \\
\hline Erbas et al. ${ }^{68}$ & Diabetic & 13 & $\mathrm{OL}$ & $10 \mathrm{mg}$ TID & 3 weeks & $\begin{array}{l}\text { Symptom reduction } \\
\text { GE improvement }\end{array}$ \\
\hline Patterson et al. ${ }^{55}$ & Diabetic & 45 & $\mathrm{RDB}$ & $10 \mathrm{mg}$ QID & 4 weeks & $\begin{array}{l}\text { Symptom reduction of } \\
38.9 \%\end{array}$ \\
\hline Dumitrascu et al. ${ }^{61}$ & Diabetic & 10 & DB & 10 mg TID & NA & $\begin{array}{l}\text { Symptom reduction } \\
\text { GE improvement of } 16 \%\end{array}$ \\
\hline
\end{tabular}

$\mathrm{DB}=$ double blind, $\mathrm{RDB}=$ randomized double blind, $\mathrm{RDBP}=$ randomized double blind placebo controlled, $\mathrm{OL}=$ open label, $\mathrm{NA}=$ not applicable, $\mathrm{GE}=$ gastric emptying

\section{Erythromycin}

Erythromycin is a motilin agonist that induces phase III migrating motor complex contractions. Erythromycin enhances gastric emptying, increases antral contractions and antroduodenal coordination but reduces fundic volume and compliance in health and disease. Intravenous administration of erythromycin is primarily of use in the management of severe gastroparesis in a clinical setting. Oral administration of erythromycin in its liquid form provides an opportunity to use erythromycin in a nonclinical setting in gastroparesis. Unfortunately long-term use is limited due to its antibacterial effect and desensitization to the therapeutic effect. 


\section{Botulinum toxin}

Mearin et al. ${ }^{69}$ observed an increased prevalence of pyloric activity in diabetics. Pyloric dysmotility in diabetic gastroparesis is manifested primarily by prolongation of periods of normal pyloric activity. In half of these patients an unusually long and intense tonic pyloric activity was observed.

These results inspired Ezzeddine and others ${ }^{70-76}$ to study the effect of intrapyloric botulinum toxin injection in patients with severe diabetic gastroparesis (Table 2.2). In recent years several open-label pilot studies have shown the effect of intrapyloric botulinum toxin injection in severe gastroparesis. In a recent article Lacy et al. $^{73}$ published their data and concluded intrapyloric botulinum toxin to be a possible addition in the treatment of mild-to-moderate diabetic gastroparesis. Miller et al. published their data on the effect of intrapyloric botulinum toxin injection in patients with severe idiopathic gastroparesis and concluded that intrapyloric injection of botulinum toxin accelerated gastric emptying and reduced symptoms of gastroparesis. Arts et al. ${ }^{74}$ showed improvement in gastric emptying for solids and symptom score after botulinum toxin injection, but did not show improvement in gastric emptying for liquids. The precise duration of the improvements of intrapyloric botulinum toxin injection on gastric emptying and symptoms are unknown, but previously mentioned open-label pilot studies have shown a duration of up to 6 weeks on gastric emptying and up to 8 weeks on symptoms. All authors ${ }^{63-66}$ acknowledged the need for further evaluation of intrapyloric botulinum toxin injection in a double blind, placebo-controlled design. Bromer et al. ${ }^{89}$ retrospectively studied the effect of open-label intrapyloric botulinum toxin injection in 63 patients with refractory gastroparesis. They observed a response rate of $43 \%$ in symptom improvement for a mean of two months. Recently published data on the effect of intrapyloric botulinum toxin injection studied in a randomized double blind crossover manner in a mixed group of patients with gastroparesis are disappointing ${ }^{90}$. They did not observe an additional effect of botulinum toxin injection compared to placebo injection, neither on symptoms nor on gastric emptying and conclude that further study in more specific groups, i.e. with pyloric dysfunction might be appropriate.

\section{Gastric pacing}

Gastric pacing or gastric electrical stimulation involves the implantation of electrodes in the smooth muscle layer of the gastric wall by laparotomy or laparoscopy. The electrodes are connected to a subcutaneously located device. The device is programmed to electrically stimulate the smooth muscle layer ${ }^{77}$. Various electrical stimuli are applied, that differ in pulse width, amplitude and frequency. Initial stimulation was targeted to mimic the physiological frequency of the gastric slow waves ( 3 contractions per minute) observed during electrogastrography (EGG) and consisted of long-pulse stimulation. Contrary to the long-pulse stimulation, short- 
pulse stimulation creates a frequency several times higher $(12 \mathrm{cpm})$ than the regular gastric slow wave frequency ${ }^{78}$. Short-pulse stimulation improved symptoms (in particular nausea and vomiting), reduced hospitalizations and improved quality of life in several open-label studies ${ }^{79-86}$ and one controlled cross-over study ${ }^{87}$, and had in most studies no effect on gastric emptying. Long-pulse stimulation improved gastric emptying and symptoms in a single open-label study ${ }^{88}$, although the effect on symptoms has been debated ${ }^{78}$. Further research is needed to determine the best stimulation algorithm and the mechanisms responsible for clinical improvement in patients. These improvements might be due to central effects.

Table 2.2 Overview of studies on the effect of intrapyloric botulinum toxin injections on symptoms and gastric emptying in gastroparesis.

\begin{tabular}{|c|c|c|c|c|c|c|}
\hline Author & Etiology & $\mathrm{N}$ & Design & Dose & Follow up & Outcome \\
\hline Ezzeddine et al. ${ }^{70}$ & Diabetic & 6 & $\mathrm{OL}$ & $100 \mathrm{IU}$ & 6 weeks & $\begin{array}{l}\text { Symptom reduction of } 55 \% \\
\text { GE improvement of } 52 \%\end{array}$ \\
\hline Miller et al. ${ }^{72}$ & Idiopathic & 10 & $\mathrm{OL}$ & $100 \mathrm{IU}$ & 4 weeks & $\begin{array}{l}\text { Symptom reduction of } 38 \% \\
\text { GE improvement of } 48 \%\end{array}$ \\
\hline Lacy et al. ${ }^{73}$ & Diabetic & 8 & $\mathrm{OL}$ & $200 \mathrm{IU}$ & 12 weeks & $\begin{array}{l}\text { Symptom reduction of } 55 \% \\
\text { GE improvement of } 33 \%\end{array}$ \\
\hline Bromer et al. ${ }^{89}$ & Mixed & 63 & $\mathrm{OL}$ & $200 \mathrm{IU}$ & & $\begin{array}{l}\text { Symptom reduction in } 43 \% \\
\text { for } 2 \text { months }\end{array}$ \\
\hline Arts et al..$^{90}$ & Mixed & 20 & $\mathrm{OL}$ & $100 \mathrm{IU}$ & 1 month & $\begin{array}{l}\text { Symptom reduction of } 29 \% \\
\text { GE improvement of } 35 \%\end{array}$ \\
\hline
\end{tabular}

$\mathrm{OL}=$ open label, $\mathrm{GE}=$ gastric emptying

\section{Conclusions}

The revised Rome III criteria for functional dyspepsia raise the question whether or not idiopathic gastroparesis should be regarded as a separate clinical diagnosis, since functional dyspepsia type A (postprandial distress syndrome) shows remarkable similarities with idiopathic gastroparesis in symptoms and signs. Moreover, labeling patients with idiopathic gastroparesis as functional dyspepsia will separate this subgroup of patients with functional delayed gastric emptying from those with a well-defined etiology, like gastroparesis due to diabetes mellitus or other systemic disorders.

When suspected, delayed gastric emptying should be quantified, preferably by scintigraphy or stable isotope breath tests. In all cases mechanical obstruction should be excluded (endoscopy).

Although current treatment options for gastroparesis are limited, most patients with mild disease will respond to dietary and life style measures and prokinetics such as domperidone, metoclopramide and erythromycin. In patients with gastroparesis that do not respond to standard treatment options additional investigations may be required. With manometry, antral and duodenal motor function can be evaluated in 
more detail. High Resolution Manometry might be a tool for further study, as it potentially provides detailed information concerning not only antral and duodenal function but also pyloric function. These methods may help to differentiate those patients that might benefit from, intrapyloric botulinum toxin injection, gastric pacing or more radical surgical interventions, like partial or total gastrectomy. 


\section{References}

1. Horowitz M, Fraser RJ. Gastroparesis: diagnosis and management. Scand J Gastroenterol Suppl 1995;213:7-16.

2. Abell TL, Bernstein RK, Cutts T, Farrugia G, Forster J, Hasler WL, McCallum RW, Olden KW, Parkman HP, Parrish CR, Pasricha PJ, Prather CM, Soffer EE, Twillman R, Vinik Al. Treatment of gastroparesis: a multidisciplinary clinical review. Neurogastroenterol Motil 2006;18:263-83.

3. Jones KL, Russo A, Stevens JE, Wishart JM, Berry MK, Horowitz M. Predictors of delayed gastric emptying in diabetes. Diabetes Care 2001;24:1264-9.

4. Buckles DC, Sarosiek I, McMillin C, McCallum RW. Delayed gastric emptying in gastroesophageal reflux disease: reassessment with new methods and symptomatic correlations. Am J Med Sci 2004;327:1-4.

5. Delgado-Aros S, Camilleri M, Cremonini F, Ferber I, Stephens D, Burton DD. Contributions of gastric volumes and gastric emptying to meal size and postmeal symptoms in functional dyspepsia. Gastroenterology 2004;127:1685-94.

6. Quigley EM. Review article: gastric emptying in functional gastrointestinal disorders. Aliment Pharmacol Ther 2004;20 Suppl 7:56-60.

7. Quartero AO, de Wit NJ, Lodder AC, Numans ME, Smout AJ, Hoes AW. Disturbed solid-phase gastric emptying in functional dyspepsia: a meta-analysis. Dig Dis Sci 1998;43:2028-33.

8. Soykan I, Sivri B, Sarosiek I, Kiernan B, McCallum RW. Demography, clinical characteristics, psychological and abuse profiles, treatment, and long-term follow-up of patients with gastroparesis. Dig Dis Sci 1998;43:2398-404.

9. Hunter RJ, Metz DC, Morris JB, Rothstein RD. Gastroparesis: a potential pitfall of laparoscopic Nissen fundoplication. Am J Gastroenterol 1996;91:2617-8.

10. Kozarek RA, Low DE, Raltz SL. Complications associated with laparoscopic anti-reflux surgery: one multispecialty clinic's experience. Gastrointest Endosc 1997;46:527-31.

11. Sodhi SS, Guo JP, Maurer AH, O'Brien G, Srinivasan R, Parkman HP. Gastroparesis after combined heart and lung transplantation. J Clin Gastroenterol 2002;34:34-9.

12. Pfeiffer RF. Gastrointestinal dysfunction in Parkinson's disease. Clin Neurosci 1998;5:136-46.

13. Goetze O, Nikodem AB, Wiezcorek J, Banasch M, Przuntek H, Mueller T, Schmidt WE, Woitalla D. Predictors of gastric emptying in Parkinson's disease. Neurogastroenterol Motil 2006;18:369-75.

14. Horowitz M, Maddern GJ, Maddox A, Wishart J, Chatterton BE, Shearman DJ. Effects of cisapride on gastric and esophageal emptying in progressive systemic sclerosis. Gastroenterology 1987;93:311-5.

15. Marie I, Levesque H, Ducrotte P, Denis P, Hellot MF, Benichou J, Cailleux N, Courtois H. Gastric involvement in systemic sclerosis: a prospective study. Am J Gastroenterol 2001;96:77-83.

16. Kristinsson JO, Hopman WP, Oyen WJ, Drenth JP. Gastroparesis in patients with inactive Crohn's disease: a case series. BMC Gastroenterol 2007;7:11.

17. Parkman HP, Hasler WL, Fisher RS. American Gastroenterological Association medical position statement: diagnosis and treatment of gastroparesis. Gastroenterology 2004;127:1589-91.

18. Parkman HP, Hasler WL, Fisher RS. American Gastroenterological Association technical review on the diagnosis and treatment of gastroparesis. Gastroenterology 2004;127:1592-622.

19. Horowitz M, Maddox AF, Wishart JM, Harding PE, Chatterton BE, Shearman DJ. Relationships between oesophageal transit and solid and liquid gastric emptying in diabetes mellitus. Eur J Nucl Med 1991;18:229-34.

20. Karamanolis G, Caenepeel P, Arts J, Tack J. Determinants of symptom pattern in idiopathic severely delayed gastric emptying: gastric emptying rate or proximal stomach dysfunction? Gut 2007;56: 29-36.

21. Guo JP, Maurer AH, Fisher RS, Parkman HP. Extending gastric emptying scintigraphy from two to four hours detects more patients with gastroparesis. Dig Dis Sci 2001;46:24-9.

22. Tougas G, Eaker EY, Abell TL, Abrahamsson H, Boivin M, Chen J, Hocking MP, Quigley EM, Koch KL, Tokayer AZ, Stanghellini V, Chen Y, Huizinga JD, Ryden J, Bourgeois I, McCallum RW. Assessment of gastric emptying using a low fat meal: establishment of international control values. Am J Gastroenterol 2000;95:1456-62. 
23. Ghoos YF, Maes BD, Geypens BJ, Mys G, Hiele MI, Rutgeerts PJ, Vantrappen G. Measurement of gastric emptying rate of solids by means of a carbon-labeled octanoic acid breath test. Gastroenterology 1993;104:1640-7.

24. Maes BD, Ghoos YF, Rutgeerts PJ, Hiele MI, Geypens B, Vantrappen G. $\left[{ }^{*} C\right]$ octanoic acid breath test to measure gastric emptying rate of solids. Dig Dis Sci 1994;39:104S-6S.

25. Braden B, Adams S, Duan LP, Orth KH, Maul FD, Lembcke B, Hor G, Caspary WF. The [13C]acetate breath test accurately reflects gastric emptying of liquids in both liquid and semisolid test meals. Gastroenterology 1995;108:1048-55.

26. Ziegler D, Schadewaldt P, Pour MA, Piolot R, Schommartz B, Reinhardt M, Vosberg H, Brosicke $H$, Gries FA. [13C]octanoic acid breath test for non-invasive assessment of gastric emptying in diabetic patients: validation and relationship to gastric symptoms and cardiovascular autonomic function. Diabetologia 1996;39:823-30.

27. Lee JS, Camilleri M, Zinsmeister AR, Burton DD, Choi MG, Nair KS, Verlinden M. Toward office-based measurement of gastric emptying in symptomatic diabetics using [13C]octanoic acid breath test. Am J Gastroenterol 2000;95:2751-61.

28. Choi MG, Camilleri M, Burton DD, Zinsmeister AR, Forstrom LA, Nair KS. [13C]octanoic acid breath test for gastric emptying of solids: accuracy, reproducibility, and comparison with scintigraphy. Gastroenterology 1997;112:1155-62.

29. Choi MG, Camilleri M, Burton DD, Zinsmeister AR, Forstrom LA, Nair KS. Reproducibility and simplification of $13 \mathrm{C}$-octanoic acid breath test for gastric emptying of solids. Am J Gastroenterol 1998;93:92-8.

30. Delbende B, Perri F, Couturier O, Leodolter A, Mauger P, Bridgi B, Bizais Y, des Varannes SB, Andriulli A, Galmiche JP. 13C-octanoic acid breath test for gastric emptying measurement. Eur J Gastroenterol Hepatol 2000;12:85-91.

31. Schwizer W, Maecke H, Fried M. Measurement of gastric emptying by magnetic resonance imaging in humans. Gastroenterology 1992;103:369-76.

32. Feinle $C$, Kunz P, Boesiger P, Fried M, Schwizer W. Scintigraphic validation of a magnetic resonance imaging method to study gastric emptying of a solid meal in humans. Gut 1999;44:106-11.

33. de Zwart I, Haans JJ, Verbeek P, Eilers PH, de Roos A, Masclee AA. Gastric accommodation and motility are influenced by the barostat device: Assessment with magnetic resonance imaging. AmJPhysiol GastrointestLiver Physiol 2007;292:G208-G14.

34. Gilja OH, Hausken T, degaard S, Berstad A. Gastric emptying measured by ultrasonography. World J Gastroenterol 1999;5:93-4.

35. Tympner F, Rosch W. [Sonographic measurement of gastric emptying time]. Ultraschall Med 1982;3:15-7.

36. de Zwart I, Mearadji B, Lamb HJ, Eilers PH, Masclee AA, de Roos A, Kunz P. Gastric motility: comparison of assessment with real-time MR imaging or barostat measurement initial experience. Radiology 2002;224:592-7.

37. Undeland KA, Hausken T, Gilja OH, Aanderud S, Berstad A. Gastric meal accommodation studied by ultrasound in diabetes. Relation to vagal tone. Scand J Gastroenterol 1998;33:236-41.

38. Fraser R, Schwizer W, Borovicka J, Asal K, Fried M. Gastric motility measurement by MRI. DigDisSci 1994;39:20S-3S.

39. Kwiatek MA, Steingoetter A, Pal A, Menne D, Brasseur JG, Hebbard GS, Boesiger P, Thumshirn M, Fried M, Schwizer W. Quantification of distal antral contractile motility in healthy human stomach with magnetic resonance imaging. J Magn Resonlmaging 2006;24:1101-9.

40. Marciani L, Gowland PA, Fillery-Travis A, Manoj P, Wright J, Smith A, Young P, Moore R, Spiller RC. Assessment of antral grinding of a model solid meal with echo-planar imaging. AmJPhysiol GastrointestLiver Physiol 2001;280:G844-G9.

41. Marciani L, Gowland PA, Spiller RC, Manoj P, Moore RJ, Young P, Fillery-Travis AJ. Effect of meal viscosity and nutrients on satiety, intragastric dilution, and emptying assessed by MRI. Am J Physiol Gastrointest Liver Physiol 2001;280:G1227-G33.

42. Kunz $P$, Feinle-Bisset $C$, Faas H, Boesiger P, Fried M, Steingotter A, Schwizer W. Effect of ingestion order of the fat component of a solid meal on intragastric fat distribution and gastric emptying assessed by MRI. J Magn Reson Imaging 2005;21:383-90. 
43. Treier R, Steingoetter A, Weishaupt D, Goetze O, Boesiger P, Fried M, Schwizer W. Gastric motor function and emptying in the right decubitus and seated body position as assessed by magnetic resonance imaging. J Magn Reson Imaging 2006;23:331-8.

44. Jones $\mathrm{KL}$, O'Donovan $\mathrm{D}$, Horowitz $\mathrm{M}$, Russo $\mathrm{A}$, Lei $\mathrm{Y}$, Hausken T. Effects of posture on gastric emptying, transpyloric flow, and hunger after a glucose drink in healthy humans. Dig Dis Sci 2006;51:1331-8.

45. Bouras EP, Scolapio JS. Gastric motility disorders: management that optimizes nutritional status. J Clin Gastroenterol 2004;38:549-57.

46. Haans JJ, Masclee AA. Intragastric acidification inhibits motilin-induced phase III activity in humans. Neurogastroenterol Motil 2006;18:637-46.

47. Desipio J, Friedenberg FK, Korimilli A, Richter JE, Parkman HP, Fisher RS. High-resolution solid-state manometry of the antropyloroduodenal region. Neurogastroenterol Motil 2007;19:188-95.

48. Karamanolis G, Tack J. Nutrition and motility disorders. Best Pract Res Clin Gastroenterol 2006;20: 485-505.

49. Abell TL, Malinowski S, Minocha A. Nutrition aspects of gastroparesis and therapies for drugrefractory patients. Nutr Clin Pract 2006;21:23-33.

50. Parrish CR. Nutrition concerns for the patient with gastroparesis. Curr Gastroenterol Rep 2007;9: 295-302.

51. Emerson AP. Foods high in fiber and phytobezoar formation. J Am Diet Assoc 1987;87:1675-7.

52. Brownlee M, Kroopf SS. Letter: Metoclopramide for gastroparesis diabeticorum. N Engl J Med 1974;291:1257-8.

53. Tonini M, Cipollina L, Poluzzi E, Crema F, Corazza GR, De PF. Review article: clinical implications of enteric and central D2 receptor blockade by antidopaminergic gastrointestinal prokinetics. Aliment Pharmacol Ther 2004;19:379-90.

54. Ahmad N, Keith-Ferris J, Gooden E, Abell T. Making a case for domperidone in the treatment of gastrointestinal motility disorders. Curr Opin Pharmacol 2006;6:571-6.

55. Patterson D, Abell T, Rothstein R, Koch K, Barnett J. A double-blind multicenter comparison of domperidone and metoclopramide in the treatment of diabetic patients with symptoms of gastroparesis. Am J Gastroenterol 1999;94:1230-4.

56. Ganzini L, Heintz RT, Hoffman WF, Casey DE. The prevalence of tardive dyskinesia in neuroleptictreated diabetics. A controlled study. Arch Gen Psychiatry 1991;48:259-63.

57. Shaffer D, Butterfield M, Pamer C, Mackey AC. Tardive dyskinesia risks and metoclopramide use before and after U.S. market withdrawal of cisapride. J Am Pharm Assoc(2003) 2004;44:661-5.

58. Camilleri M. Clinical practice. Diabetic gastroparesis. N Engl J Med 2007;356:820-9.

59. Pasricha PJ, Pehlivanov N, Sugumar A, Jankovic J. Drug Insight: from disturbed motility to disordered movement--a review of the clinical benefits and medicolegal risks of metoclopramide. Nat Clin Pract Gastroenterol Hepatol 2006;3:138-48.

60. Tarsy D. Diabetic gastroparesis. N Engl J Med 2007;357:419-20.

61. Dumitrascu DL, Weinbeck M. Domperidone versus metoclopramide in the treatment of diabetic gastroparesis. Am J Gastroenterol 2000;95:316-7.

62. Perkel MS, Moore C, Hersh T, Davidson ED. Metoclopramide therapy in patients with delayed gastric emptying: a randomized, double-blind study. Dig Dis Sci 1979;24:662-6.

63. Snape WJ, Jr., Battle WM, Schwartz SS, Braunstein SN, Goldstein HA, Alavi A. Metoclopramide to treat gastroparesis due to diabetes mellitus: a double-blind, controlled trial. Ann Intern Med 1982;96: 444-6.

64. McCallum RW, Ricci DA, Rakatansky H, Behar J, Rhodes JB, Salen G, Deren J, Ippoliti A, Olsen HW, Falchuk K. A multicenter placebo-controlled clinical trial of oral metoclopramide in diabetic gastroparesis. Diabetes Care 1983;6:463-7.

65. Schade RR, Dugas MC, Lhotsky DM, Gavaler JS, Van Thiel DH. Effect of metoclopramide on gastric liquid emptying in patients with diabetic gastroparesis. Dig Dis Sci 1985;30:10-5.

66. Ricci DA, Saltzman MB, Meyer C, Callachan C, McCallum RW. Effect of metoclopramide in diabetic gastroparesis. J Clin Gastroenterol 1985;7:25-32.

67. de Caestecker JS, Ewing DJ, Tothill P, Clarke BF, Heading RC. Evaluation of oral cisapride and metoclopramide in diabetic autonomic neuropathy: an eight-week double-blind crossover study. Aliment Pharmacol Ther 1989;3:69-81. 
68. Erbas T, Varoglu E, Erbas B, Tastekin G, Akalin S. Comparison of metoclopramide and erythromycin in the treatment of diabetic gastroparesis. Diabetes Care 1993;16:1511-4.

69. Mearin F, Camilleri M, Malagelada JR. Pyloric dysfunction in diabetics with recurrent nausea and vomiting. Gastroenterology 1986;90:1919-25.

70. Ezzeddine D, Jit R, Katz N, Gopalswamy N, Bhutani MS. Pyloric injection of botulinum toxin for treatment of diabetic gastroparesis. Gastrointest Endosc 2002;55:920-3.

71. Lacy BE, Zayat EN, Crowell MD, Schuster MM. Botulinum toxin for the treatment of gastroparesis: a preliminary report. Am J Gastroenterol 2002;97:1548-52.

72. Miller LS, Szych GA, Kantor SB, Bromer MQ, Knight LC, Maurer AH, Fisher RS, Parkman HP. Treatment of idiopathic gastroparesis with injection of botulinum toxin into the pyloric sphincter muscle. Am J Gastroenterol 2002;97:1653-60.

73. Lacy BE, Crowell MD, Schettler-Duncan A, Mathis C, Pasricha PJ. The treatment of diabetic gastroparesis with botulinum toxin injection of the pylorus. Diabetes Care 2004;27:2341-7.

74. Arts J, van Gool S, Caenepeel P, Janssens J, Tack J. Effect of intrapyloric injection of botulinum toxin on gastric emptying and meal-related symptoms in gastroparesis. Gastroenterology 2003;124:A-89.

75. Ben-Youssef R, Baron PW, Franco E, Walter MH, Lewis T, Ojogho O. Intrapyloric injection of botulinum toxin a for the treatment of persistent gastroparesis following successful pancreas transplantation. Am J Transplant 2006;6:214-8.

76. Tcherniak A, Kashtan DH, Melzer E. Successful treatment of gastroparesis following total esophagectomy using botulinum toxin. Endoscopy 2006;38:196.

77. Gourcerol G, Leblanc I, Leroi AM, Denis P, Ducrotte P. Gastric electrical stimulation in medically refractory nausea and vomiting. Eur J Gastroenterol Hepatol 2007;19:29-35.

78. Zhang J, Chen JD. Systematic review: applications and future of gastric electrical stimulation. Aliment Pharmacol Ther 2006;24:991-1002.

79. Familoni BO, Abell TL, Bhaskar SK, Voeller GR, Blair SR. Gastric electrical stimulation has an immediate antiemetic effect in patients with gastroparesis. IEEE Trans Biomed Eng 2006;53:1038-46.

80. Familoni BO, Abell TL, Voeller G, Salem A, Gaber O. Electrical stimulation at a frequency higher than basal rate in human stomach. Dig Dis Sci 1997;42:885-91.

81. de Csepel J, Goldfarb B, Shapsis A, Goff S, Gabriel N, Eng HM. Electrical stimulation for gastroparesis. Gastric motility restored. Surg Endosc 2006;20:302-6.

82. Lin Z, Sarosiek I, Forster J, McCallum RW. Symptom responses, long-term outcomes and adverse events beyond 3 years of high-frequency gastric electrical stimulation for gastroparesis. Neurogastroenterol Motil 2006;18:18-27.

83. Mason RJ, Lipham J, Eckerling G, Schwartz A, Demeester TR. Gastric electrical stimulation: an alternative surgical therapy for patients with gastroparesis. Arch Surg 2005;140:841-6.

84. McCallum R, Lin Z, Wetzel P, Sarosiek I, Forster J. Clinical response to gastric electrical stimulation in patients with postsurgical gastroparesis. Clin Gastroenterol Hepatol 2005;3:49-54.

85. Lin Z, Forster J, Sarosiek I, McCallum RW. Treatment of diabetic gastroparesis by high-frequency gastric electrical stimulation. Diabetes Care 2004;27:1071-6.

86. Abell TL, Van CE, Abrahamsson H, Huizinga JD, Konturek JW, Galmiche JP, Voeller G, Filez L, Everts B, Waterfall WE, Domschke W, Bruley dV, Familoni BO, Bourgeois IM, Janssens J, Tougas G. Gastric electrical stimulation in intractable symptomatic gastroparesis. Digestion 2002;66:204-12.

87. Abell T, McCallum R, Hocking M, Koch K, Abrahamsson H, Leblanc I, Lindberg G, Konturek J, Nowak T, Quigley EM, Tougas G, Starkebaum W. Gastric electrical stimulation for medically refractory gastroparesis. Gastroenterology 2003;125:421-8.

88. McCallum RW, Chen JD, Lin Z, Schirmer BD, Williams RD, Ross RA. Gastric pacing improves emptying and symptoms in patients with gastroparesis. Gastroenterology 1998;114:456-61.

89. Bromer MQ, Friedenberg F, Miller LS, Fisher RS, Swartz K, Parkman HP. Endoscopic pyloric injection of botulinum toxin A for the treatment of refractory gastroparesis. GastrointestEndosc 2005;61:833-9.

90. Arts J, van GS, Caenepeel P, Verbeke K, Janssens J, Tack J. Influence of intrapyloric botulinum toxin injection on gastric emptying and meal-related symptoms in gastroparesis patients. Aliment Pharmacol Ther 2006;24:661-7. 


\section{Chapter 3}

\section{Gastric accommodation and motility are influenced by the barostat device: assessment with Magnetic Resonance Imaging}

I.M. de Zwart J.J.L. Haans P. Verbeek P.H.C. Eilers

A. de Roos A.A.M. Masclee Am J Physiol Gastrointest Liver Physiol 2007;292:G208-G14 


\section{Abstract}

\section{Background}

The barostat is considered the gold standard for evaluation of proximal gastric motility especially for the accommodation response to a meal. The procedure is invasive because it involves the introduction of an intragastric catheter and bag and is not always well tolerated. Moreover, the barostat bag itself may influence motility. Nowadays Magnetic Resonance Imaging (MRI) is able to measure several aspects of gastric motility non-invasively.

\section{Aims}

To evaluate whether the accommodation response of the stomach, observed with barostat, is present during MRI and whether the barostat interferes with gastric physiology.

\section{Materials and Methods}

Gastric accommodation, motility and emptying were studied twice in fourteen healthy subjects with MRI using 3D-volume scans and 2D-dynamic scans once in the presence of a barostat bag and once when the barostat bag was not present.

\section{Results}

Fasting and postprandial intragastric volumes were significantly higher in the experiment with barostat versus without barostat (fasting: $350 \pm 132 \mathrm{ml} v \mathrm{ss} .37 \pm 21 \mathrm{ml}, \mathrm{p}<0.0001$, postprandial: $852 \pm 126 \mathrm{ml}$ vs. $361 \pm 62 \mathrm{ml}, \mathrm{p}<0.0001)$. No significant differences were found in gastric emptying ( $88 \pm 41 \mathrm{vs} .97 \pm 40 \mathrm{ml} / \mathrm{h}, \mathrm{NS}$ ) and contraction frequency between both experiments. The accommodation response observed in the presence of the barostat bag was not observed in the absence of the barostat bag.

\section{Conclusions}

The presence of an intragastric barostat bag does not interfere with gastric emptying or motility but the accommodation response measured with the barostat in situ is not observed without the barostat bag in situ. Gastric accommodation is a non-physiological barostatinduced phenomenon. 


\section{Introduction}

Assessment of gastric motility and gastric emptying is important for the diagnosis of gastric motor disorders, such as gastroparesis, functional dyspepsia and post-surgical conditions $\mathrm{s}^{1-4}$. These disorders are characterized by changes in gastric motor function that may vary from antral hyper- or hypomotility, impaired postprandial accommodation, changes in pyloric tone, to alteration in coordination of antroduodenal motility. Recognition of these characteristics may contribute to a better understanding of the various gastric motor disorders.

Several techniques are currently applied to study gastric motility but they measure or evaluate only one of the various aspects. The barostat technique is used to study proximal gastric sensory and motor function, including gastric accommodation ${ }^{1,4}$. Accommodation is considered to be a vagally mediated reflex that occurs postprandial resulting in a reduction of tone, thus providing a reservoir for the meal ${ }^{5}$. Impaired gastric accommodation is present in a considerable subset of patients with functional dyspepsia or following surgery ${ }^{6,7}$. Disadvantages of the barostat technique include the time consuming procedure and the invasive nature requiring oral intubation with intragastric positioning of a polyethylene bag $^{4}$. Questions have been raised about interference of the barostat with gastric physiology $\mathrm{y}^{8-10}$.

In recent years, Magnetic Resonance Imaging (MRI) has been used to investigate gastric motility and emptying ${ }^{11-16}$. Feinle et al. validated MRI as a tool for the analysis of gastric emptying ${ }^{13}$. A major advantage of MRI is that several aspects of gastric motility such as contractions and emptying can be measured simultaneously. In a recent publication we compared $M R I$ with the barostat for the evaluation of proximal gastric motility during simultaneous recording ${ }^{17}$. Evidence was provided that MRI is as accurate as barostat measurements in determining changes in gastric volume and gastric contractions in response to glucagon (known to relax the stomach) and erythromycin (known to contract the stomach). Previously, Bouras et al. compared Single Photon Emission Computed Tomography (SPECT) with the barostat for concurrent validity and more recently, Simonian et al. described a new technique using SPECT to simultaneously measure gastric volumes and gastric emptying ${ }^{18,19}$.

The present study was undertaken to evaluate whether (1) an accommodation response observed in the presence of a barostat bag, is also present during MRI when the barostat bag is not present and (2) the barostat interferes with gastric physiology. Simultaneous MRI and barostat recording vs. MRI recording alone in the same group of subjects in response to a meal were used to address these questions. 


\section{Materials and Methods}

\section{Subjects}

Fourteen healthy subjects ( 8 women, 6 men; mean age $23 \pm 5$ years; Body Mass Index $23.0 \pm 1.2 \mathrm{~kg} / \mathrm{m}^{2}$ ) participated in the study. None of the subjects had a history of gastrointestinal disease or abdominal surgery and none were using any medication. The medical ethics committee of the Leiden University Medical Center had approved the protocol of the study and written informed consent was obtained from each subject.

\section{Gastric barostat}

An electronic barostat (Visceral Stimulator, Medtronic, Skovlunde, Denmark) was used to distend the stomach. A polyethylene bag (1000 ml maximum capacity) was connected to the end of a multilumen catheter (16 F). Since the barostat device had to be placed outside the MRI investigation room, the multilumen catheter was elongated with a $3 \mathrm{~m}$ long catheter $(16 \mathrm{~F})$. In a previous publication ${ }^{17}$ we have shown that elongation of the multilumen catheter does not influence minimal distending pressure (MDP), nor does it influence intragastric bag volume, however elongation does result in a delay of 5 seconds in reaching maximum bag volume. The barostat device keeps the pressure in the intragastric bag at a preselected level. This means that the system injects air into the bag when the stomach relaxes, and aspirates air when the stomach contracts ${ }^{20}$. Maximal airflow was $20 \mathrm{ml} / \mathrm{sec}$.

Pressure $(\mathrm{mmHg})$, volume $(\mathrm{ml})$ and compliance $(\mathrm{ml} / \mathrm{mmHg})$ were constantly monitored, recorded and analyzed on a personal computer connected to the barostat (Polygram for Windows, SVS module, Medtronic).

\section{MRI}

The subjects underwent 1.5-T MRI (ACS-NT; Philips Medical Systems, Best, The Netherlands) using a multi receive parallel body-synergy-coil. The protocol consisted of two acquisitions: three dimensional volume MRI (20 slices with a transverse orientation, Turbo Field Echo (TFE), TE=3.5 ms, TR=10 ms, field of view $450 \mathrm{~mm}$, rectangular field of view 55\%, symmetric reduction $50 \%$, flip angle $25^{\circ}, 256 \times 256$ pixels, slice thickness $10 \mathrm{~mm}$, total scan duration 30 seconds) was performed to determine the momentary gastric volume. To assess dynamic activity of the stomach two-dimensional dynamic MRI (semi-coronal slice orientation, Turbo Field Echo, 300 images per scan, temporal resolution: 1 second, $T E=3.6 \mathrm{~ms}, \mathrm{TR}=10 \mathrm{~ms}$, field of view $450 \mathrm{~mm}$, rectangular field of view $55 \%$, symmetric reduction $50 \%$, flip angle $25^{\circ}$, 256/128 pixels, slice thickness $10 \mathrm{~mm}$ ) was performed. Both acquisitions were performed during free breathing. These MRI techniques have been used and validated previously ${ }^{12,13,17}$. 


\section{Study design}

Each subject participated in two experiments performed on separate days in random order with an interval of at least 7 days. Each experiment started at $8.30 \mathrm{AM}$ after a fast of at least 10 hours. The catheter with bag was introduced through the mouth and positioned in the fundus of the stomach as described previously ${ }^{17}$. Correct position was checked by fluoroscopy. Subjects underwent MRI in a right-sided semisupine position $\left(30^{\circ}\right)$. In one of two experiments a barostat bag was present and MRI and barostat recording were performed simultaneously, while in the other experiment a barostat bag was not present and only MRI was performed.

In the combined experiment the barostat catheter with bag was introduced through the mouth and positioned in the fundus of the stomach. Correct positioning was checked with fluoroscopy. To unfold the bag, air $(300 \mathrm{ml})$ was manually inflated with controlled pressure $(<20 \mathrm{mmHg})$, and the catheter was pulled back carefully until the lower esophageal sphincter restricted its passage. Then the catheter was introduced $2 \mathrm{~cm}$ further. Thereafter, the bag was deflated and connected to the barostat device. Minimal distending pressure (MDP), the pressure needed to overcome the intraabdominal pressure, was determined. MDP is arbitrary defined as the first pressure level that provides an intragastric bag volume of more than $30 \mathrm{ml}$ and determined by increasing the intrabag pressure in $1-\mathrm{mmHg}$ steps every minute. Thereafter the barostat was set to maintain a pressure of $2 \mathrm{mmHg}$ above MDP throughout the experiment.

Three-dimensional volume scans and two-dimensional dynamic real-time scans were obtained before, and at regular intervals (15 min) after ingestion of a $200 \mathrm{ml}$ (300 kcal; $12.5 \mathrm{~g}$ protein, $40.4 \mathrm{~g}$ carbohydrate, $9.84 \mathrm{~g}$ fat) liquid meal (Ensure Plus, Abbott, USA). The liquid meal was labeled with meglumine gadoterate (Dotarem Laboratoire Guerbet, Roissy CdG Cedex, France) for contrast enhancement. Hereafter the mixture of the meal and gastric secretions will be referred to as "gastric contents". Total duration of each experiment was $110 \mathrm{~min}$ (Figure 3.1).

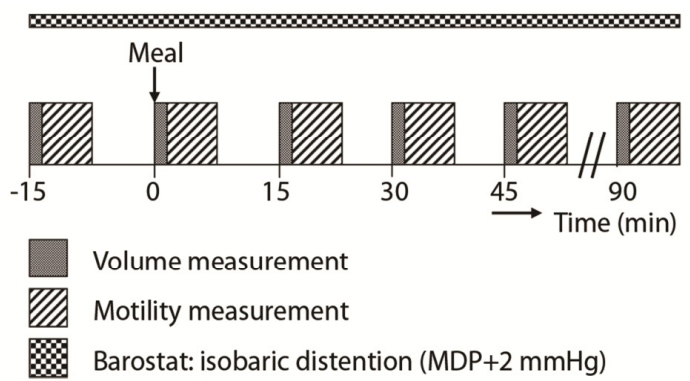

Figure 3.1 This figure summarizes the protocol of the study. Every $15 \mathrm{~min}$, volume scan and dynamic scan were acquired. 


\section{Data analysis}

Volumes measured with the barostat are given as average values over 30 seconds periods. In all images one observer (I.M.d.Z.) manually outlined the stomach. Volumes were obtained by adding the calculated surfaces of all outlined areas multiplied by the slice thickness using the $\mathrm{MASS}^{\odot}$ software package (LKEB, Leiden University Medical Center, The Netherlands).

The following volumes were analyzed:

(1) Total gastric volume, defined in the experiment without the barostat bag in situ as: volume of gastric contents plus volume of air. In the experiment with the barostat bag in situ, total gastric volume was defined as: volume of gastric contents plus volume of air plus barostat volume.

(2) Volume of gastric contents, defined as the volume of the gadolinium labeled meal plus gastric secretions.

(3) Total volume of air, defined as the total amount of air inside the stomach.

(4) Barostat volume, defined as the volume of air inside the barostat bag, measured by the barostat device.

(5) Free air volume, defined as total amount of air minus barostat bag volume of air. Gastric emptying rate was defined as the decrease in gastric contents volume $(\mathrm{ml})$ over time (min). To obtain gastric motility parameters, gastric diameters were calculated at 10 equally distributed points perpendicular to the stomach axis. Based on this diameter calculation, peristaltic contractions were detected and their frequency was calculated ${ }^{12,13,17}$. By color-coding the 10 diameter lines, the peristaltic contraction pattern was visualized in a graph.

\section{Statistical analysis}

Data were analyzed using a statistical software package (SPSS ${ }^{\oplus}$ for Windows Release 12.0.1, SPSS Inc., Chicago, USA). All data are given as mean \pm SD. A linear mixed model analysis and paired-samples t-test were used to detect differences in data between the experiments. For linear mixed model analysis data were analyzed in the model using a fixed time and intervention effect. The level of significance was set at $\mathrm{p}<0.05$.

\section{Results}

\section{Example}

A typical example of the images obtained during the experiments is given in Figure 3.2. This figure shows images of the stomach of one of the subjects with ( $C$ and $D)$ and without ( $A$ and $B$ ) the barostat bag in situ. The gastric contents are white, due to the presence of the paramagnetic contrast agent in the meal, whereas air, both 
inside and outside the barostat bag, is black. The barostat bag itself could not be visualized.
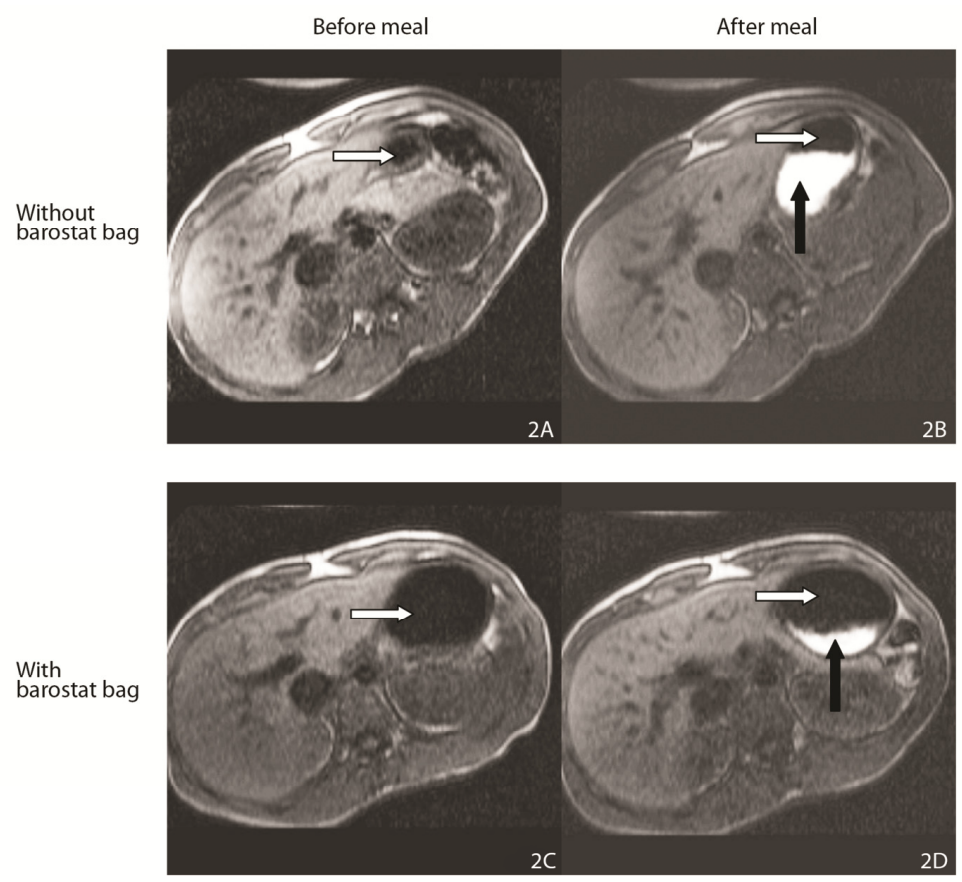

Figure 3.2 Transversal T1-weighted TFE images (3.5/10; flip angle, $\left.25^{\circ}\right)$ of the stomach in the same subject without barostat bag $(A+B)$ and with barostat bag $(C+D)$, before ingestion of the gadolinium labeled meal $(A+C)$ and immediately after ingestion of the meal $(B+D)$. Gastric contents consisting of a mixture of the gadolinium labeled meal and gastric secretions are shown by black arrows. Total gastric volume consists of both gastric contents and air (white arrow indicates air). The air-filled barostat bag cannot be visualized separately from "free air". Note that gastric volume is larger in the barostat experiment, both before and after meal ingestion.

\section{Gastric emptying}

Gastric emptying with and without the barostat bag in situ is shown in Figure 3.3. The volume of gastric contents measured 15 min after ingestion of the meal was significantly smaller for the experiment with the barostat bag compared to the experiment without the barostat bag $(225 \pm 46 \mathrm{ml}$ vs. $266 \pm 34 \mathrm{ml} ; \mathrm{p}<0.02)$. This difference in volume of gastric contents remained significant throughout the study (Figure 3.3). However, the rate of gastric emptying from 15 to $90 \mathrm{~min}$ was not significantly different between the two experiments $(88 \pm 41 \mathrm{ml} / \mathrm{h} \mathrm{vs} .97 \pm 40 \mathrm{ml} / \mathrm{h}$, with vs. without bag; NS). 


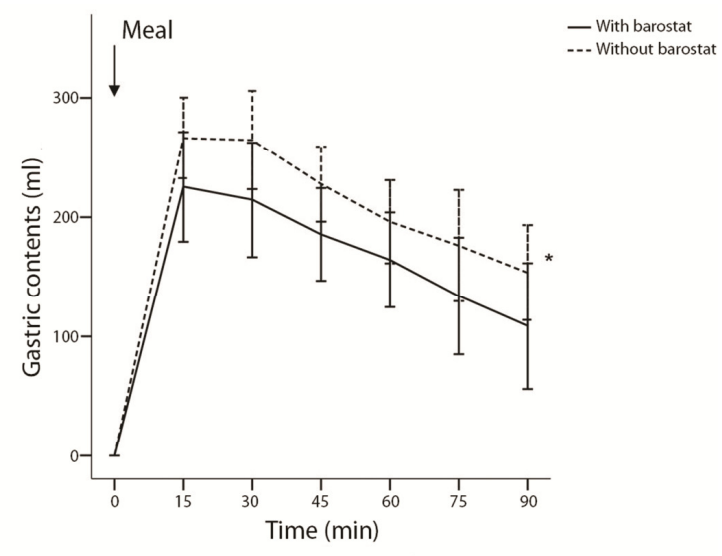

Figure 3.3 Gastric emptying of the meal with and without the barostat bag in situ. Changes in volume of gastric contents after meal ingestion are shown for the experiments without the barostat bag and with the barostat bag set at isobaric pressure (MDP $+2 \mathrm{mmHg}$ ) in 14 healthy subjects. ${ }^{*} p<0.0001$ : volume of gastric contents without barostat bag in situ vs. with bag in situ (mean \pm SD).

\section{Gastric volume}

The influence of the barostat bag on total gastric volume and gastric contents is shown in Figure 3.4. Ingestion of the meal caused a significant $(p<0.0001)$ increase over basal in total gastric volume in both experiments (Figure 3.4A and 3.4B). Total gastric volume was significantly $(p<0.0001)$ larger in the experiment with the barostat bag (Figure 3.4A) compared to the experiment without the barostat bag (Figure 3.4B), both before meal ingestion $(350 \pm 132 \mathrm{ml} v \mathrm{vs} .37 \pm 21 \mathrm{ml}, \mathrm{p}<0.0001)$ and immediately after meal ingestion $(852 \pm 126 \mathrm{ml}$ vs. $361 \pm 62 \mathrm{ml}, \mathrm{p}<0.0001)$. These differences remained significant throughout the experiment.

In addition to the significant difference in total stomach volume between the two experiments, we also noticed a difference in the rate at which total stomach volume decreased during the experiments. During the experiment with the barostat bag in situ, a significant $(p<0.0001)$ difference was shown between the rate at which the total stomach volume decreased versus the decrease in volume of gastric contents (Figure 3.4A). Such a difference was not observed during the experiment without the barostat bag (Figure $3.4 B ; p=0.15$ ). 


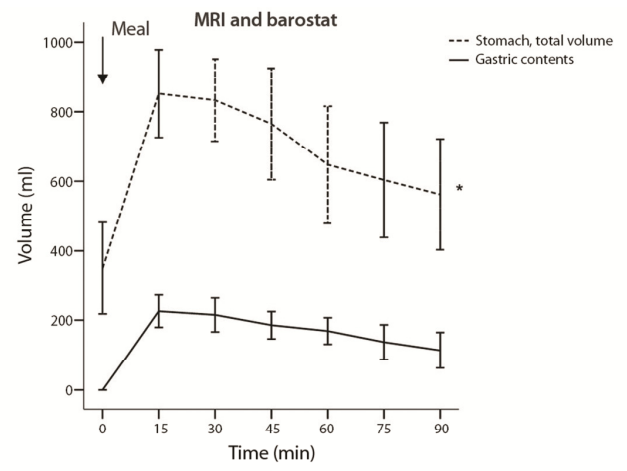

A

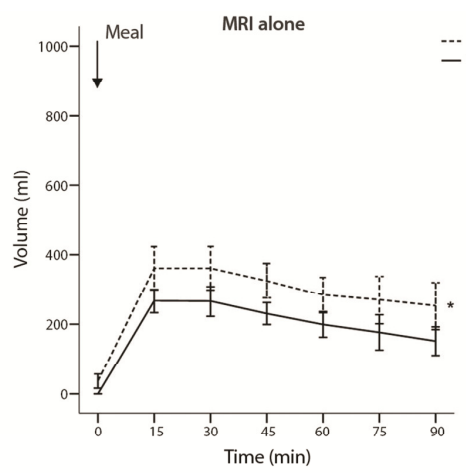

--- Stomach, total volume - Gastric contents

Figure 3.4 Total gastric volume and volume of gastric contents (mean \pm SD) before and after meal ingestion in 14 healthy subjects with barostat bag (at $M D P+2 \mathrm{mmHg}$ ) in situ $(A)$ and without barostat bag (B). Figure 3.4A: ${ }^{*} p<0.0001$ : for total volume vs. volume of gastric contents and for rate of volume decrease. Figure $3.4 \mathrm{~B}$ : ${ }^{*} \mathrm{p}<0.0001$ : for total volume vs. volume of gastric contents.

\section{Gastric air volume}

In the experiment with the barostat bag in situ, the total air volume (= total gastric volume minus volume of gastric contents) increased significantly $(p<0.01)$ over basal (time $0 \mathrm{~min}$ ) from 15 to $45 \mathrm{~min}$ after meal ingestion (Figure 3.5A). However, in the experiment without the barostat bag, total air volume did not change significantly after meal ingestion (Figure 3.5B). Total gastric volume during the experiment with the barostat bag in situ consisted of free air, that is air outside the barostat bag, and air inside the barostat bag, that is barostat bag volume (Figure 3.5C and 3.5D). An increase in free air volume during the experiment was not observed, although the volume of free air was significantly $(p<0.05)$ higher compared to the total air volume in the experiment without barostat bag (Figure 3.5D and 3.5B respectively).

\section{Gastric accommodation}

Barostat bag volume increased significantly $(p<0.05)$ at 15 and 30 min after administration of the liquid meal. This "accommodation" did not result from an increase in meal or free air volume. No change in gastric air volume was observed in the experiment with barostat, indicating that the "accommodation" measured with the barostat technique is a phenomenon that could not be observed when the barostat bag was not present. 

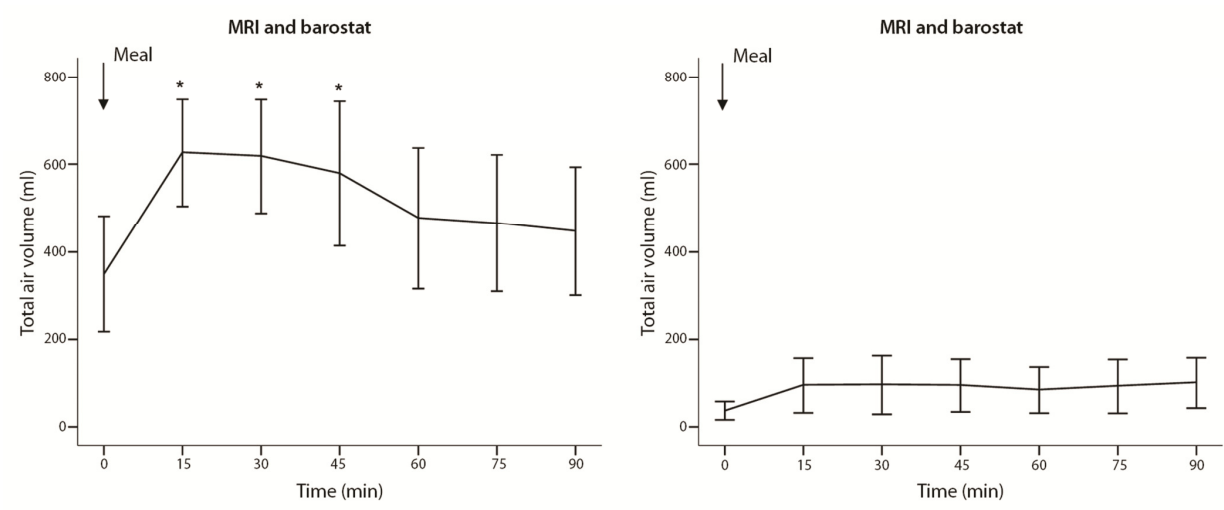

A
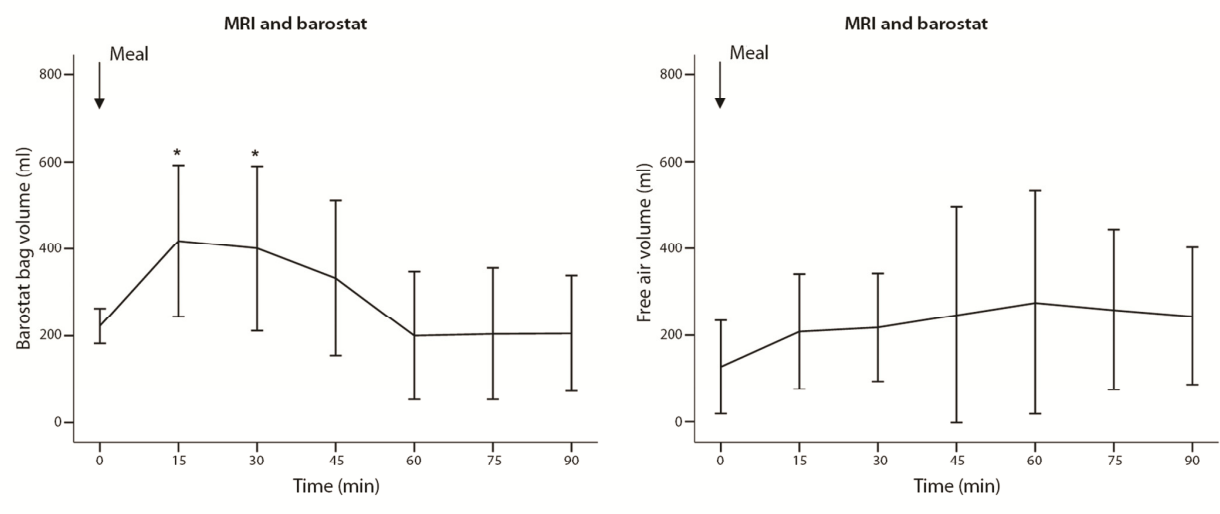

Figure 3.5 Volumes of air (mean $\pm S D$ ) before and after meal ingestion in 14 healthy subjects with barostat bag in situ $(A, C, D)$ and without barostat bag $(B)$.

A: total air volume (MRI); ${ }^{*} \mathrm{p}<0.01$ over time 0 min

B: total air volume, from experiment without barostat bag

C: volume of barostat bag (barostat); ${ }^{*} \mathrm{p}<0.05$ over time $0 \mathrm{~min}$

$D$ : free air volume: total air volume minus volume of barostat bag

\section{Contractions}

The barostat bag influences the contraction pattern. A typical example of the contraction pattern before (A) and after introduction of the barostat bag (B) is shown in Figure 3.6. We observed that the peristaltic contraction pattern became irregular with the barostat bag in situ. However, contraction frequency (Figure 3.7) before ingestion of the meal was similar in the experiments with and without the barostat bag ( $14.4 \pm 0.7$ and $14.6 \pm 0.8$ per 5 min respectively). After ingestion of the meal, the number of contractions was $13.6 \pm 1.0$ per 5 min with the barostat bag in situ and 14.1 \pm 1.7 per $5 \mathrm{~min}$ without the barostat bag (NS). At the end of the experiment, that 
is $90 \mathrm{~min}$ after meal ingestion, the number of contractions was $15.2 \pm 1.7$ per 5 min with barostat bag and $14.9 \pm 1.1$ per 5 min without barostat bag (NS).

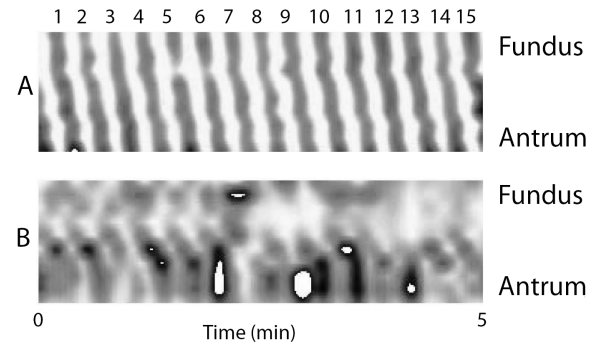

Figure 3.6 Example of the effect of barostat bag on contraction pattern. A graphical representation of the contraction pattern of one healthy subject during 5 min before introduction of the intragastric barostat bag (A) and after introduction of the intragastric barostat bag (B). In the graphs, time runs from left to right; the upper part of the graph represents the gastric fundus, and the lower part of the graph represents the antrum. Yellow represents a wide gastric diameter and black and white a narrow gastric diameter. In graph a, the red lines represent 15 peristaltic contractions. Note that without the bag, the contraction pattern is regular. After introduction of the bag, the contraction pattern becomes less regular, whilst the frequency of contractions is preserved. This pattern was seen in all subjects. Immediately after meal ingestion, the contraction pattern became even more disturbed with the intragastric barostat bag in situ versus without the barostat bag.

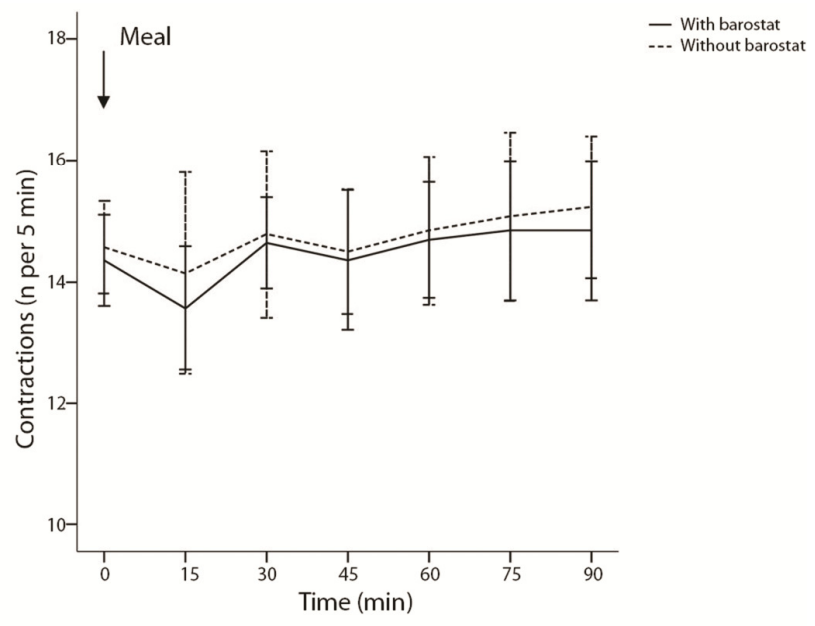

Figure 3.7 Number of contractions per 5 min (mean $\pm \mathrm{SD}$ ) in the session with and without the barostat bag in situ in 14 healthy subjects. 


\section{Discussion}

The barostat has become the gold standard for the evaluation of proximal gastric motility ${ }^{1,21}$. Recent studies employing the barostat technique indicate that gastric accommodation is impaired in a subset of patients with functional dyspepsia who have early satiety as predominant symptom ${ }^{6,22,23}$. It should however be noted that the barostat technique is invasive and it is not clear whether the barostat bag itself affects gastric motility and emptying. We have shown that the distended barostat bag did not affect the emptying rate of the meal. However, we observed significant differences in postprandial gastric contents volumes. In the presence of a barostat bag gastric contents volume, that is meal and gastric secretion, was significantly smaller compared to the experiment without a barostat bag. The reason for this difference in gastric contents volume between the two experiments is not apparent. The meal was of identical volume and composition in both experiments. As the difference occurred immediately after meal ingestion and did not change during the remaining experiment, it may be related to differences in gastric secretion. Gastric acid secretion may be impaired in the presence of a barostat bag due to a smaller secretory area exposed to nutrients.

While gastric emptying was not influenced in the presence of an intragastric barostat bag total gastric volume and gastric accommodation to the meal were affected, while the frequency of gastric contractions was not influenced by the barostat bag, the activity of contractions was converted from a regular pattern to a more irregular pattern (Figure 3.6).

The barostat has the unique ability to evaluate gastric accommodation: a vagally mediated reflex providing relaxation of the stomach wall in response to a meal ${ }^{5}$. In order to be able to measure gastric accommodation, the pressure in the barostat bag is set at a preselected distending pressure level. By applying this distending pressure level, the barostat bag is able to detect changes in gastric tone as increments or decrements in gastric volume. The increase in total gastric volume in the experiment without the intragastric barostat bag was nearly identical to the volume of the meal (Figure 3.4B) and we did not observe any accommodation response over that of the meal volume. In the presence of the barostat bag, however, a significant accommodation response was observed. One could argue that the increase in air volume, as shown in Figure 3.5B and represented by the difference in volume between total gastric volume and gastric contents, reflects an accommodation response. In our opinion this increase most likely results from the swallowing of air. This opinion is based on the finding that a similar increase in "free air volume" is observed during the experiment with the barostat bag present (Figure 3.5D). The slight increase in volume seen during the course of the experiment might result from the increased swallowing due to the presence of the gastric barostat bag. Moreover Bouras et al. ${ }^{18}$ describe in their publication on SPECT imaging of the stomach that the accommodation (volume) response to a meal typically reaches a peak within 10 
minutes after completion of the meal ingestion and is maintained at maximum level for at least 30 minutes. This effect was present in the experiment with the barostat bag, but absent in the experiment without the barostat bag (Figure 3.5A). Data we recently acquired using another protocol confirm the increase in air volume occurring already within 1 minute after meal intake. These data provide evidence for either a receptive relaxation or an increase in air volume due to swallowing of air $^{24}$. Other authors, by comparing SPECT or ultrasonography with the intragastric barostat technique, also failed to detect any accommodation response over that of the ingested volume ${ }^{8,25}$. It should be noted however that, in the studies employing SPECT and ultrasonography, comparison with the barostat was not made during simultaneous recording, as in the present study.

Gastric barostat studies have been helpful in defining subgroups of dyspeptic patients, for instance those with early satiety and an impaired meal accommodation response ${ }^{6,26}$. Notwithstanding these observations, the true physiological background of gastric barostat studies should be reconsidered. Additional studies combining barostat and MRI in these subgroups of patients are required to evaluate the phenomenon of (impaired) accommodation.

A clear advantage of MRI for evaluation of gastric emptying and motility is its noninvasive character. Furthermore, MRI provides additional information about peristaltic contractions ${ }^{17}$ and evaluates both the proximal and distal stomach simultaneously, whereas the barostat data reflect the function of the only proximal stomach. In contrast to SPECT, MRI does not expose patients to ionizing radiation and provides "real time" volumes: acquisition time 30 seconds for MRI versus approximately 15 min for SPECT.

A disadvantage of MRI is the supine position of the subject during the examination. Several studies have evaluated the effect of body position and gravity on gastric emptying and motility ${ }^{27,28}$. Horowitz et al. have shown that gravity had a major influence on the intragastric distribution of the meal, although there was relatively little effect on gastric emptying ${ }^{28}$.

We conclude that evaluated with MRI: (1) the presence of an intragastric barostat bag does not influence gastric emptying, (2) gastric accommodation as measured with the barostat bag in situ is not observed in the absence of the barostat bag and should be considered a non physiological barostat-induced phenomenon, (3) apart from gastric volume changes additional information on motility and emptying are provided. Further study on the presence of an accommodation response under physiological circumstances in health and disease is required. These data might provide more insight into the value of impaired accommodation in disease and it's clinical relevance. 


\section{References}

1. Salet GA, Samsom M, Roelofs JM, van Berge Henegouwen GP, Smout AJ, Akkermans LM. Responses to gastric distension in functional dyspepsia. Gut 1998;42:823-9.

2. Vu MK, Straathof JW, Schaar PJ, Arndt JW, Ringers J, Lamers CB, Masclee AA. Motor and sensory function of the proximal stomach in reflux disease and after laparoscopic Nissen fundoplication. Am J Gastroenterol 1999;94:1481-9.

3. Parkman HP, Hasler WL, Fisher RS. American Gastroenterological Association medical position statement: diagnosis and treatment of gastroparesis. Gastroenterology 2004;127:1589-91.

4. Whitehead WE, Delvaux M. Standardization of barostat procedures for testing smooth muscle tone and sensory thresholds in the gastrointestinal tract. The Working Team of Glaxo-Wellcome Research, UK. Dig Dis Sci 1997;42:223-41.

5. De Schepper HU, Cremonini F, Chitkara D, Camilleri M. Assessment of gastric accommodation: overview and evaluation of current methods. Neurogastroenterol Motil 2004;16:275-85.

6. Tack J, Piessevaux H, Coulie B, Caenepeel P, Janssens J. Role of impaired gastric accommodation to a meal in functional dyspepsia. Gastroenterology 1998;115:1346-52.

7. Lindeboom MY, Vu MK, Ringers J, van Rijn PJ, Neijenhuis P, Masclee AA. Function of the proximal stomach after partial versus complete laparoscopic fundoplication. Am J Gastroenterol 2003;98: 284-90.

8. Mundt MW, Hausken T, Samsom M. Effect of intragastric barostat bag on proximal and distal gastric accommodation in response to liquid meal. Am J Physiol Gastrointest Liver Physiol 2002;283: G681-G6.

9. Geliebter A. Discussion on independent influences of body mass and gastric volumes on satiation in humans. Gastroenterology 2004;127:1276-7.

10. Kim DY, gado-Aros S, Camilleri M, Samsom M, Murray JA, O'Connor MK, Brinkmann BH, Stephens DA, Lighvani SS, Burton DD. Noninvasive measurement of gastric accommodation in patients with idiopathic nonulcer dyspepsia. Am J Gastroenterol 2001;96:3099-105.

11. Fraser R, Schwizer W, Borovicka J, Asal K, Fried M. Gastric motility measurement by MRI. Dig Dis Sci 1994;39:20S-3S.

12. Kunz P, Crelier GR, Schwizer W, Borovicka J, Kreiss C, Fried M, Boesiger P. Gastric emptying and motility: assessment with MR imaging--preliminary observations. Radiology 1998;207:33-40.

13. Feinle $C$, Kunz P, Boesiger P, Fried M, Schwizer W. Scintigraphic validation of a magnetic resonance imaging method to study gastric emptying of a solid meal in humans. Gut 1999;44:106-11.

14. Boulby P, Moore R, Gowland P, Spiller RC. Fat delays emptying but increases forward and backward antral flow as assessed by flow-sensitive magnetic resonance imaging. Neurogastroenterol Motil 1999;11:27-36.

15. Wright J, Evans D, Gowland P, Mansfield P. Validation of antroduodenal motility measurements made by echo-planar magnetic resonance imaging. Neurogastroenterol Motil 1999;11:19-25.

16. Marciani L, Young P, Wright J, Moore R, Coleman N, Gowland PA, Spiller RC. Antral motility measurements by magnetic resonance imaging. Neurogastroenterol Motil 2001;13:511-8.

17. de Zwart IM, Mearadji B, Lamb HJ, Eilers PH, Masclee AA, de Roos A, Kunz P. Gastric motility: comparison of assessment with real-time MR imaging or barostat measurement initial experience. Radiology 2002;224:592-7.

18. Bouras EP, gado-Aros S, Camilleri M, Castillo EJ, Burton DD, Thomforde GM, Chial HJ. SPECT imaging of the stomach: comparison with barostat, and effects of sex, age, body mass index, and fundoplication. Single photon emission computed tomography. Gut 2002;51:781-6.

19. Simonian HP, Maurer AH, Knight LC, Kantor S, Kontos D, Megalooikonomou V, Fisher RS, Parkman HP. Simultaneous assessment of gastric accommodation and emptying: studies with liquid and solid meals. J Nucl Med 2004;45:1155-60.

20. Azpiroz F, Malagelada JR. Physiological variations in canine gastric tone measured by an electronic barostat. Am J Physiol 1985;248:G229-G37. 
21. Tack J, Caenepeel P, Fischler B, Piessevaux H, Janssens J. Symptoms associated with hypersensitivity to gastric distention in functional dyspepsia. Gastroenterology 2001;121:526-35.

22. Sarnelli G, Vos R, Cuomo R, Janssens J, Tack J. Reproducibility of gastric barostat studies in healthy controls and in dyspeptic patients. Am J Gastroenterol 2001;96:1047-53.

23. Boeckxstaens GE, Hirsch DP, Kuiken SD, Heisterkamp SH, Tytgat GN. The proximal stomach and postprandial symptoms in functional dyspeptics. Am J Gastroenterol 2002;97:40-8.

24. Cannon WB, Lieb CW. The receptive relaxation of the stomach. Am J Physiol 1911;29:267-73.

25. van den Elzen BD, Bennink RJ, Wieringa RE, Tytgat GN, Boeckxstaens GE. Fundic accommodation assessed by SPECT scanning: comparison with the gastric barostat. Gut 2003;52:1548-54.

26. Coffin B, Azpiroz F, Guarner F, Malagelada JR. Selective gastric hypersensitivity and reflex hyporeactivity in functional dyspepsia. Gastroenterology 1994;107:1345-51.

27. Hebbard GS, Reid K, Sun WM, Horowitz M, Dent J. Postural changes in proximal gastric volume and pressure measured using a gastric barostat. Neurogastroenterol Motil 1995;7:169-74.

28. Horowitz M, Jones K, Edelbroek MA, Smout AJ, Read NW. The effect of posture on gastric emptying and intragastric distribution of oil and aqueous meal components and appetite. Gastroenterology 1993;105:382-90. 


\section{Chapter 4}

Gastric volume changes in response to a meal: validation of Magnetic Resonance Imaging versus the barostat

J.J.L. Haans I.M. de Zwart P.H.C. Eilers J.H.C. Reiber J. Doornbos A. de Roos A.A.M. Masclee 


\section{Abstract}

\section{Aims}

To determine the accuracy of MRI volume scans: (1) to measure known meal volumes in vitro, and (2) to compare volume changes in response to a meal measured with the barostat with those measured with MRI in vivo.

\section{Materials and Methods}

Polyethylene bags were filled with known volumes and MRI volume scans were performed to determine the accuracy of the volume measurements. Barostat measurements and MRI volume scans were performed simultaneously in 14 healthy subjects before and up to $90 \mathrm{~min}$ after ingestion of a liquid meal.

\section{Results}

In vitro MRI determined volumes showed an excellent linear relationship $(r=0.995, p<0.001)$ with actual meal volumes. Although fasting gastric volume, postprandial gastric volume and relaxation volume measured with MRI were significantly larger compared to volumes measured with the barostat, volumes determined with both techniques showed excellent correlation.

\section{Conclusions}

Volumes in the range of postprandial meal volumes are accurately measured with MRI. MRI is a non-invasive technique to measure stomach volumes and volume changes in response to a meal. Volume changes in response to a meal measured with MRI correlate perfectly with those measured with the barostat device. 


\section{Introduction}

The barostat technique is currently considered the gold standard for measurement of gastric accommodation in response to a meal ${ }^{1,2}$. Gastric accommodation is a vagally mediated reflex that occurs in response to ingestion of a meal and results in a reduction of gastric wall tone with an increase in proximal stomach volume. The accommodation reflex consists of two components: receptive relaxation that occurs within seconds after the onset of gastric filling and adaptive relaxation, a process whereby stomach volume increases to twice the volume of a meal. Gastric accommodation has primarily been studied with the barostat ${ }^{3,4}$.

The barostat technique requires oral intubation of a polyethylene bag attached to a catheter that can be inflated and deflated in order to obtain a constant pressure inside the bag. Measurement of the volume changes under isobaric circumstances provides insight in the response of the proximal stomach to different stimuli, i.e. a meal. More recently non-invasive imaging techniques have been employed to study gastric volume changes ${ }^{5-7}$. In a previous study ${ }^{8}$ a good correlation between barostat and $\mathrm{MRI}$ with respect to gastric volumes and dynamic volume changes in healthy volunteers under fasting conditions and in response to glucagon (gastric relaxation) and erythromycin (antral contractions) was shown. However, further in vivo validation of the MRI technique is required. Data comparing volume changes of the stomach in response to a meal measured with the barostat and MRI technique simultaneously are lacking?.

In a recent study ${ }^{10}$ we have assessed the influence of the barostat device on gastric volume changes and motility measured with MRI. We compared data obtained with MRI in the presence of a barostat bag with data obtained with MRI when a barostat bag was not present. In that study, data on gastric volume changes measured with MRI and barostat data have not been compared or analyzed. In this study (1) additional in vitro experiments have been performed to determine the accuracy of MRI volume scans to measure known meal volumes in vitro and (2) additional analyses have been performed on previously obtained data to compare volume changes in response to a meal measured with the barostat with volume changes measured with MRI during simultaneous recording.

\section{Materials and Methods}

\section{Subjects}

Fourteen healthy subjects ( 8 women, 6 men; mean age $23 \pm 5$ years) participated in the study. None of the subjects had a history of gastrointestinal disease or abdominal surgery, or were taking medication known to influence gastrointestinal function. The 
Medical Ethics Committee had approved the study protocol and written informed consent was obtained from each participating subject.

\section{Study design}

Each experiment was started after at least 10 hours fasting. A catheter with bag was introduced through the mouth and positioned in the fundus of the stomach as described previously ${ }^{10}$.

Minimal distending pressure (MDP) was determined. MDP is arbitrarily defined as the first pressure level that provides an intragastric bag volume of more than $30 \mathrm{ml}$. MDP is determined by increasing the intrabag pressure in 1-mmHg steps every minute. Thereafter the barostat was set to maintain a pressure of MDP $+2 \mathrm{mmHg}$ throughout the experiment.

After a short period of adaptation subjects were positioned in the MRI scanner in a right-sided semi-supine position $\left(30^{\circ}\right)$. Volume scans were obtained before and at regular intervals (15 min) after ingestion of a $200 \mathrm{ml}$ liquid meal (Ensure Plus, Abbott, USA, $300 \mathrm{kcal} ; 12.5 \mathrm{~g}$ protein, $40.4 \mathrm{~g}$ carbohydrates, $9.8 \mathrm{~g}$ fat) until $90 \mathrm{~min}$ after meal ingestion. The liquid meal was labeled with $0.5 \mathrm{ml}$ meglumine gadoterate (Dotarem, Laboratoire Guerbet, Roissy CdG Cedex, France) for contrast enhancement.

\section{Gastric barostat}

An electronic barostat (Visceral Stimulator, Medtronic, Skovlunde, Denmark) was used to distend the stomach. A polyethylene bag (1000 ml maximum capacity) was connected to the end of a multilumen catheter (16 Fr). The multilumen catheter was elongated with a 3-m-long catheter (16 Fr) allowing the barostat device to be placed out of the vicinity of the MRI device. A previous study has shown that elongation of the multilumen catheter does not influence MDP, nor does it influence intragastric bag volume ${ }^{8}$. The barostat device keeps the pressure in the intragastric bag at a preselected level. To do so, the system injects air into the bag when the stomach relaxes and aspirates air when the stomach contracts. Maximal airflow was $20 \mathrm{ml} / \mathrm{s}$.

\section{Magnetic Resonance Imaging}

All images were obtained using a 1.5T MRI scanner (ASC-NT; Philips Medical Systems, Best, The Netherlands) and a 4-channel SENSE body coil. A volume scan (20 slices, thickness $10 \mathrm{~mm}$, slice gap $0 \mathrm{~mm}$, echo time $3.48 \mathrm{~ms}$, repetition time $10.00 \mathrm{~ms}$, flip angle $25^{\circ}$, field of view $450 \mathrm{~mm}$, matrix 256×256 pixels, total acquisition time $30 \mathrm{~s}$ ) was performed to determine momentary volumes. This MRI technique has been used and validated previously ${ }^{8,10-12}$. 


\section{MRI measurements of predefined meal volumes in vitro}

Eight polyethylene bags were filled with known volumes of a meglumine gadoterate (Dotarem:, Laboratoire Guerbet, Roissy CdG Cedex, France) labeled liquid meal (Ensure Plus, Abbott). Volumes ranged from 25 to $600 \mathrm{ml}$. Volume scans were acquired using previously validated MRI techniques ${ }^{8,10-12}$.

\section{Data analysis}

Intragastric air and contents were identified and outlined manually in all images using an in-house made interactive software too ${ }^{13}$. All images were reanalyzed as the interactive software tool used to determine in vitro volumes was different from the software tool used in our previous publication ${ }^{10}$. Volumes were calculated by adding the calculated surfaces of all outlined areas multiplied with the slice thickness. Total gastric volume was calculated by adding intragastric air and contents volumes. This method has been described previously ${ }^{8}$.

Several parameters were determined from the acquired data. (1) Fasting gastric volume $(\mathrm{ml})$ was defined as the volume in the period prior to consumption of the meal. (2) Postprandial gastric volume was defined as the mean of the volumes acquired at 15 and $30 \mathrm{~min}$. postprandial. (3) Relaxation volume was presented as the difference between postprandial and fasting gastric volumes, and relaxation ratio as the ratio of postprandial to fasting gastric volumes.

For comparison intragastric bag volume was determined using the mean bag volume over a $30 \mathrm{sec}$. period, equal to the acquisition time for momentary volumes measured by MRI.

\section{Statistical analysis}

Data were analyzed using a statistical software package (SPSS ${ }^{\circledR}$ for Windows Release 15.0, SPSS Inc., Chicago, USA). All data are provided as mean (SD) or mean \pm SE where appropriate. All data were tested for normality. Paired-samples t-test and Pearson's product-moment coefficient were used to detect differences in data. The level of significance was set at $p<0.05$.

\section{Results}

\section{MRI measurements of predefined meal volumes in vitro}

MRI determined meal volumes showed an excellent linear relationship with actual meal volumes $(r=0.995, p<0.001)$. However, meal volumes determined with MRI differed significantly from the actual meal volumes (mean difference of $25 \mathrm{ml}$ [4-46], 
$\mathrm{p}=0.024)$. Linear regression provided a relation, where volume $\mathrm{MRI}(\mathrm{ml})=7.6 \pm 16.4+$ $1.05 \pm 0.043 *$ volume $_{\text {actual }}$ (Figure 4.1).

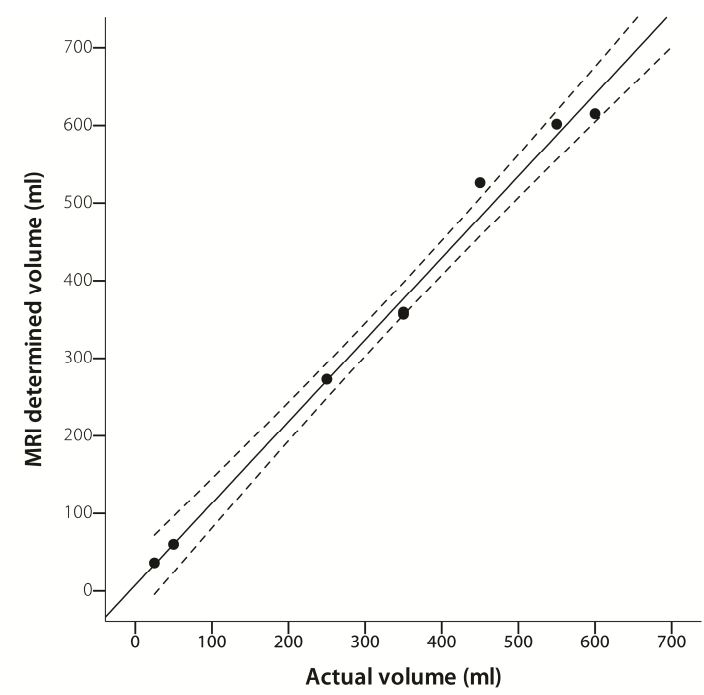

Figure 4.1 In vitro experiments: correlation of actual meal volumes ( $\mathrm{ml}$ ) and volumes measured by MRI $(\mathrm{ml})$, showing the regression line and the $95 \% \mathrm{Cl}$.

\section{Simultaneous MRI and barostat assessment of the stomach in vivo}

Figure 4.2 shows a typical tracing of the proximal stomach volume of an individual in response to a meal measured by the barostat device and MRI.

Minimal distending pressure was 4.9 (1.4) $\mathrm{mmHg}$. Fasting intragastric bag volume at MDP+2 mmHg was 223 (41) ml. Figure 4.3, adapted from de Zwart et al. ${ }^{10}$, shows mean intragastric bag volumes measured with the barostat device throughout the experiment. Intragastric bag volume $15 \mathrm{~min}$ after meal intake was 440 (154) ml, corresponding to an increase of 217 (169) $\mathrm{ml}, \mathrm{p}<0.001$.

Fasting gastric volume measured with MRI was 400 (148) ml. Postprandial gastric volume $15 \mathrm{~min}$ after meal intake was 860 (119) $\mathrm{ml}$, corresponding to an increase of 460 (197) $\mathrm{ml}, \mathrm{p}<0.001$. Table 4.1 shows fasting and postprandial bag and gastric volume measured with barostat and MRI respectively. Fasting, as well as postprandial volumes measured with MRI are significantly larger than those measured with the barostat (Figure 4.3, adapted from de Zwart et al. ${ }^{10}$ ). Nevertheless, the volume data obtained with MRI and barostat show good correlation. Relaxation volume, defined as the postprandial minus the fasting volume, and relaxation ratio, defined as the postprandial divided by the fasting volume, both measured with MRI are significantly larger than accommodation volume and accommodation ratio measured with the 
barostat (Table 4.1). These data do however show excellent correlation $(r=0.89$, $p<0.001$ and $r=0.92, p<0.001$ for accommodation/relaxation volume and accommodation/relaxation ratio, respectively). Figure 4.4 shows the association, as a regression line, and agreement, in a Bland-Altman plot, for relaxation ratio measured with MRI and accommodation ratio measured with the barostat.
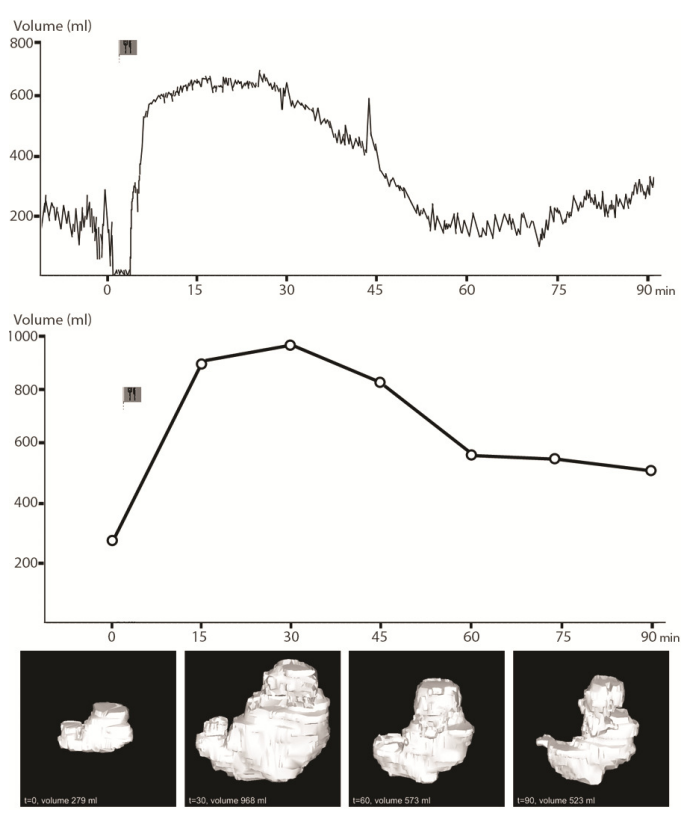

Figure 4.2 Individual tracing of the intragastric bag volume $(\mathrm{ml})$ obtained with the barostat, MRI volumes $(\mathrm{ml})$ and $3 \mathrm{D}$ visualization of stomach volumes measured by MRI $(\mathrm{ml})$ prior to and after consumption of a liquid meal.

Table 4.1 Volumes ( $\mathrm{ml}$ ) measured with MRI and barostat and the accommodation/relaxation response to a liquid meal.

\begin{tabular}{llll}
\hline & Barostat & MRI & CC \\
\hline Fasting gastric volume $(\mathrm{ml})$ & $223(41)$ & $400(148)^{*}$ & $0.71(\mathrm{p}=0.005)$ \\
Postprandial gastric volume $(\mathrm{ml})$ & $428(162)$ & $852(114)^{*}$ & $0.67(\mathrm{p}=0.008)$ \\
Accommodation/relaxation volume $(\mathrm{ml})^{\dagger}$ & $205(179)$ & $451(212)^{*}$ & $0.89(\mathrm{p}<0.001)$ \\
Accommodation/relaxation ratio $(\mathrm{ml})^{+}$ & $2.05(1.04)$ & $2.52(1.29)^{*}$ & $0.92(\mathrm{p}<0.001)$ \\
\hline
\end{tabular}

Fasting gastric volume (FGV) represents the stomach volume prior to meal ingestion. Postprandial gastric volume (PGV) represents the mean stomach volume over the first $30 \mathrm{~min}$. postprandial. Relaxation volume is defined as PGV minus FGV, whereas relaxation ratio is defined as PGV divided by FGV. Values are mean (SD). $C C=$ correlation coefficient. ${ }^{*} \mathrm{p}<0.01$ compared to barostat. ${ }^{\dagger}$ Accommodation volume for the barostat technique and relaxation volume for the MRI technique. 


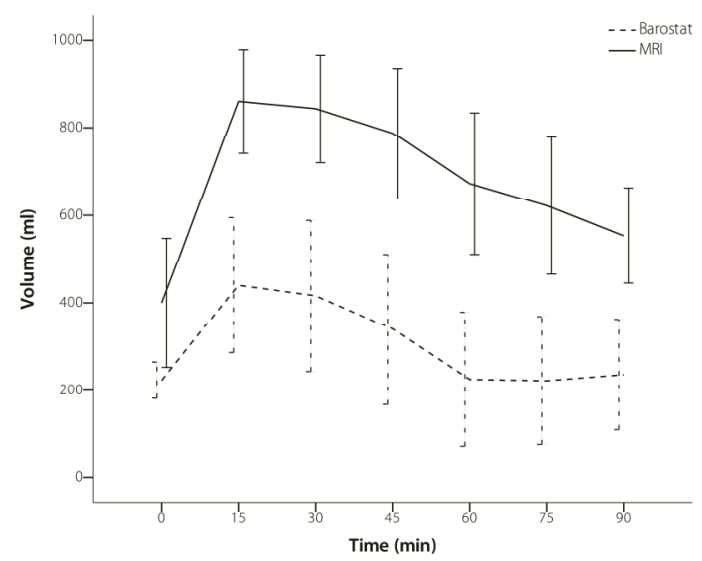

Figure 4.3 Mean intragastric bag volume $(\mathrm{ml})$ measured with the barostat device and total gastric volume (ml) measured with MRI, at 15-minute intervals, prior to and after the administration of a liquid meal. Adapted from de Zwart et al. ${ }^{10}$. Data are mean (SD), $\mathrm{n}=14$.
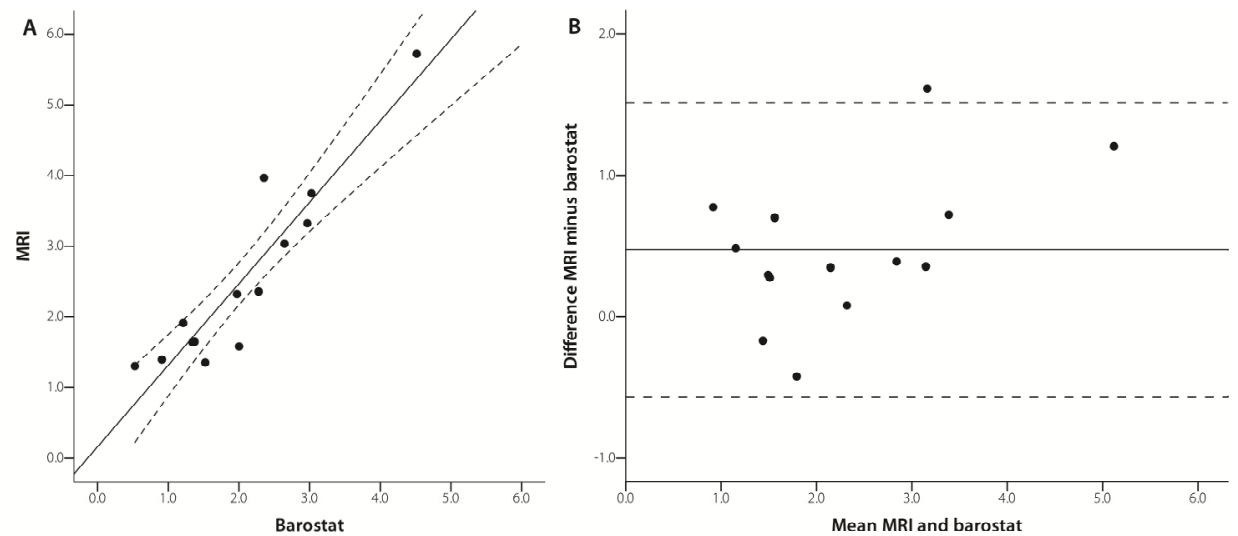

Figure 4.4 (A) Association and (B) agreement of relaxation ratios measured with MRI and accommodation ratios measured with the barostat, showing $(A)$ the regression line and the $95 \% \mathrm{Cl}$ and $(\mathrm{B})$ the limits of agreement.

\section{Discussion}

The in vitro experiments show that MRI accurately estimates meal volumes, although actual volumes are overestimated by approximately $5 \%$. This may result from the current scan protocol and is more pronounced at relatively small volumes. The overestimation is most likely due to the limited spatial resolution of the pixels and 
the slice thickness of $10 \mathrm{~mm}$ in our scan protocol. The current spatial resolution along the Z-axis (slice thickness) will be insufficient to precisely measure very small volumes (partial volume effect). In addition, the use of a paramagnetic contrast agent is likely to induce an overestimation of the measured area of the object in the XY plane due to the high MR-intensity of the region of interest.

The fasting and postprandial volumes measured with the MRI technique in the in vivo experiments were significantly larger than the volumes measured with the barostat. However, both measurements showed high correlation. It was anticipated that MRI would provide larger estimates of the volumes than those measured with the barostat method. This apparent difference in volume estimates is explained by the way MRI measurements are performed. MRI measures total gastric volume that includes not only intragastric air and contents of the proximal stomach, but also intragastric air and contents of the distal stomach. In contrast to the MRI method, the barostat provides volume estimations only for the proximal stomach, without taking into account the ingested meal or air present outside the barostat bag or located in the distal stomach. The validity of the MRI measurements is underlined by a highly significant and excellent correlation between volume changes in response to a meal, expressed as the relaxation volumes and relaxation ratios, as compared to the accommodation volumes and accommodation ratios measured with the barostat.

Our barostat data are in line with data published in various studies and performed by different groups. Tack et al. ${ }^{4}$ using a similar sized meal $(200 \mathrm{ml})$ observed an increase in accommodation volume of $223 \pm 13 \mathrm{ml}$ with a fasting bag volume of $178 \pm 14 \mathrm{ml}$. Boeckxstaens et al. ${ }^{14}$, using a similar protocol, showed an increase in accommodation volume of $183 \pm 32 \mathrm{ml}$ and a fasting bag volume of $286 \pm 23 \mathrm{ml}$. Our barostat results (Table 1) are comparable to those observed by both authors ${ }^{4,14}$.

The present study provides further data to support the concurrent validity of the MRI technique to measure postprandial gastric motor function, i.e. gastric volume changes in response to a meal. MRI has been validated versus the barostat device under fasting conditions and in response to pharmacological interventions (glucagon, erythromycin), showing a significant correlation for measured volumes ${ }^{8}$. Moreover, previous studies have validated MRI against scintigraphy in the measurement of gastric emptying. MRI has been applied to study gastric motor function in response to different nutrients and drugs. In addition to measuring volume changes and emptying, MRI provides an opportunity to study both proximal and distal intragastric meal and air distribution , $10,15-19^{\text {. }}$

A possible disadvantage of our study is the supine position of subjects while evaluating gastric function. Availability of MRI scanners that allow scanning in an upright position is limited worldwide. Treier et al. ${ }^{20}$ previously compared several parameters of human gastric motor function in up-right and supine position using an open-configuration MRI system and a regular whole body MRI system, respectively. These authors did not observe a position dependent difference in fasting and 
postprandial volumes. Moreover, no difference was observed in relaxation volume between the upright and supine position.

We conclude that volumes in the range of postprandial meal volumes are accurately measured with MRI. MRI is a non-invasive technique to measure gastric volumes and volume changes in response to a meal. Relaxation volumes and ratios measured with MRI show excellent correlation with accommodation volumes and ratios measured with the barostat device. MRI seems to be a reliable method to assess relaxation of the stomach in response to a meal; however, further validation in health and disease is required. 


\section{References}

1. Tack J, Caenepeel P, Fischler B, Piessevaux H, Janssens J. Symptoms associated with hypersensitivity to gastric distention in functional dyspepsia. Gastroenterology 2001;121:526-35.

2. De Schepper HU, Cremonini F, Chitkara D, Camilleri M. Assessment of gastric accommodation: overview and evaluation of current methods. Neurogastroenterol Motil 2004;16:275-85.

3. Mearin F, Cucala M, Azpiroz F, Malagelada JR. The origin of symptoms on the brain-gut axis in functional dyspepsia. Gastroenterology 1991;101:999-1006.

4. Tack J, Piessevaux H, Coulie B, Caenepeel P, Janssens J. Role of impaired gastric accommodation to a meal in functional dyspepsia. Gastroenterology 1998;115:1346-52.

5. Mundt MW, Samsom M. Fundal dysaccommodation in functional dyspepsia: head-to-head comparison between the barostat and three-dimensional ultrasonographic technique. Gut 2006;55:1725-30.

6. van den Elzen BD, Bennink RJ, Wieringa RE, Tytgat GN, Boeckxstaens GE. Fundic accommodation assessed by SPECT scanning: comparison with the gastric barostat. Gut 2003;52:1548-54.

7. Bouras EP, gado-Aros S, Camilleri M, Castillo EJ, Burton DD, Thomforde GM, Chial HJ. SPECT imaging of the stomach: comparison with barostat, and effects of sex, age, body mass index, and fundoplication. Single photon emission computed tomography. Gut 2002;51:781-6.

8. de Zwart IM, Mearadji B, Lamb HJ, Eilers PH, Masclee AA, de Roos A, Kunz P. Gastric motility: comparison of assessment with real-time MR imaging or barostat measurement initial experience. Radiology 2002;224:592-7.

9. Camilleri M. Response to letter from Dr Haans and Professor Masclee. Neurogastroenterol Motil 2006;18:1042.

10. de Zwart IM, Haans JJ, Verbeek P, Eilers PH, de Roos A, Masclee AA. Gastric accommodation and motility are influenced by the barostat device: Assessment with magnetic resonance imaging. Am J Physiol Gastrointest Liver Physiol 2007;292:G208-G14.

11. Kunz P, Crelier GR, Schwizer W, Borovicka J, Kreiss C, Fried M, Boesiger P. Gastric emptying and motility: assessment with MR imaging--preliminary observations. Radiology 1998;207:33-40.

12. Kunz P, Feinle C, Schwizer W, Fried M, Boesiger P. Assessment of gastric motor function during the emptying of solid and liquid meals in humans by MRI. J Magn Reson Imaging 1999;9:75-80.

13. Admiraal-Behloul F, van den Heuvel DM, Olofsen $H$, van Osch MJ, van der Grond J, van Buchem MA, Reiber JH. Fully automatic segmentation of white matter hyperintensities in MR images of the elderly. Neuroimage 2005;28:607-17.

14. Boeckxstaens GE, Hirsch DP, Kuiken SD, Heisterkamp SH, Tytgat GN. The proximal stomach and postprandial symptoms in functional dyspeptics. Am J Gastroenterol 2002;97:40-8.

15. Schwizer W, Maecke H, Fried M. Measurement of gastric emptying by magnetic resonance imaging in humans. Gastroenterology 1992;103:369-76.

16. Feinle $C$, Kunz $P$, Boesiger $P$, Fried $M$, Schwizer W. Scintigraphic validation of a magnetic resonance imaging method to study gastric emptying of a solid meal in humans. Gut 1999;44:106-11.

17. Fraser R, Schwizer W, Borovicka J, Asal K, Fried M. Gastric motility measurement by MRI. Dig Dis Sci 1994;39:20S-3S.

18. Wright J, Evans D, Gowland P, Mansfield P. Validation of antroduodenal motility measurements made by echo-planar magnetic resonance imaging. Neurogastroenterol Motil 1999;11:19-25.

19. Marciani L, Young P, Wright J, Moore R, Coleman N, Gowland PA, Spiller RC. Antral motility measurements by magnetic resonance imaging. Neurogastroenterol Motil 2001;13:511-8.

20. Treier R, Steingoetter A, Weishaupt D, Goetze O, Boesiger P, Fried M, Schwizer W. Gastric motor function and emptying in the right decubitus and seated body position as assessed by magnetic resonance imaging. J Magn Reson Imaging 2006;23:331-8. 


\section{Chapter 5}

\section{Effect of sildenafil on gastric motor function}

measured with Magnetic Resonance Imaging

J.J.L. Haans

N.P.M. Paridaans

P.H.C. Eilers

R. van der Landen J.H.C. Reiber J. Doornbos

A. de Roos A.A.M. Masclee 


\section{Abstract}

\section{Background}

Previous studies employing the barostat have shown that gastric accommodation consists of an adaptive relaxation of the stomach that is larger than the volume of the meal provided. Relaxation consists mainly of an adaptation equal to the volume of the meal provided, when measured by Magnetic Resonance Imaging (MRI). Sildenafil has been shown to enhance relaxation, when measured by barostat.

\section{Aims}

To evaluate the effect of sildenafil on gastric motor function with MRI.

\section{Materials and Methods}

Twelve healthy subjects participated in two experiments (sildenafil and placebo) performed on separate days. Momentary volume changes in response to a solid meal were studied using volume scans.

\section{Results}

Gastric retention was significantly $(p<0.05)$ larger for sildenafil compared to placebo: $74 \pm 16 \%$ vs. $64 \pm 13 \%$ at $90 \mathrm{~min}, 61 \pm 19 \%$ vs. $49 \pm 12 \%$ at $120 \mathrm{~min}, 39 \pm 23 \%$ vs. $28 \pm 12 \%$ at $180 \mathrm{~min}$ respectively. Throughout the experiment proximal gastric contents were significantly larger for sildenafil compared to placebo, whereas distal gastric contents did not differ significantly. Proximal gastric relaxation (proximal gastric volume divided by total gastric volume) was significantly $(p<0.05)$ larger for sildenafil compared to placebo; 0.563 [0.543-0.582] vs. 0.534 [0.515-0.553] respectively. Proximal receptiveness for contents (proximal contents volume divided by total contents volume) was significantly $(p<0.05)$ larger for sildenafil compared to placebo; 0.737 [0.714-0.759] and 0.695 [0.673-0.717] respectively.

\section{Conclusions}

We conclude that, measured with MRI, the phosphodiesterase inhibitor sildenafil (1) enhances proximal gastric relaxation, (2) affects intragastric meal distribution with more pronounced proximal meal receptiveness and (3) delays the onset of gastric emptying but does not affect emptying rate. 


\section{Introduction}

Gastric accommodation is the response of the stomach to a meal and consists of receptive and adaptive relaxation'. The barostat technique is currently considered the gold standard for measurement of gastric accommodation ${ }^{2,3}$. Many papers have been published concerning gastric accommodation in health, disease and in response to pharmacological interventions ${ }^{4-8}$.

Magnetic Resonance Imaging (MRI) has become an attractive, non-invasive alternative method to document gastric emptying, gastric motility and changes in gastric volume ${ }^{9-13}$. In a previous study $M R I$ has been validated as a technique to measure gastric motility and volume changes, by comparing MRI and the barostat technique during simultaneous recording ${ }^{10,14}$. The magnitude of postprandial volume changes however is more pronounced when recorded by the barostat, because an inflated intra-gastric barostat bag distends the stomach ${ }^{15}$.

A vagovagal reflex pathway is involved in the accommodation reflex with nitric oxide (NO) as an important neurotransmitter. Previous barostat studies have shown an increase in postprandial gastric volume in response to intravenous nitrate administration ${ }^{16,17}$. Sildenafil, a selective phosphodiesterase type 5-inhibitor (PDE-5), is known to affect this vagovagal reflex pathway. Sildenafil inhibits PDE-5, an enzyme that breaks down cyclic guanosine monophosphate (cGMP). Hence, in the presence of sildenafil, NO-induced cGMP accumulates, decreasing cystosolic $\mathrm{Ca}^{2+}$ levels and inducing smooth muscle relaxation ${ }^{16,18,19}$

Contrasting results have been reported with respect to the effect of sildenafil on gastric motor function in humans. This may result from different techniques being employed that only measure certain aspects of gastric function separately. While Sarnelli et al. ${ }^{16}$ pointed to an increase in proximal gastric accommodation and a delay in gastric emptying, Cho et al. did not observe changes in gastric emptying after ingestion of sildenafil ${ }^{18}$.

Aim of our study was to evaluate human gastric motor function in response to sildenafil with MRI, allowing simultaneous measurement of gastric volumes, relaxation, emptying and intragastric distribution. This may provide further insight in the role of NO in gastric motor function and possibly answers previously unresolved questions that are due to technical and methodological aspects.

\section{Materials and Methods}

\section{Subjects}

Twelve healthy subjects (two men, ten women; mean age 21.3 years; range 18-26 years; BMI $23 \pm 3 \mathrm{~kg} / \mathrm{m}^{2}$ ) participated in the study. None of the subjects had a history of gastrointestinal disease or abdominal surgery and none were taking 
medication known to influence gastrointestinal motor or sensory function. The Medical Ethics Committee had approved the study protocol and written informed consent was obtained from each subject.

\section{Study protocol}

A randomized single blind placebo controlled crossover study was performed consisting of two experiments. The experiments were performed on separate days, in random order, with an interval of at least 6 days.

Each subject was studied after at least 6 hours of fasting. The subject was positioned in the MRI scanner and initial scans were performed to determine geometric position of the stomach. The study was started with a volume scan to determine momentary gastric contents and intragastric air volume (time -30 min). Immediately thereafter either sildenafil (Viagra ${ }^{\circledR}$; Pfizer BV, Capelle a/d IJssel, the Netherlands) 50 mg or placebo was ingested orally with some water. Following administration of the study drug a volume scan was performed every $5 \mathrm{~min}$. After $30 \mathrm{~min}$ (time $0 \mathrm{~min}$ ) a solid meal was provided, consisting of a scrambled egg, two slices of white bread and 5 grams of margarine ( $261 \mathrm{kcal}$ ). The subject was asked to consume the meal within $10 \mathrm{~min}$. During and after meal consumption, volume scans were performed every 5 min until 90 min after meal consumption. Thereafter three additional scans were performed at 120,180 and $240 \mathrm{~min}$.

\section{Magnetic resonance imaging}

All images were obtained using a 1.5T MRI scanner (ASC-NT; Philips Medical Systems, Best, The Netherlands) and a 4-channel SENSE body coil. A volume scan (22 slices, thickness $10 \mathrm{~mm}$, slice gap $0 \mathrm{~mm}$, echo time $3.48 \mathrm{~ms}$, repetition time $10 \mathrm{~ms}$, flip angle $25^{\circ}$, field of view $450 \mathrm{~mm}$, matrix $256 \times 256$, total acquisition time $30 \mathrm{sec}$ ) was performed to determine momentary volumes. This MRI technique has been used and validated previously ${ }^{15,20}$.

\section{Data analysis}

Prior to analysis all data were anonymized. One observer (NP) analyzed all obtained images. Intragastric air and gastric contents were identified and outlined manually in all images using an in-house made interactive software tool (SNIPER ${ }^{\circledR}$, LKEB, Leiden University Medical Center, The Netherlands). Volumes were calculated by adding the calculated surfaces of all outlined areas multiplied with the slice thickness. Total gastric volume was calculated by adding intragastric air and gastric contents volumes. This method has been described previously ${ }^{10}$.

Several parameters were determined from acquired data. (1) Fasting gastric volume ( $\mathrm{ml}$ ) was defined as the volume in the period prior to consumption of the meal. (2) Postprandial gastric volume was defined as the mean of the volumes acquired at 
15 and 30 min postprandial. (3) Relaxation volume was defined as the difference between postprandial and fasting gastric volume.

The well-known bi-phasic model by Siegel et al. ${ }^{21}$ was used to fit gastric contents data and obtain parameters of gastric emptying. Parameters determined included lag time, half emptying time and retention. Lag time was defined as the time at which $5 \%$ of gastric contents were emptied from the stomach. Retention was defined as the percentage of gastric contents remaining in the stomach at predefined moments (90, 120, 180 and $240 \mathrm{~min})$ after meal ingestion.

Intragastric distribution was defined as the distribution of intragastric contents over the proximal and distal part of the stomach and expressed as contents volume ( $\mathrm{ml}$ ). The stomach was divided in a proximal and distal part by anatomical localization of the incisura ${ }^{13}$. In a 3D reconstruction of the stomach, the incisura was localized and the slice position determined. This slice and all cranially located slices were considered 'proximal'. All slices caudally located were considered 'distal'. Hence proximal and distal volumes for intragastric air, gastric contents and gastric volume could be determined. In addition, we determined the proximal volume in relation to total volume for (a) gastric volume and (b) gastric contents volume. Here PGV/TGV represents the proximal gastric volume (PGV) divided by the total gastric volume (TGV), whereas PCV/TCV represents the proximal contents volume (PCV) divided by the total contents volume (TCV). PGV/TGV provides data concerning proximal relaxation, whereas $\mathrm{PCV} / \mathrm{TCV}$ provides data concerning proximal distribution (receptiveness) of gastric contents.

\section{Statistical analysis}

Data were analyzed using a statistical software package (SPSS ${ }^{\circledR}$ for Windows Release 18.0, SPSS Inc., Chicago, USA). All data are provided as mean \pm SD. All samples were tested for normality. A generalized linear model (GLM) univariate analysis and pairedsamples t-test was used to detect differences in data between the experiments. For GLM univariate analysis, data was analyzed in the model using time and intervention as fixed factors. The level of significance was set at $p<0.05$.

\section{Results}

Two subjects were excluded because analysis showed that their stomach was partially filled with gastric contents prior to the experiment; data of 10 subjects were used for further analysis. 


\section{Gastric volumes}

Fasting gastric volumes at baseline (time $-30 \mathrm{~min}$ ) were not significantly different; $51 \pm 27 \mathrm{ml}$ vs. $52 \pm 24 \mathrm{ml}$ for sildenafil and placebo respectively. Sildenafil did not affect fasting gastric volumes. Fasting gastric volumes at time 0 min were $55 \pm 33 \mathrm{ml}$ and $57 \pm 30 \mathrm{ml}$ for sildenafil and placebo respectively.

Gastric volumes in response to the meal for both experiments are shown in Figure 5.1. The meal significantly increased gastric volume in both experiments. Immediately after meal ingestion (time $10 \mathrm{~min}$ ) gastric volumes were not significantly different; $251 \pm 48 \mathrm{ml}$ vs. $266 \pm 30 \mathrm{ml}$ for sildenafil and placebo respectively. Throughout the experiment gastric volume was significantly larger for sildenafil compared to placebo. The area under the curve for gastric volume was significantly larger for sildenafil compared to placebo; $44265 \pm 7931 \mathrm{ml} \cdot \mathrm{min}$ vs. $40067 \pm 6108$ $\mathrm{ml} \cdot \mathrm{min}$ respectively (Figure 5.2). Relaxation volume in response to a meal did not differ significantly $(p=0.798)$ between sildenafil and placebo; $192 \pm 17 \mathrm{ml}$ vs. $188 \pm 18 \mathrm{ml}$ respectively.

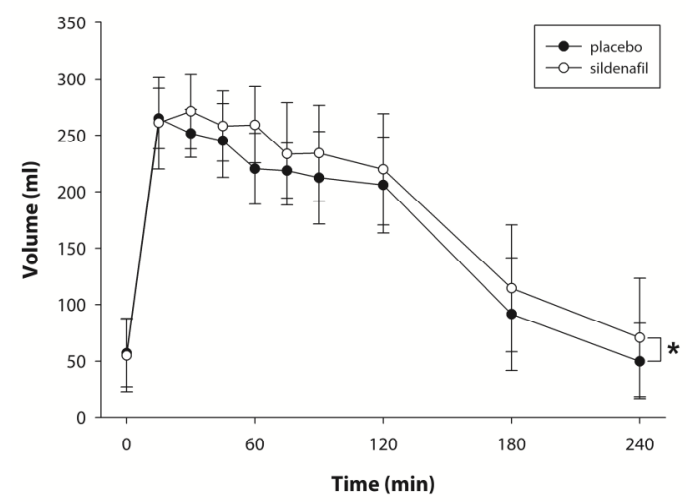

Figure 5.1 Gastric volumes before and after meal ingestion in ten healthy subjects after administration of either sildenafil or placebo. Values are shown as mean \pm SD. ${ }^{*} p<0.05$ compared to placebo throughout the experiment.

\section{Gastric contents}

Figure 5.3 shows the effect of sildenafil on gastric contents during the postprandial period. Immediately after meal ingestion (time $10 \mathrm{~min}$ ) gastric contents did not differ significantly between the experiments; $182 \pm 29 \mathrm{ml}$ vs. $195 \pm 20 \mathrm{ml}$ for sildenafil and placebo respectively. However, throughout the experiment gastric contents were significantly larger for sildenafil compared to placebo. In line, the area under the curve for gastric contents was significantly larger for sildenafil compared to placebo; $28953 \pm 6589 \mathrm{ml} \cdot \mathrm{min}$ vs. $24925 \pm 3630 \mathrm{ml} \cdot \mathrm{min}$ respectively (Figure 5.2). 
Data on gastric emptying are given in Table 5.1. Half emptying time, lag time, retention and emptying rate were not significantly different between the experiments. However, at 90,120 and 180 min significantly more of the meal was retained in the stomach during the sildenafil experiment.

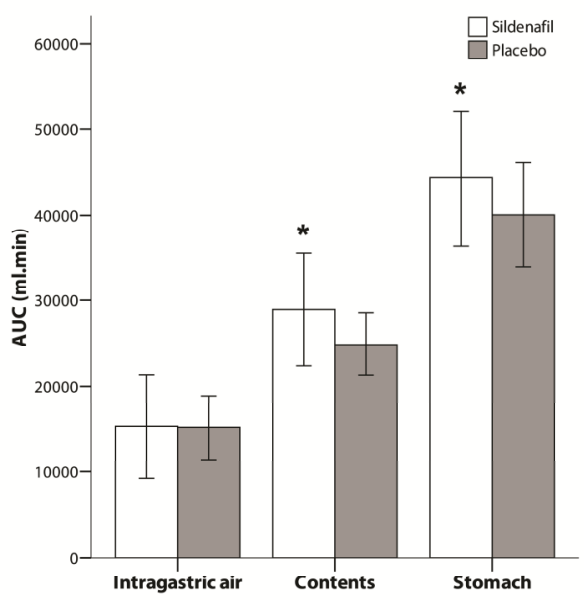

Figure 5.2 Area under the curve (AUC) for the postprandial period for intragastric air, gastric contents and gastric volume. Values are shown as mean \pm SD. ${ }^{*} p<0.05$ compared to placebo.

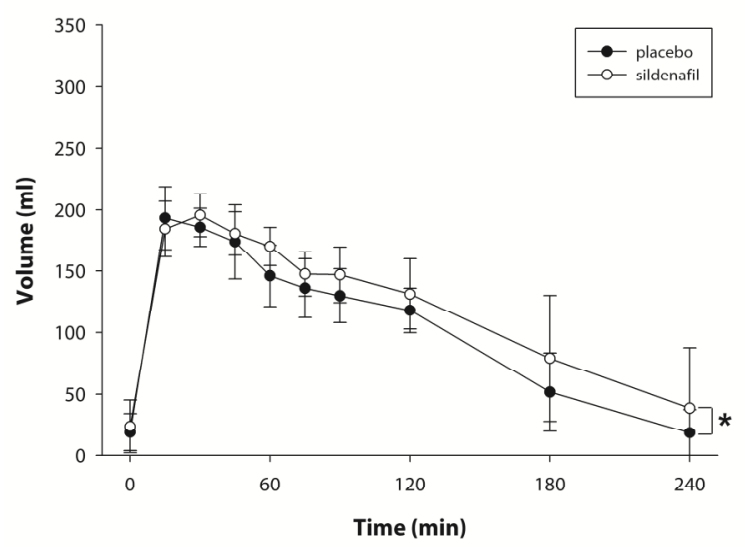

Figure 5.3 Gastric contents in ten healthy subjects after administration of either sildenafil or placebo. 
Table 5.1 Gastric emptying data.

\begin{tabular}{|c|c|c|c|}
\hline & sildenafil & placebo & p-value \\
\hline $\mathrm{T} 1 / 2(\min )$ & $157 \pm 84$ & $120 \pm 34$ & 0.083 \\
\hline Lag time (min) & $55 \pm 47$ & $29 \pm 17$ & 0.075 \\
\hline Emptying rate (ml/min) & $0.69 \pm 0.29$ & $0.68 \pm 0.25$ & 0.888 \\
\hline \multicolumn{4}{|l|}{ Retention } \\
\hline $90 \min (\%)$ & $74 \pm 16$ & $64 \pm 13$ & 0.044 \\
\hline $120 \min (\%)$ & $61 \pm 19$ & $49 \pm 12$ & 0.025 \\
\hline $180 \min (\%)$ & $39 \pm 23$ & $28 \pm 12$ & 0.037 \\
\hline $240 \min (\%)$ & $24 \pm 22$ & $16 \pm 10$ & 0.107 \\
\hline
\end{tabular}

Data are shown as mean \pm SD.

\section{Intragastric air}

Fasting intragastric air volume at time 0 min did not differ significantly between the experiments. After meal ingestion air volume increased in both experiments to $69 \pm 34 \mathrm{ml}$ and $71 \pm 23 \mathrm{ml}$ for sildenafil and placebo respectively. Thereafter air volume decreased in both experiments to baseline values at $\mathrm{t}=240 \mathrm{~min}$. As shown in Figure 5.2 , the area under the curve for intragastric air did not differ significantly between sildenafil and placebo; $15277 \pm 6051 \mathrm{ml} \cdot \mathrm{min}$ vs. $15157 \pm 3736 \mathrm{ml} \cdot \mathrm{min}$ respectively.

\section{Intragastric distribution}

Figure 5.4A and 5.4B show curves of gastric contents immediately after and up to 240 min after meal ingestion for the "proximal" and "distal" part of the stomach respectively. Throughout the experiment distal gastric contents did not differ significantly $(p=0.098$ ) between the experiments (Figure 5.4B). However, proximal gastric contents were significantly larger for sildenafil compared to placebo (Figure 5.4A).

PGV/TGV, as a measure for proximal relaxation, was significantly larger sildenafil compared to placebo throughout the experiment: 0.563 [0.543-0.582] and 0.534 [0.515-0.553] respectively, $p=0.041$ for intervention, $p=0.422$ for time using univariate analysis. Similar results were obtained for PCV/TCV, as a measure for proximal receptiveness; 0.737 [0.714-0.759] and 0.695 [0.673-0.717] for sildenafil and placebo respectively, $p=0.009$ for intervention, $p=0.984$ for time using univariate analysis. 

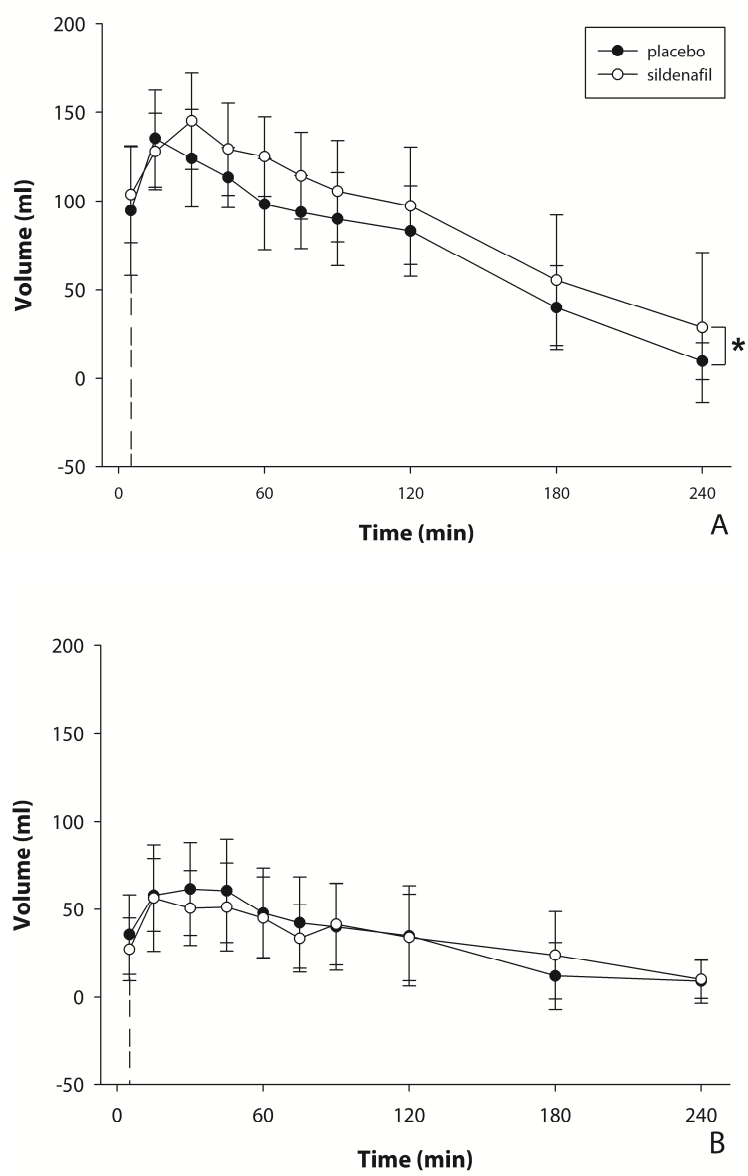

Figure 5.4 Intragastric distribution (A: proximal, B: distal) of gastric contents in ten healthy subjects after administration of either sildenafil or placebo.

\section{Discussion}

In this study we have shown that MRI, as a non-invasive technique, enables determination of pharmacologically induced changes in gastric emptying, relaxation and receptiveness. Moreover, we have shown that sildenafil affects early gastric emptying through its augmented effect on proximal gastric relaxation, thus enlarging proximal receptiveness of gastric contents.

Gastric accommodation to a meal consists of receptive and adaptive relaxation. Receptive relaxation is a vagally mediated reflex, known to dilate the corpus-fundus 
region of the stomach in response to swallowing or esophageal stimulation'. Adaptive relaxation is an intrinsic vagovagal reflex resulting in a reduction in gastric tone and increase in compliance, allowing for solids or liquids to be consumed without a significant rise in gastric pressure ${ }^{1}$. Employing the barostat device, Sarnelli et al. ${ }^{16}$ previously found that sildenafil significantly increased postprandial gastric volume. In a separate but identical protocol using scintigraphy, these authors also observed that sildenafil delayed gastric emptying of liquids. Cho et al. ${ }^{18}$ on the other hand found evidence for a decreased proximal gastric volume with shorter proximal half emptying time. In our study we partly confirm the findings of Sarnelli et al. ${ }^{16}$ but also extend on their observations.

With MRI we observed augmented relaxation and enlarged proximal receptiveness for gastric contents in response to sildenafil. This resulted in an initial retention of gastric contents in the proximal, but not in the distal stomach. Relaxation/ accommodation of the stomach depends on the presence of gastric contents and, in case of the barostat device, is also affected by the distending force that enhances accommodation ${ }^{15}$. It allows the stomach to adjust to an applied pressure or introduced volume, such as a meal. The adaptive relaxation in response to a meal that has been observed in many studies applying the barostat device ${ }^{4,5,7}$ is more pronounced when the barostat bag is present in the stomach at pressures slightly above the minimal distending pressure ${ }^{15}$. Further evaluation of the MRI technique is warranted especially with respect to the pathophysiological concept of impaired gastric relaxation in functional dyspepsia before the non-invasive MRI technique can be applied for evaluation of dyspeptic patients.

In our study early gastric emptying was delayed in response to sildenafil. However, overall gastric emptying was not affected by sildenafil, as gastric retention at the end of the study and gastric emptying rate did not differ significantly. These data are in line with previous studies on the effect of sildenafil on gastric emptying using either scintigraphy ${ }^{19}$ or the ${ }^{13} \mathrm{C}$ octanoic acid breath test ${ }^{16}$. From $90-180$ min gastric emptying was significantly delayed by sildenafil, but at 240 min postprandial most of the meal had emptied and gastric emptying was no longer significantly different from placebo. Since MRI allows simultaneous measurement of several gastric functions, we were able to relate the early delay in gastric emptying to the augmented proximal relaxation induced by sildenafil, hence influencing the onset of gastric emptying. Although we did not study the effects of sildenafil on acid secretion, it is not likely that this may account for the difference in gastric and gastric contents volumes. It has been shown previously that nitric oxide (NO) inhibits gastric acid secretion and this process depends upon stimulation of a cyclic guanosine monophosphate (cGMP) dependent mechanism in the parietal cell ${ }^{22-24}$. As sildenafil inhibits PDE-5, an enzyme that breaks down cGMP, NO-induced cGMP accumulates and is more likely to reduce gastric acid secretion.

Our data point to a change in intragastric meal distribution induced by sildenafil, but are different from the data by Cho et al. ${ }^{18}$. We observed an increase in proximal but 
not in distal gastric contents after sildenafil. Cho et al. ${ }^{18}$ used scintigraphy to observe a decreased proximal meal volume and an increased distal meal volume after sildenafil, most likely due to an increased transport of the meal from the proximal to the distal stomach. A possible explanation for the difference in results between their study and ours is not readily available. It might be related to the technique employed. MRI allows simultaneous recording of several motility parameters and measures actual volumes and volume changes. Scintigraphy, on the other hand, determines gastric retention based on the amount of radioactivity in the gastric region and is not capable to detect other motility parameters. In addition, we divided the stomach based on anatomical structures, whereas Cho et al. ${ }^{18}$ divided the stomach in two equal sized areas.

We observed a distinct but small increase in intragastric air during ingestion of the meal. This increase in intragastric air may be attributed to the receptive accommodation reflex in response to ingestion of a meal ${ }^{1,25,26}$. However, the increase in intragastric air during meal ingestion was equal in the sildenafil and placebo experiment and most likely resulted from swallowing of air as this occurs during eating, drinking and daily activities ${ }^{27,28}$.

As the effect of sildenafil is most pronounced in the early postprandial period, with a delay in the onset of gastric emptying and retention of gastric contents especially in the proximal stomach, one should consider evaluation of a potential beneficial effect of phosphodiesterase inhibitors in conditions with markedly accelerated gastric emptying such as dumping syndrome or in dyspeptic patients with impaired proximal gastric relaxation. In a subgroup of patients with functional dyspepsia proximal gastric accommodation is impaired with more rapid delivery of gastric content to the distal stomach. It should be taken into account that other gastrointestinal effects or systemic reactions of phosphodiesterase inhibitors may override the effect on gastric motor function.

The present study, by simultaneous evaluation of several gastric functions with MRI, contributes to our understanding of gastric motor physiology. We have shown that MRI is able to detect and quantify changes in gastric emptying related to intragastric distribution, proximal relaxation and proximal receptiveness of gastric contents. We conclude that, measured with MRI, the phosphodiesterase inhibitor sildenafil: (1) enhances proximal gastric relaxation and (2) influences intragastric meal distribution with increased proximal meal receptiveness thus (3) delaying the onset of gastric emptying. 


\section{References}

1. Gilja $\mathrm{OH}$, Lunding J, Hausken T, Gregersen H. Gastric accommodation assessed by ultrasonography. World J Gastroenterol 2006;12:2825-9.

2. Moragas G, Azpiroz F, Pavia J, Malagelada JR. Relations among intragastric pressure, postcibal perception, and gastric emptying. Am J Physiol 1993;264:G1112-G7.

3. van der Schaar PJ, Lamers CB, Masclee AA. The role of the barostat in human research and clinical practice. Scand J Gastroenterol Suppl 1999;230:52-63.

4. Mearin F, Cucala M, Azpiroz F, Malagelada JR. The origin of symptoms on the brain-gut axis in functional dyspepsia. Gastroenterology 1991;101:999-1006.

5. Tack J, Piessevaux H, Coulie B, Caenepeel P, Janssens J. Role of impaired gastric accommodation to a meal in functional dyspepsia. Gastroenterology 1998;115:1346-52.

6. Klatt S, Bock W, Rentschler J, Beckh K, Adler G. Effects of tropisetron, a 5-HT3 receptor antagonist, on proximal gastric motor and sensory function in nonulcer dyspepsia. Digestion 1999;60:147-52.

7. van der Schaar PJ, Bremer Y, Lamers CB, Masclee AA. Role of cholecystokinin in relaxation of the proximal stomach. Scand J Gastroenterol 2001;36:361-6.

8. Kuiken SD, Vergeer M, Heisterkamp SH, Tytgat GN, Boeckxstaens GE. Role of nitric oxide in gastric motor and sensory functions in healthy subjects. Gut 2002;51:212-8.

9. Schwizer W, Maecke H, Fried M. Measurement of gastric emptying by magnetic resonance imaging in humans. Gastroenterology 1992;103:369-76.

10. de Zwart IM, Mearadji B, Lamb HJ, Eilers PH, Masclee AA, de Roos A, Kunz P. Gastric motility: comparison of assessment with real-time MR imaging or barostat measurement initial experience. Radiology 2002;224:592-7.

11. Fraser R, Schwizer W, Borovicka J, Asal K, Fried M. Gastric motility measurement by MRI. Dig Dis Sci 1994;39:20S-3S.

12. Wright J, Evans D, Gowland P, Mansfield P. Validation of antroduodenal motility measurements made by echo-planar magnetic resonance imaging. Neurogastroenterol Motil 1999;11:19-25.

13. Marciani L, Gowland PA, Fillery-Travis A, Manoj P, Wright J, Smith A, Young P, Moore R, Spiller RC. Assessment of antral grinding of a model solid meal with echo-planar imaging. Am JPhysiol Gastrointest Liver Physiol 2001;280:G844-G9.

14. Haans JJ, de Zwart IM, Eilers PH, Reiber JH, Doornbos J, de Roos A, Masclee AA. Gastric volume changes in response to a meal: Validation of magnetic resonance imaging versus the barostat. J Magn Reson Imaging 2011;34:685-90.

15. de Zwart IM, Haans JJ, Verbeek P, Eilers PH, de Roos A, Masclee AA. Gastric accommodation and motility are influenced by the barostat device: Assessment with magnetic resonance imaging. Am J Physiol Gastrointest Liver Physiol 2007;292:G208-G14.

16. Sarnelli G, Sifrim D, Janssens J, Tack J. Influence of sildenafil on gastric sensorimotor function in humans. Am J Physiol Gastrointest Liver Physiol 2004;287:G988-G92.

17. Thumshirn M, Camilleri M, Choi MG, Zinsmeister AR. Modulation of gastric sensory and motor functions by nitrergic and alpha2-adrenergic agents in humans. Gastroenterology 1999;1 16:573-85.

18. Cho SH, Park H, Kim JH, Ryu YH, Lee SI, Conklin JL. Effect of sildenafil on gastric emptying in healthy adults. J Gastroenterol Hepatol 2006;21:222-6.

19. Madsen JL, Sondergaard SB, Fuglsang S, Rumessen JJ, Graff J. Effect of sildenafil on gastric emptying and postprandial frequency of antral contractions in healthy humans. Scand J Gastroenterol 2004;39:629-33.

20. Kunz P, Crelier GR, Schwizer W, Borovicka J, Kreiss C, Fried M, Boesiger P. Gastric emptying and motility: assessment with MR imaging--preliminary observations. Radiology 1998;207:33-40.

21. Siegel JA, Urbain JL, Adler LP, Charkes ND, Maurer AH, Krevsky B, Knight LC, Fisher RS, Malmud LS. Biphasic nature of gastric emptying. Gut 1988;29:85-9.

22. Konturek JW, Fischer H, Gromotka PM, Konturek SJ, Domschke W. Endogenous nitric oxide in the regulation of gastric secretory and motor activity in humans. Aliment Pharmacol Ther 1999;13: 1683-91.

23. Berg A, Redeen S, Ericson AC, Sjostrand SE. Nitric oxide-an endogenous inhibitor of gastric acid secretion in isolated human gastric glands. BMC Gastroenterol 2004;4:16. 
24. Berg A, Redeen S, Grenegard M, Ericson AC, Sjostrand SE. Nitric oxide inhibits gastric acid secretion by increasing intraparietal cell levels of cGMP in isolated human gastric glands. Am J Physiol Gastrointest Liver Physiol 2005;289:G1061-G6.

25. Cannon WB, Lieb CW. The receptive relaxation of the stomach. Am J Physiol 1911;29:267-73.

26. Schwizer W, Steingotter A, Fox M, Zur T, Thumshirn M, Bosiger P, Fried M. Non-invasive measurement of gastric accommodation in humans. Gut 2002;51 Suppl 1:i59-i62.

27. Ogami J, Ono S, Naka N, Watanuki K, Ishida S. X-ray examination of the stomach bubble after frequent experimental swallowing of saliva: the mechanism of aerophagia. J Med Dent Sci 2005;52:171-5.

28. Bredenoord AJ, Weusten BL, Timmer R, Smout AJ. Air swallowing, belching, and reflux in patients with gastroesophageal reflux disease. Am J Gastroenterol 2006;101:1721-6. 


\section{Chapter 6}

Non-invasive measurement of early postprandial volume changes in functional dyspepsia using Magnetic Resonance Imaging

JJL Haans IM de Zwart AY Thijssen CHM Clemens JHC Reiber A de Roos AAM Masclee 


\section{Abstract}

\section{Background}

Impaired gastric accommodation is one of the pathophysiological mechanisms in functional dyspepsia (FD). Several studies using the barostat technique found impaired gastric accommodation in patients with FD.

\section{Aims}

To explore whether Magnetic Resonance Imaging (MRI) is an alternative, non-invasive technique to measure volume changes of the stomach in response to a meal.

\section{Materials and Methods}

Measurements were performed in 21 healthy subjects (controls) and 21 patients with FD. MRI was used to obtain volume scans prior to and up to $30 \mathrm{~min}$ after intake of a liquid meal. Stomach, gastric contents, intragastric air volume and intragastric meal distribution were determined. PGV/TGV (proximal gastric volume divided by total gastric volume) and PCV/TCV (proximal contents volume divided by total contents volume) were calculated.

\section{Results}

Stomach and gastric contents volumes did not differ significantly between FD and controls. Initial postprandial gastric volume changes exceeded that of the meal volume and resulted mostly from an increase in intragastric air. Proximal and distal stomach and gastric contents volumes did not differ significantly between groups. Four out of 21 FD patients (19\%) had impaired proximal relaxation (PGV/TGV) and/or reduced proximal receptiveness for gastric contents (PCV/TCV) compared to controls.

\section{Conclusions}

MRI is a non-invasive technique that (1) allows detailed measurement of early changes in postprandial volumes and intragastric meal distribution and (2) is able to differentiate a subgroup of FD patients with impaired proximal relaxation and reduced proximal receptiveness for gastric contents from controls based on early changes in gastric volumes and intragastric meal distribution. 


\section{Introduction}

Functional dyspepsia (FD) is a gastrointestinal disorder defined as the presence of symptoms originating from the gastroduodenal region, in the absence of any organic, systemic, or metabolic disease, likely to explain the symptoms. More recently an FD subgroup classification into postprandial distress syndrome and epigastric pain syndrome has been proposed. Typical symptoms of FD are bothersome postprandial fullness, early satiation, epigastric pain and epigastric burning.

Several pathophysiological mechanisms have been identified in FD such as delayed gastric emptying, abnormal antroduodenal motility, hypersensitivity to gastric distension, altered duodenal sensitivity to acid or nutrients and impaired gastric accommodation?.

The stomach typically relaxes and accommodates in response to a meal, providing capacity for food to be stored and broken down into smaller particles. Impaired accommodation is associated with symptoms of early satiety in FD. Gastric accommodation can be measured using barostat equipment. Previous barostat studies have provided evidence for impaired accommodation in up to $40 \%$ of FD patients ${ }^{2,3}$. Unfortunately the barostat is an invasive technique limiting its application in daily practice ${ }^{4}$. It is not exactly known whether postprandial gastric relaxation or accommodation can be accurately measured with non-invasive imaging techniques such as 3D ultrasonography, SPECT or MRI, because data are either not available or conflicting $^{5-9}$. In a previous study we have validated MRI as a technique to measure proximal gastric motility and volume changes, by comparing MRI and the barostat technique during simultaneous recording ${ }^{10}$. The magnitude of a postprandial volume change however is more pronounced when recorded using the barostat technique, because the intra-gastric barostat balloon distends the stomach ${ }^{11}$.

Aim of the present study is to evaluate whether Magnetic Resonance Imaging is a useful non-invasive method that (1) allows detailed measurement of early changes in postprandial gastric volumes, gastric contents and intragastric distribution and (2) is able to differentiate patients with meal-related FD from controls based on early postprandial volume changes or intragastric contents distribution.

\section{Materials and Methods}

\section{Subjects}

Twenty-one patients with FD (8 men, 13 women; mean age 43 years; range 20-59 years; BMI $24 \pm 3 \mathrm{~kg} / \mathrm{m}^{2}$ ) and twenty-one controls ( 6 men, 15 women; mean age 37 years; range $19-59$ years; $\mathrm{BMI} 23 \pm 2 \mathrm{~kg} / \mathrm{m}^{2}$ ) participated in the study. Patients were recruited from the outpatient clinic of the department of internal medicine and 
gastroenterology-hepatology of the Diaconessen Hospital Leiden. Patients had at least one of the following symptoms: bothersome postprandial fullness, early satiation, epigastric pain or epigastric burning. Structural abnormalities were excluded by endoscopy and/or ultrasonography. Previous abdominal surgery was an exclusion criterion. All patients were asked to discontinue any medication known to influence gastrointestinal motor and sensory function at least 7 days prior to participation. None of the controls had a history of gastrointestinal disease or abdominal surgery and none was taking medication known to influence gastrointestinal motor and sensory function. The Medical Ethics Committee of our institution had approved the protocol and written informed consent was obtained from each subject.

\section{Study design}

Subjects were studied after at least 8 hours of fasting. The subject was positioned in the MRI scanner and initial scans were performed to determine geometric position of the stomach. The subject was studied in a semi-supine, right side down position $\left(30^{\circ}\right)$ and remained within the MRI scanner throughout the experiment.

The experiment started with a three-dimensional volume scan prior to consumption of $200 \mathrm{ml}$ of a high caloric $\left(300 \mathrm{Kcal}\right.$ ) dietary drink (Nutridrink ${ }^{\circledast}$, NV Nutricia, Zoetermeer, The Netherlands). The drink was labeled with $0.5 \mathrm{ml}$ of a paramagnetic MRI contrast agent, meglumine gadoterate (Dotarem ${ }^{\circledast}$, Laboratoire Guerbet, CdG Cedex, France) ${ }^{12}$. Immediately after consumption of the drink a volume scan was performed (time $0 \mathrm{~min}$ ). Hereafter two additional volume scans were obtained at 15 and $30 \mathrm{~min}$ postprandial. Measurements were restricted to the early postprandial phase.

\section{Magnetic Resonance Imaging}

All images were obtained using a 1.5T MRI scanner (ASC-NT; Philips Medical Systems, Best, The Netherlands) and a 4-channel SENSE body coil. A volume scan (22 slices, thickness $10 \mathrm{~mm}$, slice gap $0.00 \mathrm{~mm}$, echo time $3.5 \mathrm{~ms}$, repetition time $10.00 \mathrm{~ms}$, flip angle $25^{\circ}$, field of view $450.00 \mathrm{~mm}$, matrix $256 \times 256$ pixels, total acquisition time 30 $\mathrm{sec}$ ) was performed to determine momentary volumes. This MRI technique has been used and validated previously ${ }^{10,11,13}$.

\section{Data analysis}

Intragastric air and gastric contents were identified and outlined manually in all volume images by one observer (J.H.) using an in-house made interactive software tool (SNIPER ${ }^{\circledast}$, LKEB, Leiden University Medical Center, The Netherlands). Volumes were calculated by adding the calculated surfaces of all outlined areas multiplied with the slice thickness. Total gastric volume was calculated by adding intragastric air 
and gastric contents volumes. This method has been described and validated previously ${ }^{10}$.

Several parameters were determined from acquired data. (1) Fasting gastric volume ( $\mathrm{ml}$ ) was defined as the volume in the period prior to consumption of the meal. (2) Postprandial gastric volume was defined as the mean of the volumes acquired at 15 and 30 min postprandial. (3) Relaxation volume was defined as the difference between postprandial and fasting gastric volume?.

Intragastric distribution was defined as the distribution of intragastric contents over the proximal and distal part of the stomach and expressed as gastric contents volume $(\mathrm{ml})$. The stomach was divided in a proximal and distal part by anatomical localization of the incisure ${ }^{14}$. In a 3D reconstruction of the stomach, the incisure was localized and the slice position determined. This slice and all cranially located slices were considered 'proximal'. All slices caudally located were considered 'distal'. Hence proximal and distal volumes for intragastric air, gastric contents and gastric volume could be determined. In addition, we determined the proximal volume in relation to total volume for (a) gastric volume and (b) for intragastric contents volume. Here PGV/TGV represents the proximal gastric volume (PGV) divided by the total gastric volume (TGV), whereas PCV/TCV represents the proximal contents volume (PCV) divided by the total contents volume (TCV). Abnormal (impaired) proximal relaxation and abnormal proximal distribution (reduced receptiveness) of gastric contents was considered to be present in FD with values below the $5^{\text {th }}$ percentile of PGV/TGV and $\mathrm{PCV} / \mathrm{TCV}$ in controls.

\section{Statistical analysis}

Data was analyzed using a statistical software package (PASW Statistics ${ }^{\circledR}$ Release 18.0.0, SPSS Inc, Chicago, USA). All data are provided as mean \pm SD. All samples were tested for normality. Independent-samples t-test was used to detect differences in data between groups. The level of significance was set at $p<0.05$.

\section{Results}

\section{Gastric volumes}

Figure 6.1A shows curves of gastric volumes, gastric contents and intragastric air prior to and up to 30 min after meal intake in both FD patients and controls.

Fasting gastric volumes (time $-5 \mathrm{~min}$ ) were not significantly different between FD and controls, $45 \pm 18 \mathrm{ml}$ and $39 \pm 24 \mathrm{ml}$ respectively. Immediately after meal intake (time 0 min) gastric volume increased to $313 \pm 61 \mathrm{ml}$ and $305 \pm 51 \mathrm{ml}$ in FD and controls respectively, further increasing to $331 \pm 54 \mathrm{ml}$ and $330 \pm 54 \mathrm{ml}$ at $15 \mathrm{~min}$. Data of gastric volumes did not differ significantly between groups (FD and controls). 

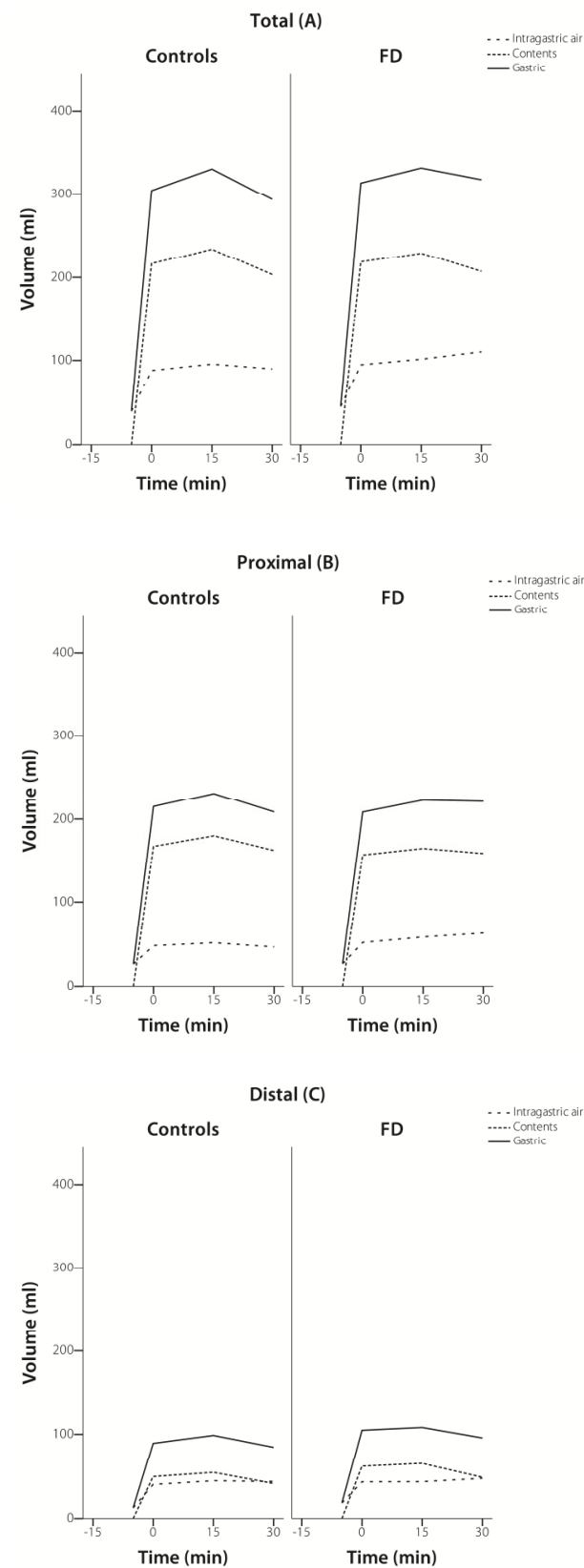

Figure 6.1 Volumes (mean) in both FD and controls prior to and after intake of a $200 \mathrm{ml}$ 
Similar volume changes were observed for gastric contents. After meal intake MR images showed homogeneous gastric contents and no disintegration or layering of the meal. Initially (0-15 min) gastric contents increased in both FD and controls. Hereafter $(15-30 \mathrm{~min})$ a small but significant $(p<0.05)$ decrease in gastric contents was observed, $-23 \pm 11 \mathrm{ml}$ and $-31 \pm 10 \mathrm{ml}$ for FD and controls respectively. Between groups gastric contents volumes did not differ significantly.

Fasting intragastric air volume (time $-5 \mathrm{~min}$ ) was not significantly different between FD and controls. Intragastric air volume increased significantly immediately after onset of meal intake to $95 \pm 40 \mathrm{ml}$ and $88 \pm 41 \mathrm{ml}$ in FD and controls respectively. Subsequently, no significant changes were observed. Intragastric air volumes did not differ significantly between groups. Thus, the initial postprandial gastric volume change exceeded that of the meal volume $(200 \mathrm{ml})$ and resulted mostly from an increase in intragastric air.

Table 6.1 shows parameters determined from acquired volume data, commonly used to differentiate between FD and controls. Fasting gastric volume, postprandial gastric volume and relaxation volume did not differ significantly between both FD and controls. None of the patients with FD had a relaxation volume lower than the $5^{\text {th }}$ percentile of relaxation volume in controls, i.e. $185 \mathrm{ml}$.

Table 6.1 Gastric volumes $(\mathrm{ml})$ measured with $\mathrm{MRI}$ in response to a liquid meal.

\begin{tabular}{lrr}
\hline & FD & Controls \\
\hline Fasting gastric volume $(\mathrm{ml})$ & $45 \pm 18$ & $39 \pm 24$ \\
Postprandial gastric volume $(\mathrm{ml})$ & $321 \pm 53$ & $309 \pm 46$ \\
Relaxation volume $(\mathrm{ml})$ & $276 \pm 44$ & $270 \pm 38$ \\
\hline
\end{tabular}

Fasting gastric volume represents the stomach volume prior to meal ingestion. Postprandial gastric volume represents the mean gastric volume over the first $30 \mathrm{~min}$ postprandial. Relaxation volume is defined as postprandial gastric volume minus fasting gastric volume. Data are shown as mean \pm SD. ${ }^{*} \mathrm{p}<0.05$ compared to controls.

\section{Intragastric distribution}

Figure $6.1 \mathrm{~B}$ and $6.1 \mathrm{C}$ show curves of gastric volumes, gastric contents and intragastric air prior to and up to $30 \mathrm{~min}$ after meal intake in both FD and controls for the "proximal" and "distal" part of the stomach respectively. After meal intake, mean proximal gastric contents were smaller for FD compared to controls, $157 \pm 43 \mathrm{ml}$ and $167 \pm 31 \mathrm{ml}$ at $0 \mathrm{~min}$ respectively and $165 \pm 32 \mathrm{ml}$ and $180 \pm 36 \mathrm{ml}$ at $15 \mathrm{~min}$ respectively, but none of the differences were statistically significant. Distal gastric contents were larger for FD compared to controls, $62 \pm 43 \mathrm{ml}$ and $49 \pm 27 \mathrm{ml}$ at $0 \mathrm{~min}$ respectively and $65 \pm 50 \mathrm{ml}$ and $54 \pm 31 \mathrm{ml}$ at $15 \mathrm{~min}$ respectively. However none of these differences were statistically significant. Moreover, proximal and distal gastric volumes were neither significantly different between FD and controls. 
Figure 6.2 shows individual data of PGV/TGV and PCV/TCV immediately after meal intake (time $0 \mathrm{~min}$ ). PGV/TGV in FD did not differ significantly from controls: $0.67 \pm 0.13$ vs. $0.71 \pm 0.09$ respectively immediately after meal intake (time $0 \mathrm{~min}$ ). This was also true for mean PGV/TGV over the entire postprandial period, 0 until $30 \mathrm{~min}$. Moreover, PCV/TCV in FD was neither significantly different from controls, $0.72 \pm 0.18$ vs. $0.78 \pm 0.11$ respectively immediately after meal intake (time $0 \mathrm{~min}$ ). This was also true for mean PGV/TGV over the entire postprandial period.
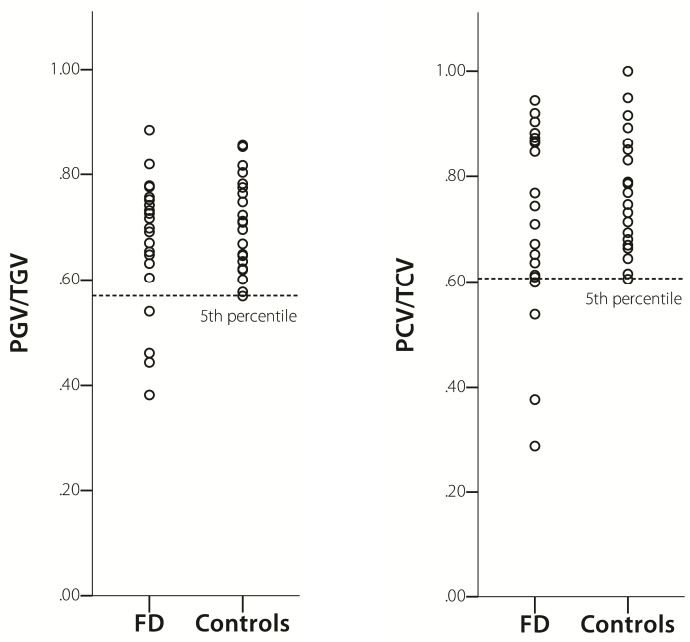

Figure 6.2 PGV/TGV and PCV/TCV in FD patients and controls immediately after meal intake (at $0 \mathrm{~min}$ ). $5^{\text {th }}$ percentile of normal for PGV/TGV and PCV/TCV immediately after meal intake (at 0 min), 0.570 and 0.607 respectively.

When considering the $5^{\text {th }}$ percentile for PGV/TGV in controls as cut off, 4 out of 21 FD patients (19\%) had impaired proximal relaxation immediately after meal intake (time $0 \mathrm{~min}$ ). Two out of $21 \mathrm{FD}$ patients (10\%) had impaired proximal relaxation taking into account the 30 min postprandial period. Considering the $5^{\text {th }}$ percentile for PCV/TCV in controls as cut off, 4 of the 21 FD patients (19\%) had reduced proximal receptiveness for gastric contents immediately after meal intake (time $0 \mathrm{~min}$ ). Three of 21 FD patients (14\%) had a reduced proximal receptiveness taking into account the 30 min postprandial period.

\section{Discussion}

In the present study, we have shown that MRI, as a non-invasive technique, enables determination of early postprandial volume changes in both health and disease. Although absolute early postprandial volumes and volume changes did not differ 
significantly between controls and patients with FD, MRI was able to detect impaired proximal relaxation in a subgroup of FD patients. In addition, an altered intragastric distribution, more precisely a reduced proximal receptiveness for gastric contents, was observed in the same subgroup. The differences in proximal relaxation and receptiveness were most pronounced immediately after meal intake.

With MRI we observed impaired relaxation and reduced proximal receptiveness in $19 \%$ of FD patients. Other investigators using non-invasive imaging techniques such as SPECT and ultrasonography found impaired accommodation or impaired relaxation in $41-67 \%$ of $\mathrm{FD}^{5,6,8,9,15}$. In studies employing non-MR imaging modalities for the detection of impaired accommodation or impaired relaxation, meal volumes varied between $300 \mathrm{ml}$ and $500 \mathrm{ml}$, and were at least $1.5 \mathrm{x}$ larger than the volume used in our study, thus providing a more pronounced stimulus $s^{5-9}$. We believe that a more pronounced stimulus will help to improve the differentiation between those with and without impaired relaxation within a group of FD patients. Evidence for this hypothesis is supported by data from a previous study by Fruehauf et al. ${ }^{16}$ utilizing $\mathrm{MRI}$ and showing a more pronounced difference in volume responses between controls and FD for a high volume liquid meal $(800 \mathrm{ml})$ compared to a low volume liquid meal $(200 \mathrm{ml})$. Furthermore, indirect evidence comes from studies on FD patients employing drinking tests. These tests have been designed to induce maximum symptom discomfort at a certain rate of volume ingestion. These drinking tests show volumes for maximum discomfort that vary between $648 \mathrm{ml}$ and $1818 \mathrm{ml}$ in controls and between $333 \mathrm{ml}$ and $1148 \mathrm{ml}$ in FD, depending on composition of the drink and speed of ingestion ${ }^{4,17-19}$. Use of the slow nutrient drinking test, in particular, was helpful in differentiating patients with FD having impaired gastric accommodation, in both tertiary care (academic) as well as secondary care (nonacademic) centers ${ }^{18,20}$. It should be noted that this has not been confirmed in other studies using different protocols for drink composition and speed of ingestion ${ }^{4}$.

We observed a small increase in postprandial gastric volume in addition to that of the meal volume, which can be explained by gastric relaxation. This gastric relaxation resulted from an increase in both intragastric air and gastric contents. These results are in line with data from previous studies ${ }^{7,21,22}$. Similar to other reports that used imaging techniques like SPECT and ultrasonography, we did not observe a significant difference in absolute postprandial volumes between FD patients and controls ${ }^{5,7-9}$.

Although the pattern of postprandial volume changes was identical to that seen when using the barostat, volumes determined with MRI were significantly smaller compared to those observed in barostat studies ${ }^{11}$. This is not surprising since a barostat procedure is performed in such way that the gastric wall is distended with an intragastric balloon pressurized slightly above intra-abdominal pressure. One should realize that volume changes measured with the barostat as such reflect a change in muscle tone of the proximal gastric wall. Imaging techniques like MRI do not affect muscle tone of the proximal wall, hence are not capable of measuring actual smooth muscle relaxation, that consists of lengthening of the muscular 
component and activation of elongation, but not tension receptors ${ }^{23}$. With the current study protocol we observed an impaired proximal relaxation in 19\% of FD patients, whereas others using the current gold-standard barostat technique found impaired accommodation/relaxation in up to $40 \%$ of FD patients ${ }^{2,3,24}$. Not only technical aspects, but also meal-related effects might account for the observed difference in percentage of FD patients with impaired relaxation between the two techniques. We have used a liquid meal similar to that used in standard barostat protocols $\mathrm{s}^{2,3,25}$. This meal consists of $200 \mathrm{ml}$ of a mixed nutrient high caloric drink (proteins, carbohydrates and fat; $1.5 \mathrm{kcal} / \mathrm{ml}$ ). In studies using the barostat, the intragastric barostat balloon had a postprandial volume that varied between $298 \mathrm{ml}$ and $403 \mathrm{ml}$ for FD patients and $401 \mathrm{ml}$ and $469 \mathrm{ml}$ for healthy controls $\mathrm{s}^{2,3,24}$. These volumes did not include the volume of the meal $(200 \mathrm{ml})$ and that of the remaining, distal, part of the stomach. Hence the total gastric volume will account for a volume of over $500 \mathrm{ml}$ in FD patients and over $600 \mathrm{ml}$ in controls. In our study gastric volumes did not exceed $331 \pm 54$ and $330 \pm 54 \mathrm{ml}$ for FD and controls respectively. Apparently, in order to further differentiate between FD and controls, stimuli that result in larger gastric volumes are necessary. Although MRI is different in both technical aspects and setting from the barostat, MRI is able to discriminate a subset of FD patients from controls based on early postprandial gastric volume changes.

Further evaluation and optimization of the MRI technique and protocol in the analysis and work up of FD patients is needed. To date, we are the first to indicate that MRI allows the evaluation of (impaired) relaxation of the proximal stomach. Future studies should address the possible discrepancy in impaired postprandial gastric volume changes measured with MRI (relaxation) and barostat (accommodation). Standardization of meal volume and composition will help to obtain normal values for MRI relaxation and allows head to head comparison between the barostat and MRI technique.

MRI is an attractive tool to study gastric physiology because it is non-invasive, enables us to measure volume changes, provides information on intragastric meal distribution and gastric emptying. In addition, MRI allows measurement of contraction frequency, amplitude and direction (antegrade or retrograde). Because several parameters of gastric physiology can be measured non-invasively and simultaneously, MRI studies will help to substantially increase our knowledge and understanding of gastric physiology in both health and disease.

We conclude that MRI is a suitable non-invasive technique that (1) allows detailed measurement of early postprandial changes in gastric volumes, and intragastric meal distribution and (2) is able to differentiate a subgroup of FD patients with impaired proximal relaxation and reduced proximal receptiveness for gastric contents from controls based on early changes in gastric volumes and intragastric meal distribution. 


\section{References}

1. Tack J, Bisschops R, Sarnelli G. Pathophysiology and treatment of functional dyspepsia. Gastroenterology 2004;127:1239-55.

2. Tack J, Piessevaux H, Coulie B, Caenepeel P, Janssens J. Role of impaired gastric accommodation to a meal in functional dyspepsia. Gastroenterology 1998;115:1346-52.

3. Boeckxstaens GE, Hirsch DP, Kuiken SD, Heisterkamp SH, Tytgat GN. The proximal stomach and postprandial symptoms in functional dyspeptics. AmJGastroenterol 2002;97:40-8.

4. Boeckxstaens GE, Hirsch DP, van den Elzen BD, Heisterkamp SH, Tytgat GN. Impaired drinking capacity in patients with functional dyspepsia: relationship with proximal stomach function. Gastroenterology 2001;121:1054-63.

5. Mundt MW, Samsom M. Fundal dysaccommodation in functional dyspepsia: head-to-head comparison between the barostat and three-dimensional ultrasonographic technique. Gut 2006;55:1725-30.

6. Gilja $\mathrm{OH}$, Hausken T, Wilhelmsen I, Berstad A. Impaired accommodation of proximal stomach to a meal in functional dyspepsia. DigDisSci 1996;41:689-96.

7. van den Elzen BD, Bennink RJ, Wieringa RE, Tytgat GN, Boeckxstaens GE. Fundic accommodation assessed by SPECT scanning: comparison with the gastric barostat. Gut 2003;52:1548-54.

8. Bredenoord AJ, Chial HJ, Camilleri M, Mullan BP, Murray JA. Gastric accommodation and emptying in evaluation of patients with upper gastrointestinal symptoms. ClinGastroenterolHepatol 2003;1: 264-72.

9. Kim DY, gado-Aros S, Camilleri M, Samsom M, Murray JA, O'Connor MK, Brinkmann BH, Stephens DA, Lighvani SS, Burton DD. Noninvasive measurement of gastric accommodation in patients with idiopathic nonulcer dyspepsia. AmJGastroenterol 2001;96:3099-105.

10. de Zwart IM, Mearadji B, Lamb HJ, Eilers PH, Masclee AA, de Roos A, Kunz P. Gastric motility: comparison of assessment with real-time MR imaging or barostat measurement initial experience. Radiology 2002;224:592-7.

11. de Zwart IM, Haans JJ, Verbeek P, Eilers PH, de Roos A, Masclee AA. Gastric accommodation and motility are influenced by the barostat device: Assessment with magnetic resonance imaging. AmJPhysiol GastrointestLiver Physiol 2007;292:G208-G14.

12. Schwizer W, Fraser R, Maecke H, Siebold K, Funck R, Fried M. Gd-DOTA as a gastrointestinal contrast agent for gastric emptying measurements with MRI. Magn ResonMed 1994;31:388-93.

13. Kunz P, Crelier GR, Schwizer W, Borovicka J, Kreiss C, Fried M, Boesiger P. Gastric emptying and motility: assessment with MR imaging--preliminary observations. Radiology 1998;207:33-40.

14. Treier R, Steingoetter A, Weishaupt D, Goetze O, Boesiger P, Fried M, Schwizer W. Gastric motor function and emptying in the right decubitus and seated body position as assessed by magnetic resonance imaging. JMagn Resonlmaging 2006;23:331-8.

15. van Lelyveld N, Scheffer R, Mundt M, Samsom M. Partial gastric volumes and upper abdominal sensations in functional dyspeptic and GERD patients: a 3D ultrasonographic study. Am J Gastroenterol 2006;101:1845-52.

16. Fruehauf $H$, Steingoetter A, Fox MR, Kwiatek MA, Boesiger $P$, Schwizer W, Fried M, Thumshirn M, Goetze $O$. Characterization of gastric volume responses and liquid emptying in functional dyspepsia and health by MRI or barostat and simultaneous C-acetate breath test. Neurogastroenterol Motil 2009;21:697-e37.

17. Jones MP, Hoffman S, Shah D, Patel K, Ebert CC. The water load test: observations from healthy controls and patients with functional dyspepsia. Am J Physiol Gastrointest Liver Physiol 2003;284:G896-904.

18. Kindt S, Coulie B, Wajs E, Janssens J, Tack J. Reproducibility and symptomatic predictors of a slow nutrient drinking test in health and in functional dyspepsia. Neurogastroenterol Motil 2008;20:320-9.

19. van den Elzen BD, Bennink RJ, Holman R, Tytgat GN, Boeckxstaens GE. Impaired drinking capacity in patients with functional dyspepsia: intragastric distribution and distal stomach volume. Neurogastroenterol Motil 2007;19:968-76. 
20. Tack J, Caenepeel P, Piessevaux H, Cuomo R, Janssens J. Assessment of meal induced gastric accommodation by a satiety drinking test in health and in severe functional dyspepsia. Gut 2003;52:1271-7.

21. Fruehauf $H$, Goetze $O$, Steingoetter A, Kwiatek $M$, Boesiger $P$, Thumshirn $M$, Schwizer W, Fried M. Intersubject and intrasubject variability of gastric volumes in response to isocaloric liquid meals in functional dyspepsia and health. Neurogastroenterol Motil 2007;19:553-61.

22. Fidler J, Bharucha AE, Camilleri M, Camp J, Burton D, Grimm R, Riederer SJ, Robb RA, Zinsmeister AR. Application of magnetic resonance imaging to measure fasting and postprandial volumes in humans. Neurogastroenterol Motil 2009;21:42-51.

23. Tack J, Caenepeel $P$, Corsetti M, Janssens J. Role of tension receptors in dyspeptic patients with hypersensitivity to gastric distention. Gastroenterology 2004;127:1058-66.

24. Karamanolis G, Caenepeel P, Arts J, Tack J. Association of the predominant symptom with clinical characteristics and pathophysiological mechanisms in functional dyspepsia. Gastroenterology 2006;130:296-303.

25. Sarnelli G, Vos R, Cuomo R, Janssens J, Tack J. Reproducibility of gastric barostat studies in healthy controls and in dyspeptic patients. AmJGastroenterol 2001;96:1047-53. 


\section{Chapter 7}

Comparison of gastric emptying determined by stable isotope breath test and Magnetic Resonance Imaging during simultaneous recording

J.J.L. Haans

N.P.M. Paridaans

C. Wong

P.H.C. Eilers

J. Doornbos

A. de Roos

A.A.M. Masclee 


\section{Abstract}

\section{Background}

Magnetic Resonance Imaging (MRI) potentially is the most physiological and valid direct method for investigation of gastric motor function and gastric emptying. Indirect stable isotope breath tests are frequently applied but need validation against direct imaging techniques, preferably during simultaneous recording.

\section{Aims}

To compare the indirect stable isotope breath test technique with the direct MRI technique for gastric emptying of solids and liquids during simultaneous recording and to compare different mathematical models currently used to determine gastric emptying parameters in stable isotope breath test analysis with MRI.

\section{Materials and Methods}

28 subjects participated in studies with simultaneous recording of gastric emptying by stable isotope breath test and MRI for a liquid meal $\left({ }^{13} \mathrm{C}\right.$-acetate; $\left.\mathrm{n}=16\right)$ or a solid meal $\left({ }^{13} \mathrm{C}\right.$-octanoate; $n=12)$.

\section{Results}

Reliability of MRI volume analysis was excellent with high inter-observer agreement and intraobserver reproducibility. We found a strong correlation between peak excretion time determined by stable isotope breath test and half emptying time determined by MRI $(r=0.758$; $p=0.001$ ) for liquid gastric emptying. The correlation was weaker for solid gastric emptying $(r=0.634 ; p=0.027)$.

\section{Conclusions}

We have demonstrated that reliability of MRI volume analysis is excellent. Second, our data indicate that correlation between stable isotope breath test and MRI for liquid emptying is better than that for solid gastric emptying. Third, mathematical correction of stable isotope breath test data did not improve the outcome of gastric emptying parameters. 


\section{Introduction}

Reliable measurement of gastric emptying is essential for diagnosis and treatment of patients suspected of disorders that either delay or accelerate gastric emptying ${ }^{1}$.

Several techniques are currently applied to measure gastric emptying. These techniques either measure gastric emptying directly, such as scintigraphy, ultrasonography and Magnetic Resonance Imaging (MRI) or indirectly ${ }^{2-4}$. The direct techniques rely on imaging to obtain a two- or three-dimensional representation of gastric contents over time. Techniques that measure gastric emptying indirectly include isotope breath tests, acetaminophen absorption test, or other tests using markers that are absorbed and detected in blood or exhaled air ${ }^{4}$. With these techniques, the transit of a meal from the stomach to the duodenum is assumed to be the rate-limiting step while other factors, such as absorption and metabolism of the marker are considered to be constant ${ }^{5,6}$.

In the past decade an increasing number of studies has been performed using the stable isotope breath test method. Most frequently employed are the ${ }^{13} \mathrm{C}$-octanoate and ${ }^{13} \mathrm{C}$-acetate breath test for solid and liquid gastric emptying respectively ${ }^{7}$. In these tests the stable ${ }^{13} \mathrm{C}$-isotope is mixed and incorporated into either a solid or liquid meal. The meal is ingested and approximately $90 \%$ of the active compound is absorbed in the duodenum. Thereafter ${ }^{13} \mathrm{CO}_{2}$ is formed in the liver when the active compound is disintegrated. ${ }^{13} \mathrm{CO}_{2}$ is exhaled and from the exhaled breath the ratio of ${ }^{13} \mathrm{CO}_{2}$ and ${ }^{12} \mathrm{CO}_{2}$ is determined. Since the ${ }^{13} \mathrm{C}$-breath test is an indirect test, it needs validation against direct gastric emptying tests, preferably during simultaneous comparison, as gastric emptying may vary on a day-to-day basis. Data on the accuracy of the ${ }^{13} \mathrm{C}$-breath test for measurement of gastric emptying compared to scintigraphy are conflicting ${ }^{5,8-17}$. While several studies have shown a linear correlation between ${ }^{13} \mathrm{C}$-breath test and scintigraphy others did not find any correlation between the two techniques.

Various mathematical models $s^{5,15,18-20}$ have been employed to increase the accuracy of the ${ }^{13} \mathrm{C}$-breath test in determining half-emptying time compared to direct measurement of gastric emptying, mostly scintigraphy. These models have been applied in order to correct for the contribution of distribution and elimination of the isotope in the ${ }^{13} \mathrm{CO}_{2}$ excretion process ${ }^{21}$.

Recent studies indicate that MRI is potentially the most physiological and valid method for investigation of gastric function, especially gastric motility and emptying ${ }^{2,22,23}$. Up to now, evaluation of gastric emptying by MRI has been limited to research settings. As MRI is potentially the most valid method, indirect techniques, such as the stable isotope breath test, should preferably be compared with MRI.

Aims of our study were (1) to compare the indirect stable isotope breath test technique with the direct MRI technique for both solid and liquid gastric emptying during simultaneous recording and (2) to compare different mathematical models 
currently used to determine gastric emptying parameters in stable isotope breath test analysis with MRI.

\section{Materials and Methods}

\section{Subjects}

Twenty-eight healthy subjects (four men, twenty-four women; mean age 21 years; range 18-26 years; BMI $22.6 \mathrm{~kg} / \mathrm{m}^{2}$; range $19.5-27.8 \mathrm{~kg} / \mathrm{m}^{2}$ ) participated in the study. None of the subjects had a history of gastrointestinal disease or abdominal surgery and none was taking any medication, known to influence gastrointestinal motility or secretion. The Medical Ethics Committee of the Leiden University Medical Center (LUMC) had approved the study protocol and written informed consent was obtained from each subject.

\section{Study protocol}

Sixteen subjects participated in the study on liquid gastric emptying and 12 subjects in the study on solid gastric emptying. Each subject was fasted for at least 6 hours prior to the study. Subjects underwent MRI in right-sided semi-supine position (30 degrees). Initial scans were performed to determine geometric position of the stomach. The study was started at $\mathrm{t}=0 \mathrm{~min}$ with a volume scan immediately followed by the collection of a breath sample. For the liquid gastric emptying study each subject consumed a $300 \mathrm{ml}$ high caloric (450 kcal, $17.4 \mathrm{~g} \mathrm{fat,} 18 \mathrm{~g}$ proteins, $55.2 \mathrm{~g}$ carbohydrates) dietary drink (Nutridrink ${ }^{\circledR}$, Nutricia NV, Zoetermeer, The Netherlands). For the solid gastric emptying study a scrambled egg, two slices of white bread and 5 grams of margarine (261 kcal, $11.2 \mathrm{~g}$ fat, $12.5 \mathrm{~g}$ proteins, $26.8 \mathrm{~g}$ carbohydrates) were consumed. After ingestion of the solid meal a volume scan was performed. Breath samples were collected at regular predefined intervals in all subjects. MRI volume scans were performed until 120 min after the start of the study at times $0,15,30,45$, $60,75,90,105$ and $120 \mathrm{~min}$. Three additional scans were performed in the solid emptying study, at times 150, 180 and 240 min. Breath samples were collected until 240 min after the start of the study for both liquid and solid emptying studies; time 0 , $15,30,45,60,75,90,105,120,150,180,210$ and $240 \mathrm{~min}$.

\section{Magnetic Resonance Imaging}

All images were obtained using a 1.5T MRI scanner (ASC-NT; Philips Medical Systems, Best, The Netherlands) and a 4-channel SENSE body coil. A volume scan (22 slices, thickness $10 \mathrm{~mm}$, slice gap $0.00 \mathrm{~mm}$, echo time $3.48 \mathrm{~ms}$, repetition time $10.00 \mathrm{~ms}$, flip angle $25^{\circ}$, field of view $450.00 \mathrm{~mm}$, matrix $256 \times 256$, total acquisition time $30 \mathrm{sec}$ ) was performed to determine momentary volumes. This MRI technique has been 
described and validated previously ${ }^{24-26}$. A paramagnetic MRI contrast agent, meglumine gadoterate (Dotarem ${ }^{\circledast}$, Laboratoire Guebet, CdG Cedex, France), was added to the liquid meal for contrast enhancement.

\section{Breath test}

A substrate labeled with a stable ${ }^{13} \mathrm{C}$-isotope was added to the meal. For liquid emptying $150 \mathrm{mg}{ }^{13} \mathrm{C}$-sodium acetate was added to the dietary drink. For solid emptying $100 \mathrm{mg}{ }^{13} \mathrm{C}$-sodium octanoate was added to the egg yolk prior to scrambling and baking the egg.

Breath samples were collected to determine the ratio of ${ }^{13} \mathrm{CO}_{2} /{ }^{12} \mathrm{CO}_{2}$ and analyzed using an infrared isotope analyzer (IRIS $2^{\mathrm{TM}}$, Wagner Analysen Technik GmbH, Bremen, Germany). This technique has been described and validated previously ${ }^{6}$.

\section{Data analysis}

\section{Analysis of MRI volumes}

MR images were analyzed using an in-house made interactive software tool (SNIPER ${ }^{\circledR}$, LKEB, Leiden University Medical Center, The Netherlands) ${ }^{26}$. Data analysis was performed in a semi-automated manner. Gastric contents were outlined using a 3D algorithm and corrected manually where necessary. Gastric air was outlined manually. Volumes were calculated by adding the measured surfaces of all outlined areas multiplied by slice thickness. This method has been described and validated previously ${ }^{24}$.

Two observers (NP, JH) independently analyzed all data obtained in the liquid emptying study in order to determine reliability of analysis. The intra- and interobserver reliability was evaluated in all 16 subjects. In addition a similarity index ${ }^{27}$ was obtained to determine whether observers identified the contents and air inside the stomach in a similar manner. For further analysis mean values of volume data as analyzed by observer 1 (NP) and observer $2(\mathrm{JH})$ were used for the liquid emptying study.

In order to determine specific gastric emptying related parameters, such as halfemptying time and lag time, MRI volume data were fit to different models described previously ${ }^{28-31}$. Model fit was performed using the method of least squares. Test for goodness-of-fit of each model was evaluated using raw volumes and fit volumes, with parallel model of reliability. Several parameters were determined from the fit data: (1) gastric half-emptying time $\left(t_{1 / 2 \mathrm{MRI}}\right)$, defined as time at which half of the initial gastric contents had emptied from the stomach, (2) lag time $\left(t_{\text {lagMRI }}\right)$, defined as time at which $5 \%$ of the initial gastric contents had emptied from the stomach and (3) gastric emptying rate $\left(G E R_{M R l}\right)$. 


\section{Analysis of Breath Test ${ }^{13} \mathrm{CO}_{2}$ recovery data}

The classic model by Ghoos et al. ${ }^{5}$ was applied to fit cumulative ${ }^{13} \mathrm{CO}_{2}$ recovery data to the equation $y_{t}=a t^{b} e^{-c t}$. The model by Maes et al. ${ }^{32}$ was applied to fit ${ }^{13} \mathrm{CO}_{2}$ recovery data to the equation $y_{t}=m k \beta e^{-k t}\left(1-e^{-k t}\right)^{\beta-1}$.

These models are commonly applied for analyses of breath test data on gastric emptying. Fitting these models using the method of least squares yields the constants $a, b, c, m, k$ and $\beta$. Several parameters ${ }^{14}$ were determined from these constants: (1) gastric half-emptying time; $t_{1 / 2 B T}=-1 / k \cdot \ln \left(1-2^{-1 / \beta}\right)$, (2) peak excretion time, defined as the time of maximal ${ }^{13} \mathrm{CO}_{2}$ excretion of the fitted curve; $t_{\max B T}=\ln (\beta) / k$, (3) lag time, defined as the time at which $5 \%$ of ${ }^{13} \mathrm{CO}_{2}$ of the total amount was excreted; $t_{\text {lagB }}=-1 / k \cdot \ln \left(1-0.05^{1 / \beta}\right)$ and (4) Gastric Emptying Coefficient, a global indicator for gastric emptying rate; $G E C=\ln (a)$.

In addition we performed a correction of the breath test data according to Sanaka et al. ${ }^{18}$, using the Wagner-Nelson method that corrects for distribution and elimination of the isotope in the ${ }^{13} \mathrm{CO}_{2}$ excretion process. The Wagner-Nelson method uses the following equation $F_{t}=\left(A \cup C_{t}+C_{t} / K_{e l}\right) / A U C_{\infty}$ or $F_{t}=A_{t} / A_{\infty}=\left(1+\left(k \beta / K_{e l}-1\right) e^{-k t}\right) \cdot\left(1-e^{-k t}\right)^{\beta-1}$, where $F_{t}$ is the fractional dose of ${ }^{13} \mathrm{CO}_{2}$ emptied, $A U C_{t}$ is the cumulative amount of ${ }^{13} \mathrm{CO}_{2}$ recovered in breath by time $\mathrm{t}$ (\%dose), $A U C_{\infty}$ is the ultimate cumulative amount of ${ }^{13} \mathrm{CO}_{2}$ recovered in breath (\%dose), $C_{t}$ is the ${ }^{13} \mathrm{CO}_{2}$ excretion rate (\%dose/h) and $K_{e l}$ is the first-order rate constant for total elimination of ${ }^{13} \mathrm{CO}_{2}$. The fractional dose of ${ }^{13} \mathrm{CO}_{2}$ emptied $\left(F_{t}\right)$ can be re-calculated into gastric retention using $G R_{t}=100 \bullet\left(1-F_{t}\right) \%$, thus providing an "emptying curve" when gastric retention $\left(G R_{t}\right)$ is plotted against time (t). Parameters of gastric emptying, such as half-emptying time $\left(t_{1 / 2 B T C}\right)$, lag time $\left(t_{\text {lagBTc }}\right)$ and gastric emptying rate $\left(G E R_{B T C}\right)$ can be determined from these data. An example is provided in Figure 7.1.

\section{Statistical analysis}

Model fit using the least-squares method was done using MATLAB ${ }^{\oplus}$ Release 2007a for Mac OSX, MathWorks ${ }^{\oplus}$, USA and Microsoft ${ }^{\oplus}$ Excel $^{\circledast}$ for Mac 2011, Microsoft Corporation, USA. Data were analyzed using a statistical software package (IBM ${ }^{\oplus}$ SPSS $^{\circledR}$ Statistics for Mac OSX Release 19.0.0, SPSS Inc., an IBM ${ }^{\star}$ Company, USA). All data are given as mean \pm SD. All samples were tested for normality. Paired-samples $t-$ tests were used to detect differences in data between the two methods. Pearson's correlation coefficient was used to test for association. The level of significance was set at $p<0.05$. 

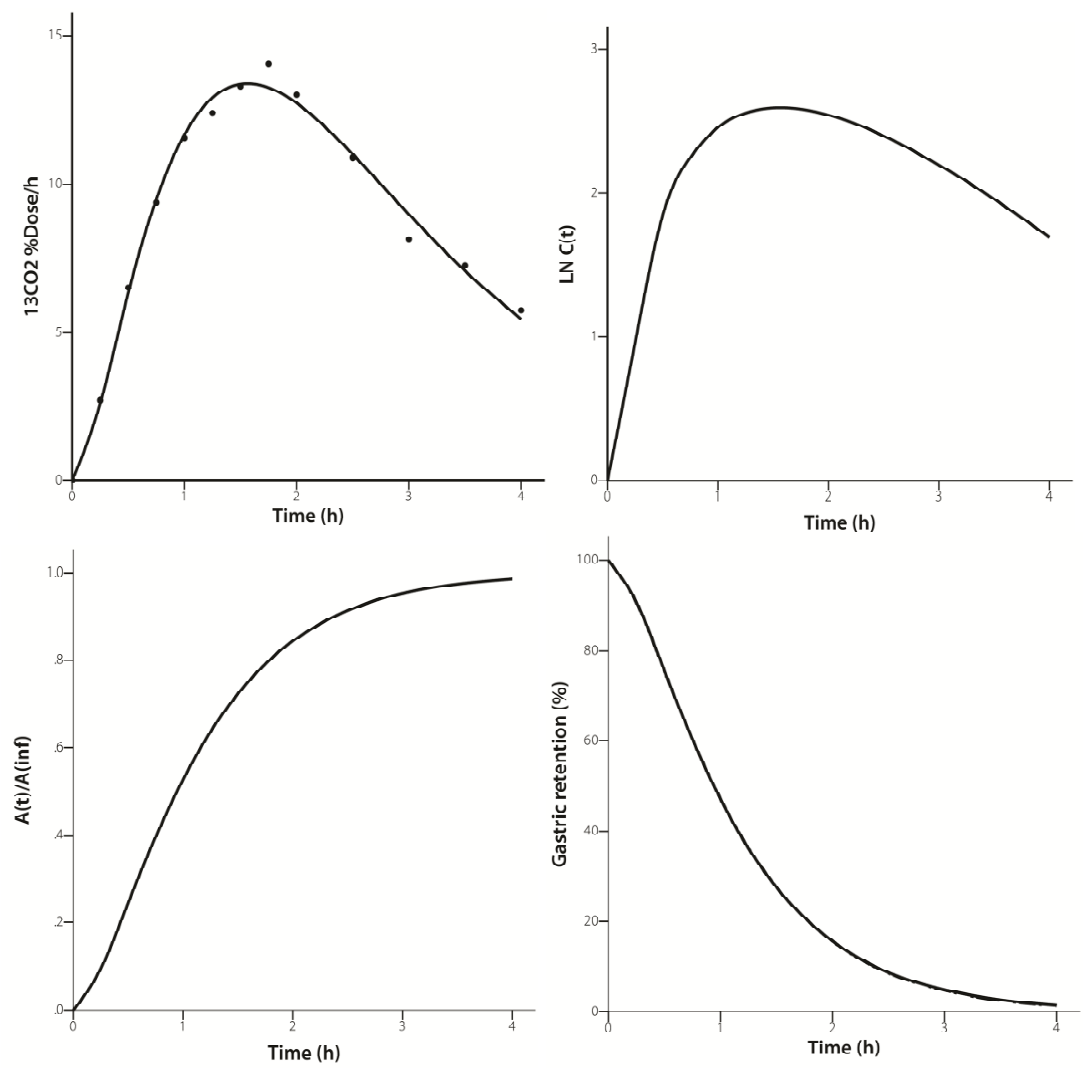

Figure 7.1 Correction of stable isotope breath test data using the Wagner-Nelson method.

\section{Results}

\section{Reliability of MRI volume analysis}

Reliability was determined from the liquid emptying data, analyzed independently by two observers. Table 7.1 shows very high inter-observer agreement and intraobserver reproducibility. The similarity index showed good agreement. 
Table 7.1 Intra- and inter-observer reliability of MRI volume analyses between two observers; Intraclass Correlation Coefficient (ICC), Squared Correlation $\left(\mathrm{R}^{2}\right)$ and Similarity Index (SI).

\begin{tabular}{cccc}
\hline & Intragastric air & Contents & Stomach \\
\hline Intra-observer $1(\mathrm{n}=16)$ & & & \\
$\mathrm{ICC}(95 \% \mathrm{Cl})$ & $0.954(0.940-0.966)$ & $0.993(0.990-0.994)$ & $0.988(0.985-0.991)$ \\
$\mathrm{R}^{2}$ & 0.911 & 0.986 & 0.980 \\
$\mathrm{SI}$ & 0.841 & 0.915 & - \\
Inter-observer $(\mathrm{n}=16)$ & & & $0.979(0.972-0.984)$ \\
$\mathrm{ICC}(95 \% \mathrm{Cl})$ & $0.968(0.958-0.976)$ & $0.963(0.951-0.972)$ & 0.970 \\
$\mathrm{R}^{2}$ & 0.958 & 0.979 & - \\
$\mathrm{SI}$ & 0.832 & 0.911 & \\
\hline
\end{tabular}

\section{MRI data fitting}

MRI data analysis was performed on 15 out of 16 subjects for the liquid emptying study, because for one subject part of the postprandial MRI data were missing, thereby hindering accurate fitting to an emptying model. MRI data analysis was performed on all 12 subjects for the solid emptying study.

Table 7.2 shows goodness-of-fit results for each of the models employed. Liquid emptying was best fit with the well-known bi-phasic model of Siegel et al. ${ }^{31}$ $y_{t}=1-\left(1-e^{k t}\right)^{\beta} ; R^{2}=0.974$. Parameters of gastric emptying ${ }^{14,31}$ that were calculated: (1) gastric half-emptying time; $t_{1 / 2 M R I-l i q u i d}=-1 / k \cdot \ln \left(1-2^{-1 / \beta}\right)$, (2) lag time; $t_{\text {lagMRI-liquid }}=-1 / k \cdot \ln \left(1-0.05^{1 / \beta}\right)$ and (3) gastric emptying rate; $G E R_{\text {MRI-liquid }}=k$.

Solid emptying was best fit with a power exponential model ${ }^{30} y_{t}=m e^{-k t^{\beta}} ; R^{2}=0.943$. Parameters of gastric emptying ${ }^{30}$ that were calculated: (1) gastric half-emptying time; $t_{1 / 2 M R I-\text { solid }}=(-\ln (0.5) / k)^{1 / \beta}$, (2) lag time; $t_{\text {lagMRI-solid }}=(-\ln (0.95) / k)^{1 / \beta}$ and 3$)$ gastric emptying rate; $G E R_{\text {MRI-solid }}=k$.

Table 7.2A Liquid gastric emptying by MRI: goodness-of-fit for different models.

\begin{tabular}{lcc}
\hline & Intraclass Correlation Coefficient & Squared Correlation \\
\hline Elashoff et al. $^{28}$ & $0.937(0.915-0.953)$ & 0.885 \\
Goetze et al. $^{29}$ & $0.880(0.843-0.909)$ & 0.781 \\
Power exponential $^{30}$ & $0.985(0.979-0.989)$ & 0.969 \\
Siegel et al. ${ }^{31}$ & $0.987(0.982-0.990)$ & 0.974 \\
\hline
\end{tabular}

Table 7.2B Solid gastric emptying by MRI: goodness-of-fit for different models.

\begin{tabular}{lcc}
\hline & Intraclass Correlation Coefficient & Squared Correlation \\
\hline Elashoff et al. $^{28}$ & $0.942(0.915-0.961)$ & 0.898 \\
Goetze et al. $^{29}$ & $0.919(0.883-0.944)$ & 0.844 \\
Power exponential $^{30}$ & $0.970(0.956-0.980)$ & 0.943 \\
Siegel et al. $^{31}$ & $0.965(0.947-0.977)$ & 0.935 \\
\hline
\end{tabular}

\section{Liquid gastric emptying}

The gastric emptying model by Siegel et al. ${ }^{31}$ was used to fit gastric contents MRI data. ${ }^{13} \mathrm{C}$-breath test and MRI determined liquid gastric emptying parameters are 
provided in Table 7.3.

Half-emptying time estimated by BT was significantly different from half-emptying time determined by MRl; $t_{1 / 2 B T} 148 \pm 17$ min vs. $t_{1 / 2 \text { MRI-liquid }} 97 \pm 13 \mathrm{~min}, \mathrm{p}=0.000$. However, half-emptying time estimated by BT showed a strong $(r=0.737)$ and significant $(p=0.002)$ association with half-emptying time determined by MRI. The linear regression model for $t_{1 / 2 B T}$ on $t_{1 / 2 M R I-l i q u i d}$ was estimated to be $t_{1 / 2 B T}=0.93 \cdot t_{1 / 2 M R I-\text { liquid }}+58$. With respect to $\mathrm{CBT}$ and MRI a significant difference was observed for half-emptying time; $t_{1 / 2 C B T} 59 \pm 11 \mathrm{~min}$ vs. $t_{1 / 2 \text { MRI-liquid }} 97 \pm 13 \mathrm{~min}, \mathrm{p}=0.000$. Half-emptying time for $\mathrm{CBT}$ and MRI showed a significant association $(r=0.732$, $p=0.002$ ). Figure $7.2 A$ shows gastric emptying curves resulting from $c B T$ and $M R I$ data.

Table 7.3 Liquid and solid gastric emptying parameters determined by ${ }^{13} \mathrm{C}$-breath test and Magnetic Resonance Imaging.

\begin{tabular}{llccc}
\hline & & $\mathrm{BT}$ & $\mathrm{cBT}$ & $\mathrm{MRI}$ \\
\hline Liquid & & & & \\
& $t_{1 / 2}(\min )$ & $148 \pm 17^{*}$ & $59 \pm 11^{*}$ & $97 \pm 13$ \\
& $t_{\text {lag }}(\min )$ & $39 \pm 7$ & $10 \pm 4^{*}$ & $42 \pm 13$ \\
& $t_{\max }(\min )$ & $98 \pm 14$ & & \\
\multirow{5}{*}{ Solid } & $G E R / G E C$ & $3.37 \pm 0.20^{*}$ & $1.13 \pm 0.11^{*}$ & $1.49 \pm 0.42$ \\
& & & & \\
& $t_{1 / 2}(\min )$ & $222 \pm 69^{*}$ & $93 \pm 15^{*}$ & $37 \pm 22$ \\
& $t_{\text {lag }}(\min )$ & $58 \pm 14^{*}$ & $16 \pm 6^{*}$ & \\
& $t_{\max }(\min )$ & $144 \pm 38$ & & $0.19 \pm 0.17$ \\
\hline
\end{tabular}

$\mathrm{MRI}=$ Magnetic Resonance Imaging, BT = Breath Test, $\mathrm{CBT}=$ corrected Breath Test. GER = gastric emptying rate for $\mathrm{MRI}, \mathrm{GEC}=$ gastric emptying coefficient. ${ }^{*} \mathrm{p}<0.05$ compared to MRI.
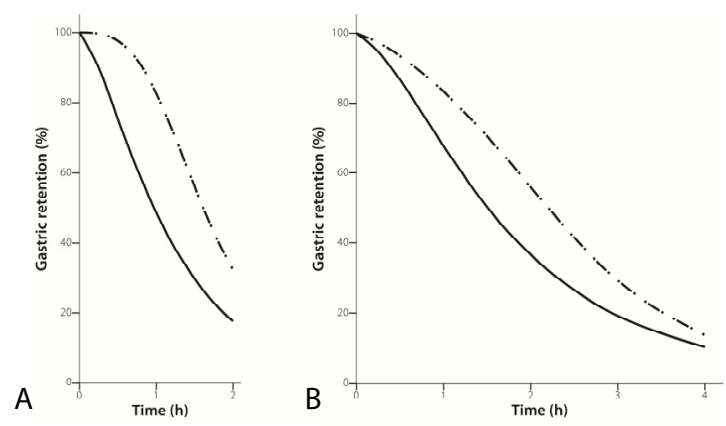

Figure 7.2 Gastric emptying curves determined by 13C-breath test, corrected according to Sanaka et al., and Magnetic Resonance imaging for liquid (A) and solid (B) gastric emptying. Gastric emptying curve by MRI (dotted line) and by corrected Breath Test (solid line).

Peak excretion time estimated by BT did not differ significantly from half-emptying time determined by MRI (Table 7.3). A strong $(r=0.758)$ and significant $(p=0.001)$ association was found between $t_{\operatorname{maxBT}}$ and $t_{1 / 2 M R I-l i q u i d}$ (Figure 7.3A). Agreement for 
peak excretion time and half-emptying time between BT and MRI are presented as a Bland-Altman plot in Figure $7.4 \mathrm{~A}^{32}$. The mean difference was $-1 \mathrm{~min}$ with $95 \%$ limits of agreement between -19 and $18 \mathrm{~min}$.

Lag time estimated by BT did not differ significantly from lag time determined with MRI (Table 7.3). However, there was no association between $t_{\text {lagBT }}$ and $t_{\text {lagmRI-liquid }}$ $(r=0.139, p=0.622)$. Lag time estimated by $c B T$ was significantly different from lag time determined with MRI; $t_{\text {lagcBT }} 10 \pm 4$ vs. $t_{\text {lagMRI-liquid }} 42 \pm 13 \mathrm{~min}, \mathrm{p}=0.000$. No association existed between $t_{\text {lagcBT }}$ and $t_{\text {lagMRI-liquid }}(r=0.029, \mathrm{p}=0.920)$.

GEC estimated by BT and GER estimated by $\mathrm{CBT}$ were significantly different from GER determined with MRI (Table 7.3).
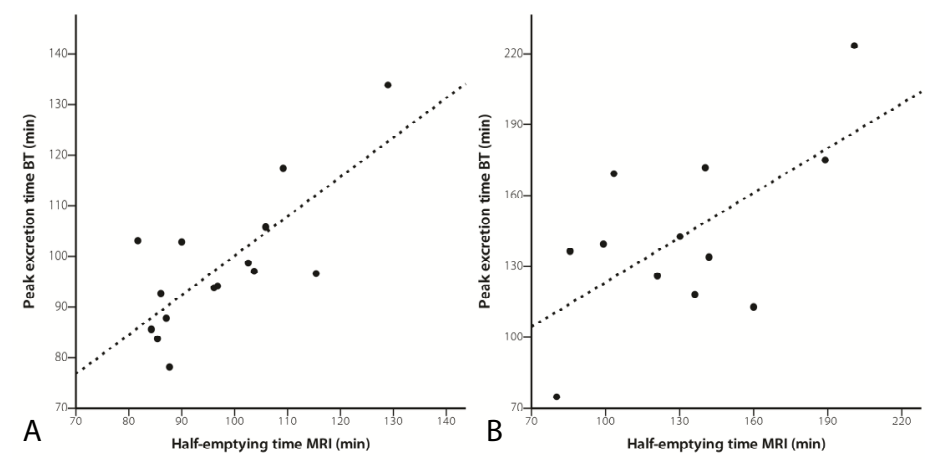

Figure 7.3 Correlation between peak excretion time determined by ${ }^{13} \mathrm{C}$-breath test and half-emptying time determined by Magnetic Resonance imaging for liquid (A) and solid (B) gastric emptying. $\mathrm{MRI}=$ Magnetic Resonance Imaging, $\mathrm{BT}=$ Breath Test. Liquid: $r=0.758, p=0.001$, Solid: $r=0.634, p=0.027$.
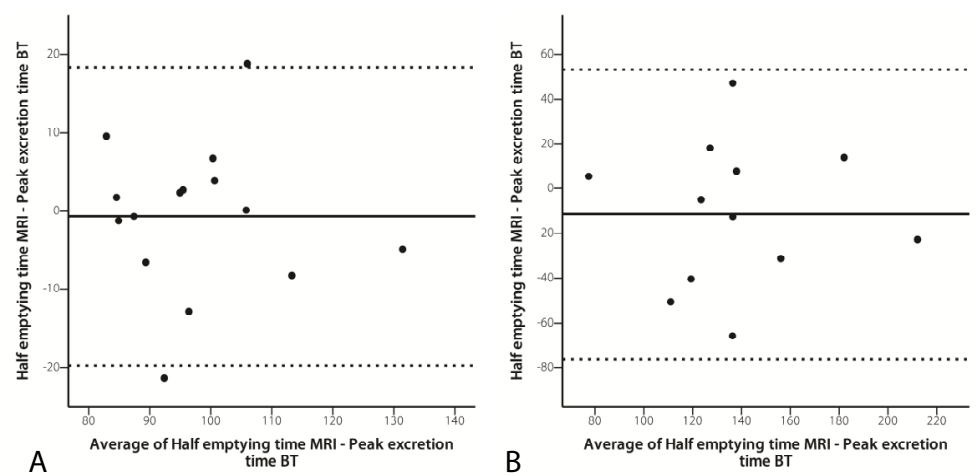

Figure 7.4 Agreement by Bland altman plots between peak excretion time determined by ${ }^{13} \mathrm{C}-$ breath test and half-emptying time determined by Magnetic Resonance imaging for liquid $(A)$ and solid (B) gastric emptying. Mean difference (solid line) for liquid (-1 min) and solid (-11 min) $95 \%$ limits of agreement (dotted lines) for liquid (-19-18 $\mathrm{min}$ ) and solid (-76-53 $\mathrm{min})$. 


\section{Solid emptying}

Gastric contents data obtained with MRI were fit to a power exponential model ${ }^{30}$. ${ }^{13} \mathrm{C}$-breath test and MRI determined solid gastric emptying parameters are provided in Table 7.3.

Half-emptying time estimated by BT was significantly different from half-emptying time determined by MRI (Table 7.3). Half-emptying time estimated by BT showed a moderate $(r=0.622)$ but significant $(p=0.031)$ association with half-emptying time determined by MRI. The linear regression model for $t_{1 / 2 B T}$ on $t_{1 / 2 M R l-s o l i d}$ was estimated to be $t_{1 / 2 B T}=1.13 \cdot t_{1 / 2 M R I-s o l i d}+73$. With respect to CBT and MRI a significant difference was observed for half-emptying time; $t_{1 / 2 C B T} 93 \pm 15$ vs. $t_{1 / 2 M R l-\text { solid }} 132 \pm 38 \mathrm{~min}, \mathrm{p}=0.005$. There was no significant association between $t_{1 / 2 c B T}$ and $t_{1 / 2 M R l-s o l i d}(r=0.089, \mathrm{p}=0.783)$. Figure $7.2 \mathrm{~B}$ shows gastric emptying curves resulting from $\mathrm{CBT}$ and $\mathrm{MRI}$ data.

Peak excretion time estimated by BT did not differ significantly from half-emptying time determined by MRI (Table 7.3). Moreover a moderate ( $r=0.634)$ and significant $(\mathrm{p}=0.027)$ association between $t_{\operatorname{maxBT}}$ and $t_{1 / 2 M R l-s o l i d}$ was found (Figure 7.3B). The Bland-Altman plot in Figure 7.4B shows the agreement for peak excretion time and half-emptying time between BT and MRI. The mean difference was -11 min with $95 \%$ limits of agreement between -76 and 53 min.

Lag time estimated by BT was significantly different from lag time determined with MRI (Table 7.3). Moreover, there was no significant association between $t_{\text {lagBT }}$ and $t_{\text {lagMRl-solid }}(\mathrm{r}=-0.490, \mathrm{p}=0.106)$. Lag time estimated by CBT was significantly different from lag time determined with MRl; $t_{\text {lag BT }} 16 \pm 6$ vs. $t_{\text {lagMRl-solid }} 37 \pm 22 \mathrm{~min}, \mathrm{p}=0.000$. No association existed between $t_{\text {lagcBT }}$ and $t_{\text {lagMRl-solid }}(\mathrm{r}=-0.113, \mathrm{p}=0.726)$.

GEC determined by BT and GER determined by CBT were significantly different from GER determined with MRI (Table 7.3).

\section{Discussion}

We have demonstrated that reliability of MRI volume analysis is excellent. Second, our data indicate that correlation between stable isotope breath test and MRI for liquid emptying is better than that for solid gastric emptying. Third, mathematical correction of stable isotope breath test data did not improve the outcome of gastric emptying parameters.

Magnetic Resonance Imaging (MRI) has been validated previously to measure gastric emptying of both liquid and solid meals $\mathrm{s}^{33-36}$. In the past two decades MRI has been used more frequent for research than for clinical purposes regarding gastric motor function. Gastric emptying has been evaluated using MRI in health and disease ${ }^{37-39}$, after surgical or pharmacological interventions $\mathrm{s}^{40-44}$, to study intragastric distribution and meal layering and to analyze gastric motility, i.e. antral contractions ${ }^{45}$. 
The MRI technique has been validated for gastric volume measurements both in vitro and in vivo ${ }^{26,45}$ but data on inter- and intra-observer agreement in determining stomach and intragastric volumes have not been reported previously. We have shown that, using our in-house developed interactive software tool, inter- and intraobserver agreement was excellent with respect to total stomach volume, intragastric air volume and intragastric contents volume.

For analysis of MRI emptying data we used several models to determine goodnessof-fit. The best fit for liquid emptying was obtained with the bi-phasic model of Siegel et al. ${ }^{31}$ and for solid emptying the best fit was obtained with the power exponential model described by Camilleri et al. ${ }^{30}$. The model described by Goetze et al. ${ }^{29}$ is perfectly suited to also describe increments in volume immediately after meal ingestion that result from gastric acid secretion. Our sequence of data acquisition did not include measurements in the immediate postprandial phase and thus does not allow application of this model.

Our data on correlation between ${ }^{13} \mathrm{C}$-breath test and MRI are in line with previous studies comparing ${ }^{13} \mathrm{C}$-breath test with scintigraphy. These studies have primarily focused on solid gastric emptying and parameters like $t_{\text {lag }}$ and $t_{1 / 2}$. These studies showed correlations between the two methods for $t_{1 / 2}$ varying between 0.01 and 0.98 , with most studies showing a correlation coefficient over $0.70^{5,8-17,46}$. In studies comparing ${ }^{13} \mathrm{C}$-breath test with scintigraphy for liquid gastric emptying, correlation for $t_{1 / 2}$ was found varying between 0.09 and $0.95^{5,10,12,13}$. In our study half-emptying time determined by ${ }^{13} \mathrm{C}$-breath test correlated better for liquid gastric emptying than for solid gastric emptying when compared to MRI.

In all studies comparing ${ }^{13} \mathrm{C}$-breath test with scintigraphy a significant difference between $t_{1 / 2}$ determined with scintigraphy and $t_{1 / 2}$ determined with ${ }^{13} \mathrm{C}$-breath test was found, where $t_{1 / 2}$ for ${ }^{13} \mathrm{C}$-breath test is always prolonged compared to scintigraphy. Our study is one of the first to compare the stable isotope breath test against MRI during simultaneous recording, thereby excluding day-to-day variations in gastric emptying that might hinder comparison between the two techniques. We considered MRI as the gold standard for gastric emptying. A consistent difference in half-emptying time obtained with ${ }^{13} \mathrm{C}$-breath test and MRI was noted. Similar observations have been made in studies comparing ${ }^{13} \mathrm{C}$-breath test with ultrasonography ${ }^{47}$ and scintigraphy ${ }^{5,6,10,16,46}$. This time difference, i.e. delay, is believed to represent the time required for absorption, metabolism, oxidation and exhalation of the stable isotope from the ${ }^{13} \mathrm{C}$-octanoate or ${ }^{13} \mathrm{C}$-acetate substrate incorporated in the meal. Previous studies using direct intraduodenal administration of ${ }^{13} \mathrm{C}$-octanoate and ${ }^{13} \mathrm{C}$-acetate showed a delay of $9-16 \mathrm{~min}^{48-50}$ for ${ }^{13} \mathrm{C}$ to appear in breath.

In order to correct for the time needed for absorption, post-processing and exhalation of ${ }^{13} \mathrm{C}$-octanoate and ${ }^{13} \mathrm{C}$-acetate, we used the previously described method by Sanaka et al. ${ }^{18}$. These authors have shown that correction of ${ }^{13} \mathrm{C}$-breath test data by the Wagner-Nelson method results in better agreement between the half-emptying times determined by the ${ }^{13} \mathrm{C}$-breath test (indirect method) and 
scintigraphy (direct method) ${ }^{51}$. In that study differences in half-emptying time between the corrected breath test and scintigraphy for both liquids and solids were not statistically significant. Unfortunately, no data on a possible association or agreement were provided. In our study corrected breath test data underestimate half-emptying time compared to MRI, whereas uncorrected breath test data overestimate half-emptying time. These findings are in line with previous studies using scintigraphy ${ }^{52,53}$. In their first study Sanaka et al. ${ }^{18}$ compared liquid halfemptying time determined by corrected breath test with liquid half-emptying time determined by ultrasonography. Half-emptying time determined by corrected breath test did not differ significantly from half-emptying time determined by ultrasonography. Moreover a good and significant correlation ( $r=0.884)$ between the two methods was found (data not provided in the original paper). In a systematic and well-designed study, Goetze et al. ${ }^{50}$ explored the postgastric processing ${ }^{\circ}{ }^{13} \mathrm{C}$ acetate by direct intraduodenal administration simulating different physiological conditions. These authors did not observe any influence of volume or caloric delivery of the meal, but found postgastric processing to be dependent on postgastric marker delivery speed (emptying rate) and marker dose. In their hands the Wagner-Nelson method proved to be highly accurate under well-controlled conditions and provided an excellent correction for postgastric processing. It should be noted however that the accuracy of the Wagner-Nelson method is highly dependent on correct estimation of the elimination constant factor. Estimation of this factor is more accurate and precise when emptying rate is not variable, a condition that does not reflect physiological human gastric emptying. In fact, the Wagner-Nelson method and other analytical methods need to be validated for each test meal, tracer and volume and should preferably be compared with a direct method of emptying ${ }^{50}$.

Odunsi et al. ${ }^{21}$ compared several mathematical models for ${ }^{13} \mathrm{C}$-breath test correction against scintigraphy. An excellent correlation and agreement was found for the methods described by Viramontes et al. ${ }^{19}$ and Szarka et al. ${ }^{1}$. This is not surprising since both methods have been derived from actual scintigraphy data through linear regression, implicitly providing a good correlation and agreement. Fruehauf et al..$^{54}$ have compared MRI and ${ }^{13} \mathrm{C}$-breath test in healthy controls and patients with functional dyspepsia during simultaneous recording. A significant but weak correlation ( $r=0.53, p=0.002)$ between MRI and breath test determined half-emptying time was observed. Correlation differed depending on meal volume. Half-emptying time determined by MRI was shorter after a large volume meal $(800 \mathrm{ml}$, caloric load $0.375 \mathrm{kcal} / \mathrm{ml}$ ) compared to a small volume $(200 \mathrm{ml}$, caloric load $1.5 \mathrm{kcal} / \mathrm{ml})$ meal. ${ }^{13} \mathrm{C}$-breath test, however, did not detect the faster emptying of the large volume meal. These results show that ${ }^{13} \mathrm{C}$-breath test results can only be compared when obtained under similar conditions with identical test meals, indicating that ${ }^{13} \mathrm{C}$-breath test is accurate with respect to comparison of within group results when identical meals have been used and the parameter or intervention to be studied does not 
influence either absorption, metabolism or exhalation of ${ }^{13} \mathrm{C}$-octanoate and ${ }^{13} \mathrm{C}$-acetate.

Delbende et al. ${ }^{46}$ in a multicenter study compared solid gastric emptying in both health and disease using half-emptying times determined by scintigraphy and ${ }^{13} \mathrm{C}$-breath test. They found a highly significant correlation $(r=0.744)$ with an intercept between the two methods of $67 \mathrm{~min}$, similar to the intercept previously observed by Ghoos et al. ${ }^{5}$. Our data on solid emptying are in line with these observations. A delay of half-emptying time determined with ${ }^{13} \mathrm{C}$-breath test over scintigraphy has been reported in several studies, with differences from 55-67 min for solid emptying and $49 \mathrm{~min}$ for liquid emptying ${ }^{5,6,46}$. The difference in delay between liquid and solid emptying is most likely substrate related. Low-molecular-weight acetate is absorbed and oxidized slightly more rapidly than octanoate ${ }^{55}$.

A much weaker correlation between ${ }^{13} \mathrm{C}$-breath test and scintigraphy does exist with respect to lag time. In our study lag time for liquid gastric emptying, but not for solid gastric emptying, determined by ${ }^{13} \mathrm{C}$-breath test was nearly identical to lag time determined by MRI. However no association was found. Our data are in line with previous studies showing a poor correlation between ${ }^{13} \mathrm{C}$-breath test and scintigraphy for lag time ${ }^{12,13}$. Others, however, did find a significant correlation comparing ${ }^{13} \mathrm{C}$-breath test and scintigraphy determined lag time, although much weaker compared to half-emptying times ${ }^{5,10,16}$. This might be related to technical difficulties in quantifying lag time obtained with scintigraphy ${ }^{11}$.

In conclusion, we have shown good correlation and agreement between ${ }^{13} \mathrm{C}$-breath test and MRI obtained parameters for liquid gastric emptying, but to a lesser extent so for solid gastric emptying. Several models to correct breath test data can be employed in order to improve comparison with a direct emptying method. The accuracy of these models depends on various factors. These factors should be recognized and preferably standardized in order to apply a stable isotope breath test in the clinical setting. 


\section{References}

1. Szarka LA, Camilleri M. Methods for measurement of gastric motility. Am J Physiol Gastrointest Liver Physiol 2009;296:G461-75.

2. Camilleri M. New imaging in neurogastroenterology: an overview. Neurogastroenterol Motil 2006;18:805-12.

3. Kondo T. Routine gastric emptying tests. J Gastroenterol 2000;35:476-8.

4. Kim DY, Myung SJ, Camilleri M. Novel testing of human gastric motor and sensory functions: rationale, methods, and potential applications in clinical practice. Am J Gastroenterol 2000;95: 3365-73.

5. Ghoos YF, Maes BD, Geypens BJ, Mys G, Hiele MI, Rutgeerts PJ, Vantrappen G. Measurement of gastric emptying rate of solids by means of a carbon-labeled octanoic acid breath test. Gastroenterology 1993;104:1640-7.

6. Braden B, Adams S, Duan LP, Orth KH, Maul FD, Lembcke B, Hor G, Caspary WF. The [13C]acetate breath test accurately reflects gastric emptying of liquids in both liquid and semisolid test meals. Gastroenterology 1995;108:1048-55.

7. Braden B. Methods and functions: Breath tests. Best Pract Res Clin Gastroenterol 2009;23:337-52.

8. Bromer MQ, Kantor SB, Wagner DA, Knight LC, Maurer AH, Parkman HP. Simultaneous measurement of gastric emptying with a simple muffin meal using [13C]octanoate breath test and scintigraphy in normal subjects and patients with dyspeptic symptoms. Dig Dis Sci 2002;47:1657-63.

9. Punkkinen J, Konkka I, Punkkinen O, Korppi-Tommola T, Farkkila M, Koskenpato J. Measuring gastric emptying: comparison of 13C-octanoic acid breath test and scintigraphy. Dig Dis Sci 2006;51:262-7.

10. Chen CP, Chen CY, Lu CL, Chang FY, Lee SD, Chu LS, Liu RS, Wu HC. Infrared spectrometry based 13Coctanoic acid breath test in measuring human solid gastric emptying. J Gastroenterol Hepatol 2003; 18:41-6.

11. Chey WD, Shapiro B, Zawadski A, Goodman K. Gastric emptying characteristics of a novel (13)Coctanoate-labeled muffin meal. J Clin Gastroenterol 2001;32:394-9.

12. Choi MG, Camilleri M, Burton DD, Zinsmeister AR, Forstrom LA, Nair KS. [13C]octanoic acid breath test for gastric emptying of solids: accuracy, reproducibility, and comparison with scintigraphy. Gastroenterology 1997;112:1155-62.

13. Choi MG, Camilleri M, Burton DD, Zinsmeister AR, Forstrom LA, Nair KS. Reproducibility and simplification of $13 \mathrm{C}$-octanoic acid breath test for gastric emptying of solids. Am J Gastroenterol 1998;93:92-8.

14. Maes BD, Ghoos YF, Geypens BJ, Mys G, Hiele MI, Rutgeerts PJ, Vantrappen G. Combined carbon-13glycine/carbon-14-octanoic acid breath test to monitor gastric emptying rates of liquids and solids. J Nucl Med 1994;35:824-31.

15. Maes BD, Mys G, Geypens BJ, Evenepoel P, Ghoos YF, Rutgeerts PJ. Gastric emptying flow curves separated from carbon-labeled octanoic acid breath test results. Am J Physiol 1998;275:G169-G75.

16. Perri F, Clemente R, Festa V, Andriulli A. 13C-Octanoic acid breath test: valueless test for gastric emptying? Gastroenterology 1998;114:857-9.

17. Dickman R, Steinmetz A, Bernnstine H, Groshar D, Niv Y. A novel continuous breath test versus scintigraphy for gastric emptying rate measurement. J Clin Gastroenterol 2011;45:22-5.

18. Sanaka M, Yamamoto T, Ishii T, Kuyama Y. The Wagner-Nelson method can generate an accurate gastric emptying flow curve from $\mathrm{CO} 2$ data obtained by a $13 \mathrm{C}$-labeled substrate breath test. Digestion 2004;69:71-8.

19. Viramontes BE, Kim DY, Camilleri M, Lee JS, Stephens D, Burton DD, Thomforde GM, Klein PD, Zinsmeister AR. Validation of a stable isotope gastric emptying test for normal, accelerated or delayed gastric emptying. Neurogastroenterol Motil 2001;13:567-74.

20. Lee JS, Camilleri M, Zinsmeister AR, Burton DD, Choi MG, Nair KS, Verlinden M. Toward office-based measurement of gastric emptying in symptomatic diabetics using [13C]octanoic acid breath test. Am J Gastroenterol 2000;95:2751-61.

21. Odunsi ST, Camilleri M, Szarka LA, Zinsmeister AR. Optimizing analysis of stable isotope breath tests to estimate gastric emptying of solids. Neurogastroenterol Motil 2009;21:706-e38. 
22. Schwizer W, Fox M, Steingotter A. Non-invasive investigation of gastrointestinal functions with magnetic resonance imaging: towards an "ideal" investigation of gastrointestinal function. Gut 2003;52 Suppl 4:iv34-iv9.

23. De Schepper HU, Cremonini F, Chitkara D, Camilleri M. Assessment of gastric accommodation: overview and evaluation of current methods. Neurogastroenterol Motil 2004;16:275-85.

24. de Zwart IM, Mearadji B, Lamb HJ, Eilers PH, Masclee AA, de Roos A, Kunz P. Gastric motility: comparison of assessment with real-time MR imaging or barostat measurement initial experience. Radiology 2002;224:592-7.

25. de Zwart IM, Haans JJ, Verbeek P, Eilers PH, de Roos A, Masclee AA. Gastric accommodation and motility are influenced by the barostat device: Assessment with magnetic resonance imaging. Am J Physiol Gastrointest Liver Physiol 2007;292:G208-G14.

26. Haans JJ, de Zwart IM, Eilers PH, Reiber JH, Doornbos J, de Roos A, Masclee AA. Gastric volume changes in response to a meal: Validation of magnetic resonance imaging versus the barostat. J Magn Reson Imaging 2011;34:685-90.

27. Admiraal-Behloul F, van den Heuvel DM, Olofsen H, van Osch MJ, van der Grond J, van Buchem MA, Reiber JH. Fully automatic segmentation of white matter hyperintensities in MR images of the elderly. Neuroimage 2005;28:607-17.

28. Elashoff JD, Reedy TJ, Meyer JH. Analysis of gastric emptying data. Gastroenterology 1982;83: 1306-12.

29. Goetze O, Steingoetter A, Menne D, Van DVI, Kwiatek MA, Boesiger P, Weishaupt D, Thumshirn M, Fried $M$, Schwizer $W$. The effect of macronutrients on gastric volume responses and gastric emptying in humans - a magnetic resonance imaging study. Am J Physiol Gastrointest Liver Physiol 2006.

30. Camilleri M, Malagelada JR, Brown ML, Becker G, Zinsmeister AR. Relation between antral motility and gastric emptying of solids and liquids in humans. Am J Physiol 1985;249:G580-5.

31. Siegel JA, Urbain JL, Adler LP, Charkes ND, Maurer AH, Krevsky B, Knight LC, Fisher RS, Malmud LS. Biphasic nature of gastric emptying. Gut 1988;29:85-9.

32. Bland JM, Altman DG. Statistical methods for assessing agreement between two methods of clinical measurement. Lancet 1986;1:307-10.

33. Schwizer W, Maecke H, Fried M. Measurement of gastric emptying by magnetic resonance imaging in humans. Gastroenterology 1992;103:369-76.

34. Feinle C, Kunz P, Boesiger P, Fried M, Schwizer W. Scintigraphic validation of a magnetic resonance imaging method to study gastric emptying of a solid meal in humans. Gut 1999;44:106-11.

35. Kunz P, Feinle C, Schwizer W, Fried M, Boesiger P. Assessment of gastric motor function during the emptying of solid and liquid meals in humans by MRI. J Magn Reson Imaging 1999;9:75-80.

36. Carbone SF, Tanganelli I, Capodivento S, Ricci V, Volterrani L. Magnetic resonance imaging in the evaluation of the gastric emptying and antral motion: feasibility and reproducibility of a fast not invasive technique. Eur J Radiol;75:212-4.

37. Lauenstein TC, Vogt FM, Herborn CU, DeGreiff A, Debatin JF, Holtmann G. Time-resolved threedimensional MR imaging of gastric emptying modified by IV administration of erythromycin. AJR Am J Roentgenol 2003;180:1305-10.

38. Lehmann R, Borovicka J, Kunz P, Crelier G, Boesiger P, Fried M, Schwizer W, Spinas GA. Evaluation of delayed gastric emptying in diabetic patients with autonomic neuropathy by a new magnetic resonance imaging technique and radio-opaque markers. Diabetes Care 1996;19:1075-82.

39. Marciani L, Coleman NS, Dunlop SP, Singh G, Marsden CA, Holmes GK, Spiller RC, Gowland PA. Gallbladder contraction, gastric emptying and antral motility: single visit assessment of upper $\mathrm{Gl}$ function in untreated celiac disease using echo-planar MRI. J Magn Reson Imaging 2005;22:634-8.

40. Bennett J, Rhodes M, Malcolm P, Dainty J, Simpson B, Johnson I, Boddy A, Wickham M, Williams S. Assessment of the relationship between post-meal satiety, gastric volume and gastric emptying after swedish adjustable gastric banding. A pilot study using magnetic resonance imaging to assess postsurgery gastric function. Obes Surg 2009;19:757-63.

41. Schwizer W, Borovicka J, Kunz P, Fraser R, Kreiss C, D'Amato M, Crelier G, Boesiger P, Fried M. Role of cholecystokinin in the regulation of liquid gastric emptying and gastric motility in humans: studies with the CCK antagonist loxiglumide. Gut 1997;41:500-4. 
42. Borovicka J, Lehmann R, Kunz P, Fraser R, Kreiss C, Crelier G, Boesiger P, Spinas GA, Fried M, Schwizer $W$. Evaluation of gastric emptying and motility in diabetic gastroparesis with magnetic resonance imaging: effects of cisapride. Am J Gastroenterol 1999;94:2866-73.

43. Coleman NS, Marciani L, Blackshaw E, Wright J, Parker M, Yano T, Yamazaki S, Chan PQ, Wilde K, Gowland PA, Perkins AC, Spiller RC. Effect of a novel 5-HT3 receptor agonist MKC-733 on upper gastrointestinal motility in humans. Aliment Pharmacol Ther 2003;18:1039-48.

44. Kwiatek MA, Fox MR, Steingoetter A, Menne D, Pal A, Fruehauf $H$, Kaufman E, Forras-Kaufman Z, Brasseur JG, Goetze O, Hebbard GS, Boesiger P, Thumshirn M, Fried M, Schwizer W. Effects of clonidine and sumatriptan on postprandial gastric volume response, antral contraction waves and emptying: an MRI study. Neurogastroenterol Motil 2009;21:928-e71.

45. Boulby $\mathrm{P}$, Gowland $\mathrm{P}$, Adams V, Spiller RC. Use of echo planar imaging to demonstrate the effect of posture on the intragastric distribution and emptying of an oil/water meal. Neurogastroenterol Motil 1997;9:41-7.

46. Delbende B, Perri F, Couturier O, Leodolter A, Mauger P, Bridgi B, Bizais Y, des Varannes SB, Andriulli A, Galmiche JP. 13C-octanoic acid breath test for gastric emptying measurement. EurJGastroenterolHepatol 2000;12:85-91.

47. Cappello G, Malatesta MG, Ferri A, Ciccaglione AF, Toracchio S, Grossi L, Marzio L. Gastric emptying of a solid-liquid meal measured with $13 \mathrm{C}$ octanoic acid breath test and real-time ultrasonography: a comparative study. Am J Gastroenterol 2000;95:3097-100.

48. Maes BD, Ghoos YF, Rutgeerts PJ, Hiele MI, Geypens B, Vantrappen G. $\left[{ }^{*} \mathrm{C}\right]$ octanoic acid breath test to measure gastric emptying rate of solids. Dig Dis Sci 1994;39:104S-6S.

49. Maes BD, Geypens BJ, Ghoos YF, Hiele MI, Rutgeerts PJ. 13C-Octanoic acid breath test for gastric emptying rate of solids. Gastroenterology 1998;114:856-9.

50. Goetze O, Fox M, Kwiatek MA, Treier R, Schwizer W, Thumshirn M, Fried M, Fruehauf H. Effects of postgastric $13 \mathrm{C}$-acetate processing on measurement of gastric emptying: a systematic investigation in health. Neurogastroenterology and motility : the official journal of the European Gastrointestinal Motility Society 2009;21:1047-e85.

51. Sanaka M, Nakada K, Nosaka C, Kuyama Y. The Wagner-Nelson method makes the [13C]-breath test comparable to radioscintigraphy in measuring gastric emptying of a solid/liquid mixed meal in humans. Clin Exp Pharmacol Physiol 2007;34:641-4.

52. Sanaka M, Urita Y, Sugimoto M, Yamamoto T, Kuyama Y. Comparison between gastric scintigraphy and the [13C]-acetate breath test with Wagner-Nelson analysis in humans. Clin Exp Pharmacol Physiol 2006;33:1239-43.

53. Glerup H, Bluhme H, Villadsen GE, Rasmussen K, Ejskjaer N, Dahlerup JF. Gastric emptying: a comparison of three methods. Scand J Gastroenterology 2007;42:1182-6.

54. Fruehauf $H$, Steingoetter A, Fox MR, Kwiatek MA, Boesiger P, Schwizer W, Fried M, Thumshirn M, Goetze $O$. Characterization of gastric volume responses and liquid emptying in functional dyspepsia and health by MRI or barostat and simultaneous C-acetate breath test. Neurogastroenterol Motil 2009;21:697-e37.

55. Sanaka M, Yamamoto T, Kuyama Y. Retention, fixation, and loss of the [13C] label: a review for the understanding of gastric emptying breath tests. Dig Dis Sci 2008;53:1747-56. 


\section{Chapter 8}

Effect of somatostatin on gastric motility and emptying in health and functional dyspepsia, assessed with Magnetic Resonance Imaging

J.J.L. Haans

I.M. de Zwart

P.H.C. Eilers

A. de Roos

A.A.M. Masclee 


\section{Abstract}

\section{Background}

Delayed gastric emptying has been identified as a possible pathophysiological mechanism in Functional Dyspepsia (FD). The tetradecapeptide somatostatin has numerous effects on the gastrointestinal tract. Controlled data on the effect of somatostatin on gastric emptying are conflicting and data on the effect of somatostatin on postprandial symptoms in FD are lacking.

\section{Aims}

To explore the effect of somatostatin on gastric volumes, gastric emptying, motility and symptoms in health and FD using Magnetic Resonance Imaging (MRI).

\section{Materials and Methods}

Eleven healthy subjects (controls) and 11 patients with FD participated in a randomized, placebo-controlled study. The effect of either somatostatin or saline on gastric function was studied on separate days using MRI volume and dynamic scans. Data are provided as mean (SE) or mean $\pm \mathrm{SD}$.

\section{Results}

Gastric volume was significantly smaller during somatostatin compared to placebo in both FD and controls; mean difference of 70 (24) $\mathrm{ml}$ and 109 (12) $\mathrm{ml}$ respectively. Gastric emptying was delayed in FD compared to controls: half emptying time $128 \pm 22 \mathrm{~min}$ vs. $106 \pm 24 \mathrm{~min}(\mathrm{p}<0.05)$. Somatostatin significantly $(p<0.05)$ reduced lag time and 90 min retention in both groups. Neither postprandial contraction frequency nor symptoms were affected by somatostatin.

\section{Conclusions}

Measured with MRI, somatostatin reduces postprandial gastric volumes and contents in patients with FD and controls through more rapid initiation and acceleration of gastric emptying without affecting gastric contractions. Somatostatin did not result in postprandial symptom reduction in FD patients. 


\section{Introduction}

Functional dyspepsia (FD) has recently been redefined by the $3^{\text {rd }}$ Rome committee on functional gastrointestinal disorders as the presence of symptoms thought to originate in the gastroduodenal region, in the absence of any organic, systemic, or metabolic disease that is likely to explain the symptoms. A subgroup classification into postprandial distress syndrome and epigastric pain syndrome has been proposed. Typical symptoms are postprandial fullness, early satiation and epigastric pain or burning ${ }^{1}$. Several pathophysiological mechanisms have been identified in FD, such as delayed gastric emptying, hypersensitivity to gastric distension, impaired gastric accommodation to a meal, altered duodenal sensitivity to acid or nutrients and abnormal antroduodenal motility ${ }^{2-5}$. Somatostatin is a cyclic tetradecapeptide that is widely distributed throughout the nervous system and the gastrointestinal tract $^{6}$. Somatostatin and its long acting synthetic analogue octreotide exert inhibitory effects on gastric acid secretion, pancreatic enzyme secretion, gallbladder and small bowel motility ${ }^{7}$. Results of studies on the effect of somatostatin and octreotide on gastric emptying in humans have been conflicting ${ }^{8-12}$. While some authors observed an acceleration of gastric emptying by somatostatin in healthy volunteers ${ }^{8,9}$, others found evidence for the opposite: an inhibitory effect of somatostatin on gastric emptying ${ }^{10-12}$.

Both somatostatin and octreotide reduce perception to mechanical and chemical stimuli in the upper gastrointestinal tract and may therefore have potential in the treatment of dyspeptic symptoms ${ }^{13,14}$. Mertz et al. ${ }^{15}$ found a decreased compliance of the proximal stomach and an increased threshold for fullness in response to octreotide in healthy subjects. Mearadji et al. ${ }^{14}$ observed a reduction in visceral perception in healthy subjects, but found no effect on compliance of the proximal stomach. Data on the effect of either somatostatin or octreotide on gastric emptying in FD are lacking. In recent years, Magnetic Resonance Imaging (MRI) has become available as a non-invasive technical alternative to study gastric volume changes, gastric emptying and motility simultaneously ${ }^{16-19}$. Aim of the present study was to explore the effect of somatostatin on gastric volumes, gastric emptying and motility in both healthy subjects and patients with FD.

\section{Materials and Methods}

\section{Subjects}

Eleven patients with FD (four men, seven women; mean age 44 years; range 28-62 years; BMI $24.4 \pm 3.3 \mathrm{~kg} / \mathrm{m}^{2}$ ) and eleven healthy subjects (six men, five women; mean age 25 years; range $19-51$ years; BMI $22.4 \pm 3.0 \mathrm{~kg} / \mathrm{m}^{2}$ ) participated in the study. Patients were recruited from the outpatient clinic and fulfilled criteria for FD. None of 
the healthy subjects had a history of gastrointestinal disease or abdominal surgery and none was taking medication known to influence gastrointestinal motor and sensory function. The Medical Ethics Committee of the Leiden University Medical Center had approved the protocol and written informed consent was obtained from each subject.

\section{Study design}

In this randomized, single blind, placebo-controlled study each subject participated in two experiments performed on separate occasions with an interval of at least 6 days. Subjects were studied after at least 10 hours of fasting. A cannula was placed in the antecubital vein of one forearm for infusion of either somatostatin (Somatostatin UCB, UCB Pharma BV, Breda, The Netherlands) or saline. Infusion of somatostatin $(250 \mu \mathrm{g} / \mathrm{h})$ or saline was started $10 \mathrm{~min}$ prior to the start of the experiment. The subject was positioned in the MRI scanner and initial scans were performed to determine geometric position of the stomach. The subject was studied in a semisupine, right side down position $\left(30^{\circ}\right)$ and remained within the MRI scanner throughout the experiment.

The experiment started with a three-dimensional volume scan and a twodimensional dynamic scan. Hereafter, a liquid meal $(600 \mathrm{kcal})$, consisting of homogenized banana $(100 \mathrm{~g})$, cream $(100 \mathrm{ml})$, syrup $(15 \mathrm{ml})$, dextrose $(10 \mathrm{~g})$ and water (total volume $400 \mathrm{ml}$ ) was provided. This high-caloric, fat rich meal was chosen to provoke symptoms in FD patients. The meal was labeled with a paramagnetic MRI contrast agent, meglumine gadoterate (Dotarem ${ }^{\circledR}$, Laboratoire Guerbet, CdG Cedex, France $)^{20}$. The subject was asked to consume the meal within $10 \mathrm{~min}$. After consumption of the meal a volume scan and dynamic scan were performed every 15 min until 90 min after consumption of the meal.

Following each dynamic scan symptoms were scored on a self-report 10-point scale. The subject was instructed to rate symptoms of nausea, epigastric discomfort, fullness and abdominal tension on a scale ranging from 0 (no symptom) to 10 (maximum symptom).

\section{Magnetic Resonance Imaging}

All images were obtained using a 1.5T MRI scanner (ASC-NT; Philips Medical Systems, Best, The Netherlands) and a 4-channel SENSE body coil. A volume scan (20 slices, thickness $10 \mathrm{~mm}$, slice gap $0.00 \mathrm{~mm}$, echo time $3.5 \mathrm{~ms}$, repetition time $10.00 \mathrm{~ms}$, flip angle $25^{\circ}$, field of view $450.00 \mathrm{~mm}$, matrix $256 \times 256$ pixels, total acquisition time $30 \mathrm{sec}$ ) was performed to determine momentary volumes. A dynamic scan (semicoronal slice orientation, slice thickness $10 \mathrm{~mm}$, echo time $3.6 \mathrm{~ms}$, repetition time $=10$ $\mathrm{ms}$, flip angle $25^{\circ}$, field of view $450 \mathrm{~mm}$, matrix 256x128 pixels, 300 images with a temporal resolution of $1 \mathrm{sec}$ ) was performed to determine gastric motility. These MRI techniques have been used and validated previously ${ }^{17,18,21}$. 


\section{Data analysis}

Intragastric air and contents were identified and outlined manually in all volume images by one observer (I.Z.) using an in-house made interactive software tool (MASS', LKEB, Leiden University Medical Center, The Netherlands). Volumes were calculated by adding the calculated surfaces of all outlined areas multiplied with the slice thickness. Gastric volume was calculated by adding up intragastric air and contents volumes. This method has been described and validated previously ${ }^{18}$.

Several parameters were determined from acquired data: (1) Gastric volumes $(\mathrm{ml})$ in the fasting and postprandial state. (2) Gastric motility parameters were obtained at 10 equally distributed points perpendicular to the stomach axis. Peristaltic contractions (Figure 8.1) were detected and their frequency $\left(\mathrm{min}^{-1}\right)$ was calculated $^{18,21}$.

The bi-phasic model by Siegel et al. ${ }^{22}$ was used to fit contents data and obtain parameters of gastric emptying. Several parameters were calculated from the fit data: (1) Half-emptying time $(\mathrm{min})$ was defined as the moment that half of the initial contents had emptied from the stomach. (2) Lag time ( $\mathrm{min}$ ) was defined as the moment at which $5 \%$ of gastric contents were emptied from the stomach. (3) Ninetyminute retention (\%) was defined as the percentage of gastric contents remaining in the stomach at $90 \mathrm{~min}$ after meal ingestion.

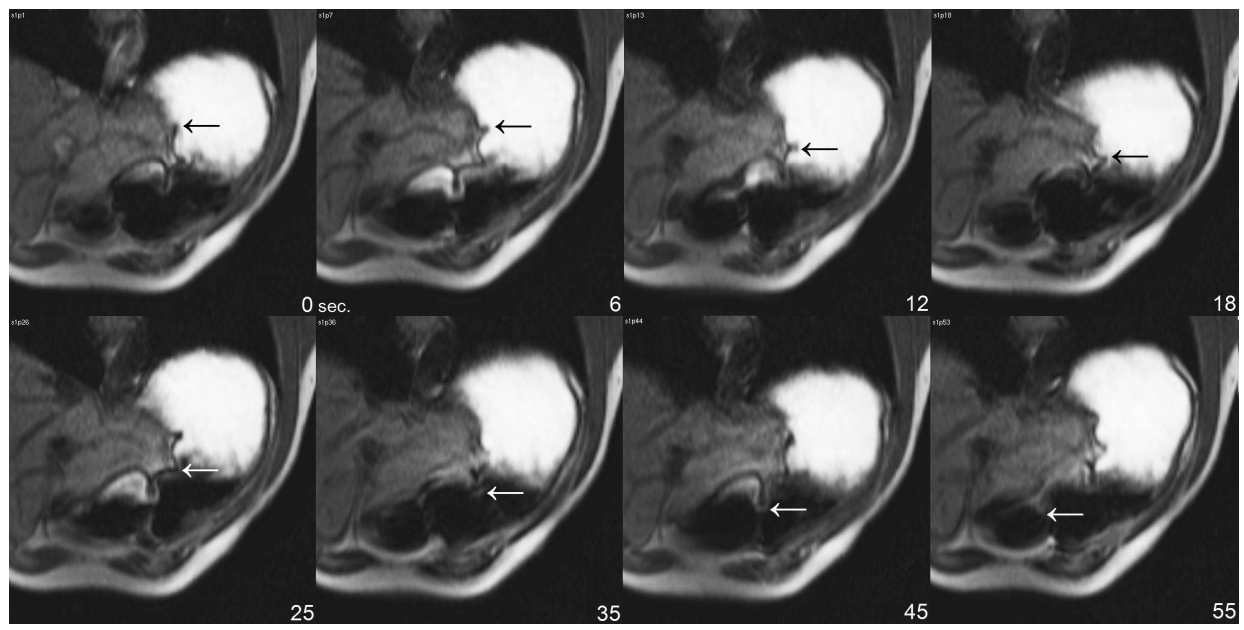

Figure 8.1 Dynamic scan sequence showing peristaltic contractions in the stomach. Peristaltic contractions (arrow) are running from the fundus to the antrum. The gadolinium labeled meal is clearly visible. 


\section{Statistical analysis}

Data was analyzed using a statistical software package (SPSS ${ }^{\circledR}$ for Windows Release 15.0, SPSS Inc, Chicago, USA). All data are provided as mean \pm SD or mean (SE). All samples were tested for normality. Linear mixed model analysis and paired-samples t-test were used to detect differences in data between groups and between experiments. For linear mixed model analysis, data was analyzed in the model using a random subject effect and a fixed time and intervention or group effect. Data was adjusted for multiple comparisons using Bonferroni's correction. The level of significance was set at $\mathrm{p}<0.05$.

\section{Results}

\section{Gastric volumes}

Fasting gastric volumes at $\mathrm{t}=0$ min were not significantly different between FD patients and controls (healthy subjects) neither for somatostatin ( $78 \pm 67 \mathrm{ml}$ vs. $56 \pm 27$ $\mathrm{ml}$ ) nor for placebo $(59 \pm 52 \mathrm{ml}$ vs. $68 \pm 23 \mathrm{ml})$. Gastric volumes in FD patients and controls increased significantly upon meal ingestion during both experiments and remained increased over basal during the entire study period (Figure 8.2). Throughout the experiment postprandial gastric volumes were significantly smaller during somatostatin compared to placebo in both FD patients (mean difference 70 (24) $\mathrm{ml}$ ) and controls (mean difference 109 (12) $\mathrm{ml}$ ).

FD

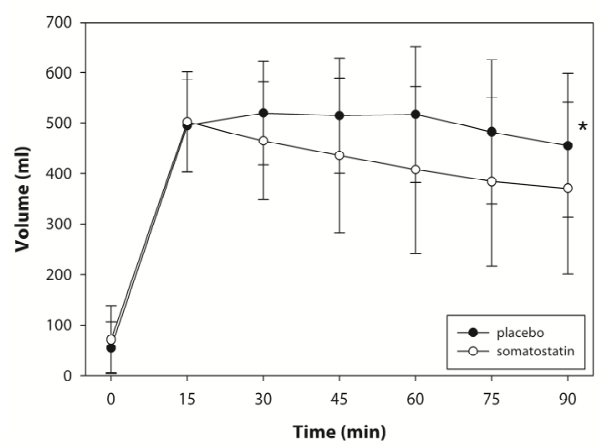

Controls

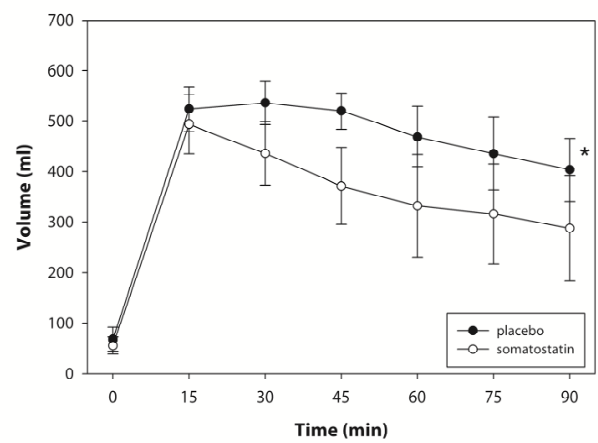

Figure 8.2 Gastric volumes $(\mathrm{ml})$ before and after meal ingestion in FD and controls in response to somatostatin and placebo. Values are shown as mean \pm SD. ${ }^{*} \mathrm{p}<0.05$ compared to somatostatin throughout the experiment. 


\section{Gastric contents}

Figure 8.3 shows the changes in gastric contents during the postprandial period in FD patients and controls in both experiments. After meal ingestion gastric contents increased and thereafter gradually decreased due to gastric emptying. The volume of gastric contents was not significantly different between FD patients and controls, neither during somatostatin nor during placebo. However, within the groups significant differences with respect to gastric contents were observed with smaller volumes during somatostatin compared to placebo in both FD patients (mean difference $80(10) \mathrm{ml}$ ) and controls (mean difference $77(12) \mathrm{ml}$ ).

FD

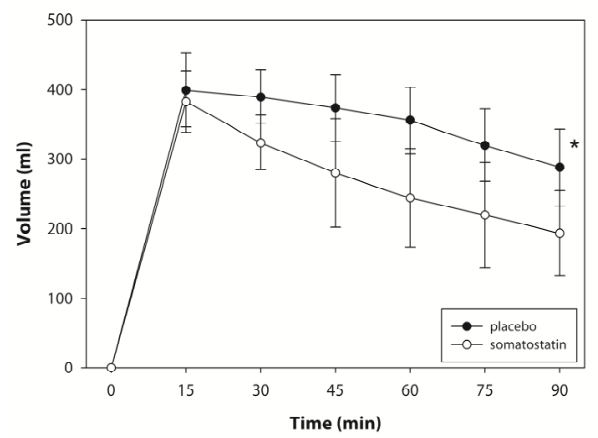

Controls

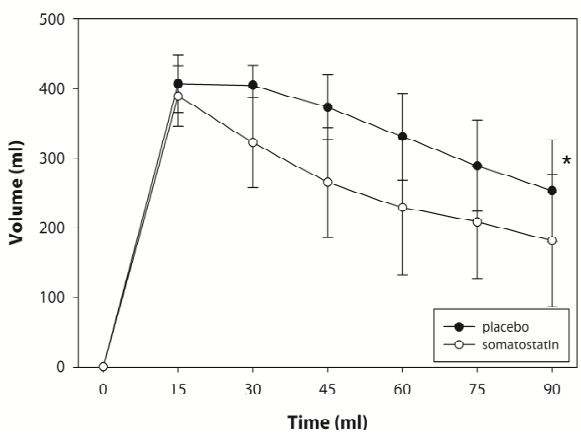

Figure 8.3 Gastric contents ( $\mathrm{ml}$ ) before and after meal ingestion in FD and controls in response to somatostatin and placebo. Values are shown as mean \pm SD. ${ }^{*} \mathrm{p}<0.05$ compared to somatostatin throughout the experiment.

Data on emptying of gastric contents are given in Table 8.1. Lag time was not significantly different between FD patients and controls, neither for somatostatin, nor for placebo. However, somatostatin significantly $(p<0.05)$ reduced lag time in both FD patients and controls. Half emptying time was significantly $(p<0.05)$ prolonged in FD patients compared to controls for placebo. In FD patients halfemptying time decreased significantly for somatostatin compared to placebo. Halfemptying time in FD patients and controls was in the same range for somatostatin. For placebo gastric retention at 90 min was not significantly different between FD patients and controls, but in both groups retention was significantly reduced by somatostatin. The rate of emptying did not differ significantly between FD patients and controls, neither during placebo, nor during somatostatin. However, gastric emptying rate was significantly higher during somatostatin compared to placebo in FD patients, but not in controls. 
Table 8.1 Gastric emptying data in patients with FD and healthy volunteers for somatostatin and placebo.

\begin{tabular}{lcccr}
\hline & \multicolumn{2}{c}{ FD } & \multicolumn{2}{c}{ Controls } \\
& Somatostatin & Placebo & Somatostatin & Placebo \\
\hline Lag time (min) & $15 \pm 16^{*}$ & $42 \pm 20$ & $16 \pm 12^{*}$ & $43 \pm 15$ \\
T 1 1 (min) & $91 \pm 41^{*}$ & $128 \pm 22^{\dagger}$ & $89 \pm 58$ & $106 \pm 24$ \\
Retention 90 $\mathrm{min}(\%)$ & $45 \pm 18^{*}$ & $70 \pm 10$ & $42 \pm 23^{*}$ & $60 \pm 17$ \\
Emptying rate (ml/min) & $-4.1 \pm 1.7^{*}$ & $-2.7 \pm 1.1$ & $-3.9 \pm 1.9$ & $-3.5 \pm 1.0$ \\
\hline
\end{tabular}

Data are shown as mean \pm SD. ${ }^{*} p<0.05$ compared to placebo. ${ }^{\dagger} p<0.05$ compared to controls.

\section{Gastric motility}

Gastric contractions are visualized in Figure 8.4. Fasting contraction frequency did not differ significantly between FD patients and controls: neither during somatostatin, with $14.8 \pm 2.1$ and $14.4 \pm 1.4$ contractions per 5 min respectively, nor during placebo, with $15.0 \pm 1.4$ and $14.1 \pm 1.0$ contractions per 5 min respectively.

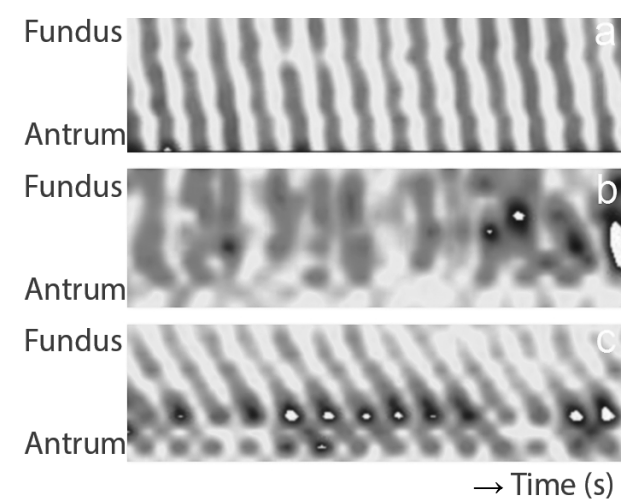

Figure 8.4 Representative contraction pattern of an individual showing 5 min periods (a) prior to meal ingestion, (b) after meal ingestion during placebo infusion and c) after meal ingestion during somatostatin infusion. The $x$-axis shows time and the $y$-axis shows the location in the stomach from fundus to antrum. Color gradients represent gastric occlusion (darker is more occluded). In (a) regular contractions migrate from proximal to distal stomach at a frequency of about 3 per min. In (b) the frequency is not affected but the (migration) pattern is irregular. In c) the irregular postprandial pattern has become a more regular pattern.

\section{Dyspeptic symptoms}

Total symptom scores (range 0-40) were significantly higher in FD patients compared to controls for both experiments (Figure 8.5). After meal ingestion total symptom score increased significantly during both experiments in FD patients but not in 
controls. Throughout the experiments total symptom score did not differ significantly between somatostatin and placebo in FD patients.

With respect to individual symptoms such as nausea, postprandial fullness and epigastric tension, similar results were obtained.

FD

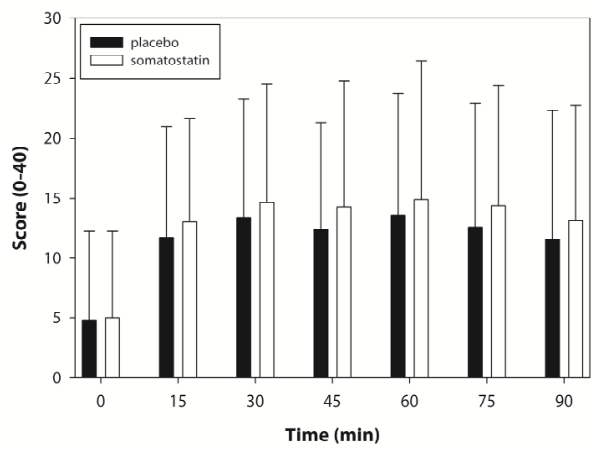

Controls

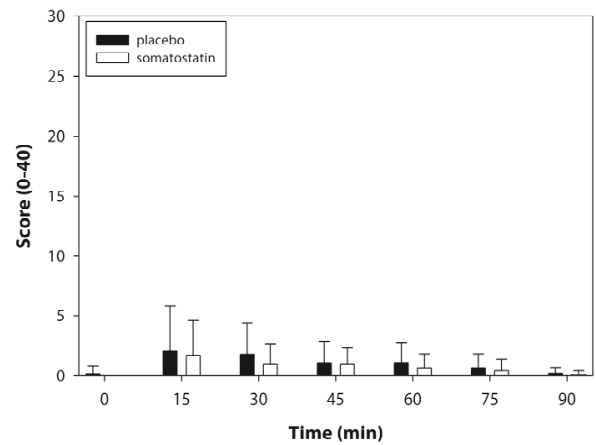

Figure 8.5 Total symptom scores before and after meal ingestion in FD and controls in response to somatostatin and placebo.

\section{Discussion}

Magnetic Resonance Imaging is a non-invasive technique that allows simultaneous measurement of several gastric functions, such as gastric volume changes, gastric emptying and motility (contractions).

The observed reductions in gastric volume by somatostatin resulted from changes in gastric contents and not from changes in intragastric air. Gastric emptying of the liquid meal was significantly accelerated during somatostatin infusion in both FD patients and healthy volunteers. Published data on gastric emptying in response to somatostatin or octreotide are conflicting ${ }^{7-12}$. Van der Ohe et al. ${ }^{9}$ observed an acceleration of initial gastric emptying of solids in response to $50 \mathrm{mcg}$ octreotide subcutaneously. In contrast, Maes et al. ${ }^{11}$ using a similar dose observed a marked delay in gastric emptying of solids in healthy volunteers using an isotope breath test. Okamoto et al. ${ }^{12}$ observed a delay in gastric emptying of liquids using a dose of 50 mcg octreotide subcutaneously. Foxx-Orenstein et al. ${ }^{10}$ studied the effect of different doses of octreotide (30 and 100 mcg subcutaneously) on liquid and solid gastric emptying using radionuclide scintigraphy. In that study octreotide delayed gastric emptying of solids but not of liquids. Using a similar dose Van Berge Henegouwen et al. ${ }^{8}$ observed an acceleration of gastric emptying of a liquid meal. 
Differences in results between the various studies may be related to the technique employed to measure gastric emptying, the doses of octreotide or somatostatin used and also to meal composition and meal consistency. Therefore, the results of the various studies cannot be directly compared.

An advantage of MRI over other techniques is that not only emptying, but also gastric volume changes and contractions can be measured simultaneously and can be related. When analyzing the previous studies 9,12 in more detail it is obvious that somatostatin accelerates the early phase of gastric emptying, but delays the late phase of gastric emptying. In our protocol we measured gastric emptying up to 90 min and therefore late emptying data are not available. The acceleration in gastric emptying by somatostatin might result from several factors. First, the lag phase was significantly shorter, pointing to more promptly onset of gastric emptying. Second, during somatostatin a significantly higher emptying rate was observed. Third, gastric postprandial contraction frequency was not affected by somatostatin, but pyloric tone is also known to affect emptying rate. Little is known however on the response of the pylorus to somatostatin or octreotide ${ }^{23}$. Fourth, previous studies have shown an inhibitory effect of somatostatin on secretion of gastrin ${ }^{24}$ and gastric acid, thereby affecting the volume of gastric contents. The latter effects are speculative and not based on our data, however, MRI is capable of determining dilution of liquid meals due to gastric acid secretion ${ }^{25}$

Contractions in the antrum or more distal part of the stomach typically occur at a max frequency of about 3 per min. We did not observe any differences in contraction frequency between experiments suggesting that somatostatin does not influence gastric motility. Although somatostatin has been shown to inhibit antral contractions in the fasting state, results concerning the effect of somatostatin on postprandial antral motility are not in harmony ${ }^{12,26,27}$. Our results are in line with a previous study by Okamoto et al. ${ }^{12}$ using ultrasonography. These authors did not observe a difference in postprandial contraction frequency between octreotide and placebo, but contraction amplitude and motility index were significantly affected during the octreotide experiment ${ }^{12}$.

An inhibitory effect of octreotide and somatostatin on visceral perception in healthy subjects has been reported previously ${ }^{14,15}$, but controlled data on the effect of somatostatin or octreotide on visceral perception or symptoms in FD are lacking. The FD patients we studied had a half emptying time that was significantly delayed compared to controls. Although somatostatin significantly accelerated gastric emptying in FD patients, no effect on postprandial symptoms such as nausea, fullness or epigastric tension was observed. Postprandial symptoms in FD patients may result from various factors or mechanisms. Impaired gastric accommodation may account for up to $40 \%$ of symptoms as indicated by Tack et al. ${ }^{28}$ using a barostat. We have not measured gastric accommodation, only gastric volumes. The accelerated gastric emptying, induced by somatostatin, may reduce symptoms of delayed emptying, but on the other hand may provoke symptoms due to more rapid 
delivery of nutrients to the duodenum. Enhanced perception in response to intraduodenal infusion of nutrients and acid has also been shown in FD ${ }^{29,30}$. In previous studies a positive correlation between somatostatin levels and the degree of symptoms in FD patients has been documented ${ }^{31,32}$.

We conclude that, measured with $\mathrm{MRI}$, somatostatin reduces postprandial gastric volumes in both health and disease (FD), through earlier initiation and acceleration of gastric emptying without quantitatively affecting gastric motility. Somatostatin did not result in postprandial symptom reduction in FD patients. 


\section{References}

1. Tack J, Talley NJ, Camilleri M, Holtmann G, Hu P, Malagelada JR, Stanghellini V. Functional gastroduodenal disorders. Gastroenterology 2006;130:1466-79.

2. van den Elzen BD, Boeckxstaens GE. Review article: a critical view on impaired accommodation as therapeutic target for functional dyspepsia. Aliment Pharmacol Ther 2006;23:1499-510.

3. Tack J, Piessevaux H, Coulie B, Caenepeel $P$, Janssens J. Role of impaired gastric accommodation to a meal in functional dyspepsia. Gastroenterology 1998;115:1346-52.

4. Coffin B, Azpiroz F, Guarner F, Malagelada JR. Selective gastric hypersensitivity and reflex hyporeactivity in functional dyspepsia. Gastroenterology 1994;107:1345-51.

5. Mearin F, Cucala M, Azpiroz F, Malagelada JR. The origin of symptoms on the brain-gut axis in functional dyspepsia. Gastroenterology 1991;101:999-1006.

6. Lieverse RJ, Jansen JB, Masclee AM, Lamers CB. Effects of somatostatin on human satiety. Neuroendocrinology 1995;61:112-6.

7. Harris AG. Somatostatin and somatostatin analogues: pharmacokinetics and pharmacodynamic effects. Gut 1994;35:S1-S4.

8. van Berge Henegouwen MI, van Gulik TM, Akkermans LM, Jansen JB, Gouma DJ. The effect of octreotide on gastric emptying at a dosage used to prevent complications after pancreatic surgery: a randomised, placebo controlled study in volunteers. Gut 1997;41:758-62.

9. von der Ohe MR, Camilleri M, Thomforde GM, Klee GG. Differential regional effects of octreotide on human gastrointestinal motor function. Gut 1995;36:743-8.

10. Foxx-Orenstein A, Camilleri M, Stephens D, Burton D. Effect of a somatostatin analogue on gastric motor and sensory functions in healthy humans. Gut 2003;52:1555-61.

11. Maes BD, Ghoos YF, Geypens BJ, Hiele MI, Rutgeerts PJ. Influence of octreotide on the gastric emptying of solids and liquids in normal healthy subjects. Aliment Pharmacol Ther 1995;9:11-8.

12. Okamoto E, Haruma K, Hata J, Tani H, Sumii K, Kajiyama G. Effects of octreotide, a somatostatin analogue, on gastric function evaluated by real-time ultrasonography. Aliment Pharmacol Ther 1997;11:177-84.

13. Ducrotte $P$, Maillot C, Leroi AM, Lalaude O, Colin R, Denis P. Octreotide in refractory functional epigastric pain with nutritional impairment--an open study. AlimentPharmacolTher 1999;13:969-75.

14. Mearadji B, Straathof JW, Biemond I, Lamers CB, Masclee AA. Effects of somatostatin on proximal gastric motor function and visceral perception. Aliment Pharmacol Ther 1998;12:1163-9.

15. Mertz H, Walsh JH, Sytnik B, Mayer EA. The effect of octreotide on human gastric compliance and sensory perception. Neurogastroenterol Motil 1995;7:175-85.

16. Marciani L, Young P, Wright J, Moore R, Coleman N, Gowland PA, Spiller RC. Antral motility measurements by magnetic resonance imaging. Neurogastroenterol Motil 2001;13:511-8.

17. de Zwart IM, Haans JJ, Verbeek P, Eilers PH, de Roos A, Masclee AA. Gastric accommodation and motility are influenced by the barostat device: Assessment with magnetic resonance imaging. Am J Physiol Gastrointest Liver Physiol 2007;292:G208-G14.

18. de Zwart IM, Mearadji B, Lamb HJ, Eilers PH, Masclee AA, de Roos A, Kunz P. Gastric motility: comparison of assessment with real-time MR imaging or barostat measurement initial experience. Radiology 2002;224:592-7.

19. Schwizer W, Maecke H, Fried M. Measurement of gastric emptying by magnetic resonance imaging in humans. Gastroenterology 1992;103:369-76.

20. Schwizer W, Fraser R, Maecke H, Siebold K, Funck R, Fried M. Gd-DOTA as a gastrointestinal contrast agent for gastric emptying measurements with MRI. Magn Reson Med 1994;31:388-93.

21. Kunz P, Crelier GR, Schwizer W, Borovicka J, Kreiss C, Fried M, Boesiger P. Gastric emptying and motility: assessment with MR imaging--preliminary observations. Radiology 1998;207:33-40.

22. Siegel JA, Urbain JL, Adler LP, Charkes ND, Maurer AH, Krevsky B, Knight LC, Fisher RS, Malmud LS. Biphasic nature of gastric emptying. Gut 1988;29:85-9.

23. Bassotti G, Germani U, Calcara C, Spinozzi F, Roselli P, Morelli A. Effects of octreotide on manometric variables in patients with neuropathic abnormalities of the small bowel. Dig Dis Sci 1997;42:1634-9. 
24. Liu Y, Vosmaer GD, Tytgat GN, Xiao SD, Ten Kate FJ. Gastrin (G) cells and somatostatin (D) cells in patients with dyspeptic symptoms: Helicobacter pylori associated and non-associated gastritis. J Clin Pathol 2005;58:927-31.

25. Goetze O, Treier R, Fox M, Steingoetter A, Fried M, Boesiger P, Schwizer W. The effect of gastric secretion on gastric physiology and emptying in the fasted and fed state assessed by magnetic resonance imaging. Neurogastroenterol Motil 2009;21:725-e42.

26. Di LC, Lucanto C, Flores AF, Idries S, Hyman PE. Effect of octreotide on gastrointestinal motility in children with functional gastrointestinal symptoms. J Pediatr GastroenterolNutr 1998;27:508-12.

27. Haruma K, Wiste JA, Camilleri M. Effect of octreotide on gastrointestinal pressure profiles in health and in functional and organic gastrointestinal disorders. Gut 1994;35:1064-9.

28. Tack J, Bisschops R, Sarnelli G. Pathophysiology and treatment of functional dyspepsia. Gastroenterology 2004;127:1239-55.

29. Feinle C, Meier O, Otto B, D'Amato M, Fried M. Role of duodenal lipid and cholecystokinin A receptors in the pathophysiology of functional dyspepsia. Gut 2001;48:347-55.

30. Samsom M, Verhagen MA, vanBerge Henegouwen GP, Smout AJ. Abnormal clearance of exogenous acid and increased acid sensitivity of the proximal duodenum in dyspeptic patients. Gastroenterology 1999;116:515-20.

31. Uvnas-Moberg K, Arn I, Theorell T, Jonsson CO. Gastrin, somatostatin and oxytocin levels in patients with functional disorders of the gastrointestinal tract and their response to feeding and interaction. J Psychosom Res 1991;35:525-33.

32. Jonsson BH, Uvnas-Moberg K, Theorell T, Gotthard R. Gastrin, cholecystokinin, and somatostatin in a laboratory experiment of patients with functional dyspepsia. Psychosom Med 1998;60:331-7. 


\section{Chapter 9}

\section{Intragastric acidification inhibits motilin-induced phase III activity in humans}

J.J.L. Haans A.A.M. Masclee

NeurogastroenterolMotil 2006;18:637-46 


\title{
Abstract
}

\begin{abstract}
Aims
In a randomized, placebo-controlled crossover design we studied the effect of gastric acidification on motilin-induced interdigestive antropyloroduodenal motility.
\end{abstract}

\section{Materials and Methods}

Ten healthy subjects participated in the study consisting of four experiments. Each experiment started after a spontaneous occurring phase III and consisted of intragastric infusion of either saline or acid $(0.08 \mathrm{M} \mathrm{HCl})$ for 90 min and intravenous infusion of either saline or motilin (4 $\mathrm{pmol} \mathrm{kg} \mathrm{min}^{-1}$ ) for $30 \mathrm{~min}$. Antropyloroduodenal motility and $\mathrm{pH}$ were recorded continuously for $240 \mathrm{~min}$.

\section{Results}

Reoccurrence of phase III was significantly $(p<0.05)$ earlier during intragastric salineintravenous motilin infusion compared to control (intragastric saline-intravenous saline), 52 [25-79] $\mathrm{min}$ and 113 [84-141] min respectively. This effect was completely abolished during intragastric acid-intravenous motilin infusion, 112 [82-142] min. The percentage of phases III of antral origin was significantly $(p<0.05)$ higher during intragastric saline-intravenous motilin infusion (90\%) compared to control (30\%). Mean area under the contraction (AUC) for phase II was significantly $(p<0.05)$ lower during intragastric saline-intravenous motilin infusion and intragastric acid-intravenous saline infusion compared to control.

\section{Conclusions}

It is concluded that in humans intragastric acidification inhibits the effect of motilin on antroduodenal motility, decreases the AUC of antral phase II contractions and delays the occurrence of phase III of the MMC. 


\section{Introduction}

Interdigestive antroduodenal motility is characterized by a cyclic motor pattern. The so-called migrating motor complex (MMC) consists of three distinct phases: phase I is a pattern of motor quiescence, phase II a pattern of irregular single contractions and phase III a pattern of intensive rhythmic contractions. Phase III of the MMC is considered to clean the gut from debris and bacteria and is often referred to as being the "housekeeper of the gut"1.

Motilin is a 22-aminoacid gastrointestinal peptide released from enterochromaffin cells in the upper part of the small intestine ${ }^{2}$. A phase III of antral origin is preceded by a peak in plasma motilin levels $\mathrm{s}^{3-5}$, pointing to a close relationship between the occurrence of an antral phase III and an increase in plasma motilin levels. In humans it has been shown that motilin, when infused intravenously, induces a phase III of antral onset ${ }^{5,6}$. These effects are dose-dependent and seen at doses from 2 to 4 pmol $\mathrm{kg}^{-1} \min ^{-1} 6$. A recent study by Luiking et al. ${ }^{7}$ showed the presence of a refractory period when exogenous infusion of motilin for a short period of time (5 min) was preceded by a phase III of antral origin. In contrast, motilin always induced a phase III when infused over a longer period of time, i.e. $30 \mathrm{~min}^{5}$.

A close relationship does exist between interdigestive antroduodenal motility and gastric acid secretion. Gastric acid secretion is low during phase I and early phase II, increases during late phase II and reaches a maximum during phase III of the $\mathrm{MMC}^{8-11}$. In previous studies it has been shown that intraluminal acidity affects interdigestive motility as shown by a suppression of antral phase III activity and delayed reoccurrence of duodenal phase III activity at low intragastric $\mathrm{pH}$ levels ${ }^{12,13}$. In patients with ulcer-like dyspepsia a decrease in frequency and duration of antroduodenal phase III has been observed. Intravenous administration of omeprazole induces the appearance of an apparently normal antroduodenal phase III, pointing to a relation between gastric acid secretion and interdigestive antroduodenal motility ${ }^{14}$. During excessive gastric acid secretion, as previously seen in patients with duodenal ulcer, MMC cycle length increases because of prolonged phase II activity ${ }^{15}$.

The data discussed above suggest a role for intragastric acidity in blocking phase III activity. In dogs it has been shown that intragastric acidification blocks spontaneous phase III activity ${ }^{16}$. This effect has also been observed during exogenous motilin infusion ${ }^{17}$. It is not known whether in humans exogenous motilin induced antroduodenal motility is dependent on intragastric acidity.

In a randomized, single blind, placebo-controlled crossover design we studied the effect of intragastric acidification on antropyloroduodenal motility induced by intravenous administration of motilin. We hypothesized that gastric acidification blocks the effect of exogenous motilin on antropyloroduodenal motility. 


\section{Materials and Methods}

\section{Subjects}

Ten healthy subjects (three men, seven women; mean age 21 years; range 19-23 years) participated in the study. None of the subjects had a history of gastrointestinal disease or abdominal surgery and none was taking any medication, known to influence gastrointestinal motility. The Medical Ethics Committee of the Leiden University Medical Center (LUMC) had approved the protocol and written informed consent was obtained from each subject.

\section{Study Protocol}

Each subject participated in four experiments performed on separate days in random order with an interval of at least 7 days between each experiment. A randomized, single blind, placebo-controlled crossover design was used to study the effect of gastric acidification on the effect of intravenously administered motilin on interdigestive antropyloroduodenal motility. The motilin used in this study was synthetic human motilin prepared for human use by Clinalfa AG (Läufelfingen, Switzerland).

Each experiment started at 09:00 hours after an overnight fast. A manometric catheter assembly, as described below, was inserted through an anaesthetized nostril, using lidocaine (Xylocaïne ${ }^{\circ} 10 \%$ spray, AstraZeneca BV, Zoetermeer, The Netherlands) and positioned across the pylorus under fluoroscopic control. A pH probe (Medical Instruments Corporation AG, Solothurn, Switzerland) was inserted through the other anaesthetized nostril and positioned intragastrically. An indwelling cannula in the antecubital vein of one arm was used for the infusion of motilin, and an indwelling cannula in the antecubital vein of the other arm was used for withdrawal of blood samples during the experiment. Subjects were studied in a semi-recumbent position. Immediately after cessation of the first spontaneously occurring phase III of the $\mathrm{MMC}$ in either antrum or duodenum, defined as time $0 \mathrm{~min}$, intragastric infusion of either saline (control) or $\mathrm{HCl}\left(0,08 \mathrm{~mol} \mathrm{I}^{-1} ; \mathrm{pH} 1.1\right)$ at $4 \mathrm{ml} \mathrm{min}^{-1}$ was started for $90 \mathrm{~min}$. After $30 \mathrm{~min}$ of intragastric infusion, defined as time $30 \mathrm{~min}$, an intravenous infusion of either saline (control) or motilin $\left(4 \mathrm{pmol} \mathrm{kg}^{-1} \mathrm{~min}^{-1}\right)$ was started and continued for $30 \mathrm{~min}$. Each subject participated in four experiments: intragastric infusion of saline and intravenous infusion of saline (control, A), intragastric infusion of saline and intravenous infusion of motilin (B), intragastric infusion of acid and intravenous infusion of saline (C), intragastric infusion of acid and intravenous infusion of motilin (D). Blood samples were collected at time 0,30 , $45,60,75,90,120,180$ and $240 \mathrm{~min}$. Antropyloroduodenal motility and intragastric $\mathrm{pH}$ were continuously monitored for $240 \mathrm{~min}$. 


\section{Antropyloroduodenal manometry}

Antropyloroduodenal pressures were recorded using a water-perfused stationary manometry system. A silicon rubber multi lumen sleeve catheter with an outer diameter of $3.5 \mathrm{~mm}$ incorporating eleven pressure side holes, a $4.5 \mathrm{~cm}$ pyloric sleeve sensor and a side hole for gastric infusion was used (Figure 9.1). Each lumen for pressure measurement was connected to a pressure transducer (Truwave PX-600F, Edwards Lifesciences, Irvine, CA, USA) and perfused with gas-free distilled water, or a saline solution, by a low-compliance pneumohydraulic infusion pump (16 Channel Mark II Horizontal Deck Pump, Dentsleeve Pty Ltd, Wayville, Australia). The outputs from the pressure transducers were recorded with a polygraph recorder (PC Polygraf $16 \mathrm{HR}$, Medtronic A/S, Skovlunde, Denmark), using a sampling rate of $16 \mathrm{~Hz}$, displayed on a monitor and stored on the hard-drive of a personal computer system pending analysis.

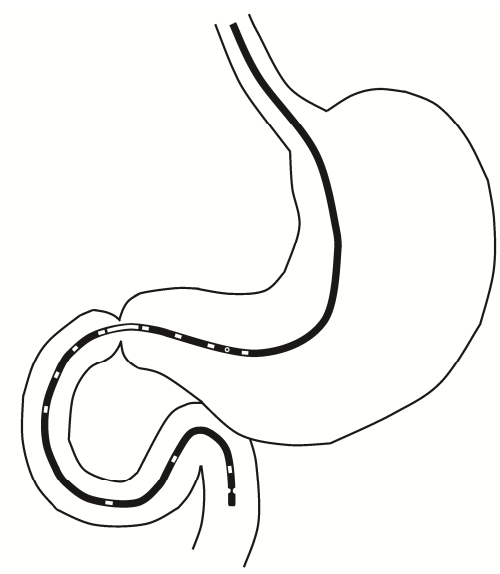

Figure 9.1 Antropyloroduodenal multi lumen sleeve catheter with an outer diameter of $3.5 \mathrm{~mm}$ incorporating 4 antral side holes (36.5-34.5-32.5-30.5 cm from catheter tip), 7 duodenal side holes (1-6-11-20-22-24-26 cm from catheter tip), a $4.5 \mathrm{~cm}$ pyloric sleeve $(26.0-30.5 \mathrm{~cm}$ from catheter tip) and a side hole for gastric infusion ( $35.5 \mathrm{~cm}$ from catheter tip).

\section{Transmucosal potential difference}

Position of the pyloric sleeve sensor was monitored using transmucosal potential difference (TMPD). Adequate sensor positioning across the pylorus is achieved when the difference between antral and duodenal potential is $\geq 15 \mathrm{mV}$. We used the first side hole proximal (antral) and distal (duodenal) from the pyloric sleeve, which were perfused with saline and connected to both a pressure transducer, as mentioned above, and an $\mathrm{Ag} / \mathrm{AgCl}$ electrode (Dri-Ref- $\mathrm{L}^{\mathrm{T}}$, World Precision Instruments, Sarasota, 
$\mathrm{FL}$, USA). A disposable regular Ag/AgCl monitoring electrode (Red Dot ${ }^{\mathrm{TM}}, 3 \mathrm{M}$ Health Care, Borken, Germany) was attached to the skin below the right side clavicle as a reference electrode. The electrodes were connected to a TMPD-module (Instrumentele Dienst Universitair Medisch Centrum Utrecht, Utrecht, The Netherlands). The outputs from the TMPD-module were recorded with a polygraph recorder (PC Polygraf $16 \mathrm{HR}$, Medtronic A/S, Skovlunde, Denmark), using a sampling rate of $16 \mathrm{~Hz}$, displayed on a monitor and stored on the hard-drive of a personal computer system pending analysis.

\section{Analysis of motility data}

Antropyloroduodenal motility recordings were analyzed both visually and automatically. The individual tracings were processed by specialized software (Polygram, Medtronic A/S, Skovlunde, Denmark) for adjusting baselines and extracting respiratory artifacts. However, the computer program does not recognize simultaneous pressure events as artifacts. Therefore, remaining artifacts obviously due to increases in intra-abdominal pressure were identified visually and excluded from further analysis. Antral and duodenal phase III of the migrating motor complex (MMC) were defined as published previously ${ }^{12}$. MMC cycle length was defined as the time between the end of a phase III in the duodenum and the end of the next phase III. Phase III reoccurrence time was defined as the time interval between the start of the study (time $0 \mathrm{~min}$ ) and the reoccurrence of a phase III. Origin (antrum or duodenum) and duration of each antral and duodenal phase III were analyzed visually. Frequency of the contractions, mean amplitude and mean area under the contraction (AUC) were measured for both phase II and phase III automatically. For phase II only the last $30 \mathrm{~min}$ prior to the following phase III were analyzed. Only pressure waves with amplitude of at least $10 \mathrm{mmHg}$ and duration of at least 1.5 seconds were considered true contractions. Additionally, motility indices of the distal antrum and the proximal duodenum were calculated as area under the contraction curves multiplied with the number of contractions.

Pyloric motility was analyzed for isolated pyloric pressure waves (IPPWs). Pressure waves recorded by the pyloric sleeve were classified IPPWs if they were $>10 \mathrm{mmHg}$ and recorded by the pyloric sleeve in the absence of a pressure wave in both the first side hole proximal (antral) and distal (duodenal) from the pyloric sleeve. A pressure wave in the first proximal or duodenal side hole from the pyloric sleeve was considered associated with a pyloric pressure wave when its onset occurred within 5 seconds of the onset of a pyloric pressure wave.

\section{Analysis of intragastric acidity}

Intragastric $\mathrm{pH}$ readings from a total recording period of $240 \mathrm{~min}$ were divided into 10-min intervals. For each 10-min interval, the log mean $\mathrm{H}+$ concentration was computed. The log mean $\mathrm{H}+$ concentration was defined as the arithmetic mean of 
the antilog of the $\mathrm{pH}$ data converted back into $\mathrm{pH}$ units by taking the log of the mean value $^{18}$.

Intragastric $\mathrm{pH}$ data were compared during two periods: 0-90 $\mathrm{min}$ and 90-240 min. During the first period (0-90 min) intragastric infusion of either saline or acid was performed, whereas during the second period $(90-240 \mathrm{~min})$ no intragastric infusion was performed.

\section{Assay of motilin}

Blood samples were collected in EDTA-containing ice-chilled tubes. The samples were centrifuged for $10 \mathrm{~min}$ at $4^{\circ} \mathrm{C}(3,000 \mathrm{~g})$. The separated plasma was stored at $-20^{\circ} \mathrm{C}$ until analysis. Plasma motilin was measured using a sensitive and specific radioimmunoassay as described previously ${ }^{6}$.

\section{Statistical analysis}

Data were analyzed using a statistical software package (SPSS for Windows Release 12.0.1, SPSS Inc., Chicago, USA). Antropyloroduodenal motility, pH and plasma level data are shown as mean $[95 \% \mathrm{Cl}]$. TMPD data are shown as mean $\pm \mathrm{SEM}$. All samples were tested for normality. Depending on the distribution of the data a linear mixed model analysis or Friedman's nonparametric analysis was used to detect differences in data between groups. All data were adjusted for multiple comparisons using Bonferroni's correction. For linear mixed model analysis data were analyzed in the model using a random subject effect and a fixed intervention effect.

\section{Results}

Each subject participated in four experiments. The experiments consisted of intragastric infusion of saline combined with intravenous infusion of saline (control, A), intragastric infusion of saline combined with intravenous infusion of motilin (B), intragastric infusion of acid combined with intravenous infusion of saline (C) and intragastric infusion of acid combined with intravenous infusion of motilin (D).

\section{Antroduodenal motility}

Each experiment was started after the occurrence of a spontaneous phase III (time = $0 \mathrm{~min}$ ). The time interval between the start of the manometry recording and the first spontaneous phase III did not differ significantly between the four experiments: 49 [28-71] $\mathrm{min}, 43$ [22-65] $\mathrm{min}, 50$ [28-70] $\mathrm{min}$ and 35 [14-56] $\mathrm{min}$ for experiment A-D respectively. The reoccurrence of phase III after the start of the experiment was significantly $(p<0.05)$ earlier for experiment $B$ compared to experiment $A, 52$ [25-79] vs. 113 [84-141] $\mathrm{min}$ respectively. However during intragastric infusion of acid in 
experiment D phase III did not occur earlier compared to experiment A, 112 [82-142] vs. 113 [84-141] min respectively (Table 9.1). The complete blocking of an antral phase III was seen in 7 out of ten subjects (Figure 9.2, showing individual manometry tracings). Part of an antropyloroduodenal recording in one subject during experiment $B$ and $D$ is shown in Figure 9.3, illustrating the absence of an antral phase III after motilin infusion when acid was infused intragastrically.

Duration of the first MMC occurring after the start of the experiment was significantly $(p<0.05)$ shorter for experiment B compared to experiment $A, 62$ [36-88] min vs. 122 [95-150] min respectively. This resulted from a significantly $(p<0.05)$ shorter duration of phase II (Table 9.1).

Table 9.1 Characteristics of first MMC cycle occurring after the start of each experiment

\begin{tabular}{lcccc}
\hline & A & B & C & D \\
\hline Reoccurence (min) & $112.6[84.2-140.8]$ & $52.1[25.2-78.9]^{*} \dagger$ & $128.2[101.4-155.1]$ & $112.3[82.3-142.2]$ \\
MMC cycle length (min) & $122.4[95.1-149.7]$ & $61.6[35.6-87.5]^{*}+$ & $135.1[109.2-161.0]$ & $121.2[92.2-150.2]$ \\
Phase I (min) & $18.6[11.6-25.6]$ & $12.9[6.2-19.5]$ & $13.0[6.4-19.7]$ & $11.2[3.8-18.6]$ \\
Phase II (min) & $99.3[71.1-127.6]$ & $43.7[16.9-70.6]^{*}+$ & $118.2[91.4-145.1]$ & $105.7[75.7-135.6]$ \\
Phase III (min) & $4.5[3.2-5.7]$ & $5.0[3.8-6.2]$ & $3.9[2.7-5.1]$ & $3.7[2.4-5.0]$ \\
Origin phase III (antral/total) & $3 / 9(33 \%)$ & $9 / 10(90 \%)^{*}$ & $3 / 10(30 \%)$ & $6 / 8(75 \%)$ \\
\hline
\end{tabular}

Values are means $[95 \% \mathrm{Cl}$. $A=$ intragastric saline and intravenous saline infusion; $B=$ intragastric saline and intravenous motilin infusion; $C=$ intragastric acid and intravenous saline infusion; $D=$ intragastric acid and intravenous motilin infusion. ${ }^{*} p<0.05$ compared to $A ;+p<0.05$ compared to $C$.
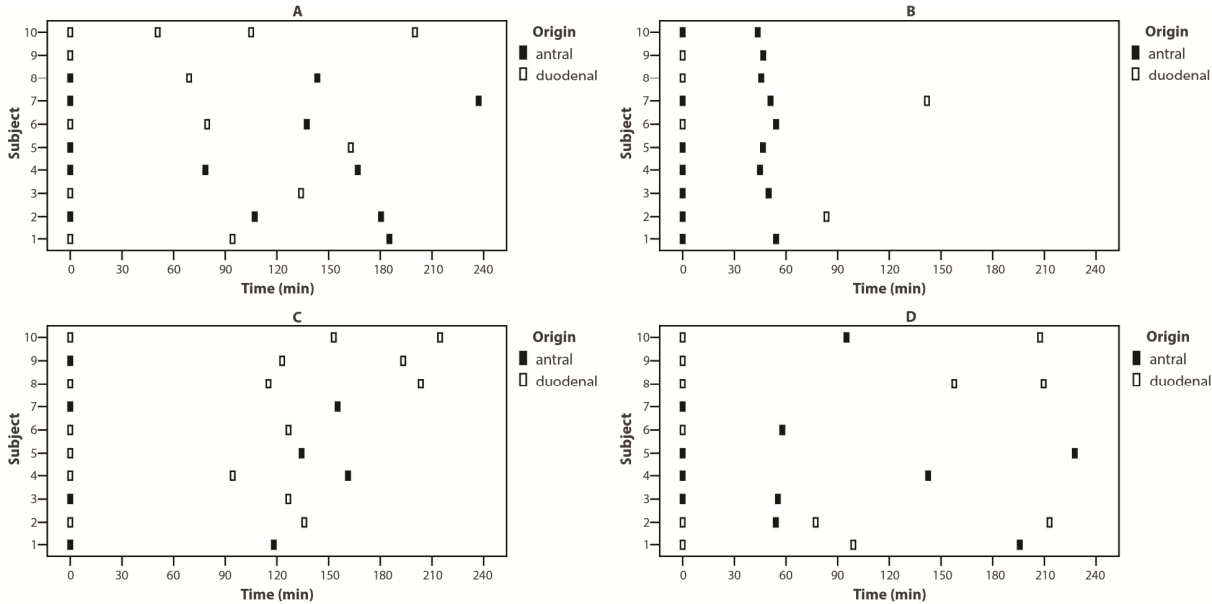

Figure 9.2 Individual manometry tracings, where boxes locate the occurrence of phase III of MMC in 10 healthy subjects during intragastric saline and intravenous saline infusion $(A)$, intragastric saline and intravenous motilin infusion (B), intragastric acid and intravenous saline infusion (C) and intragastric acid and intravenous motilin infusion (D). 

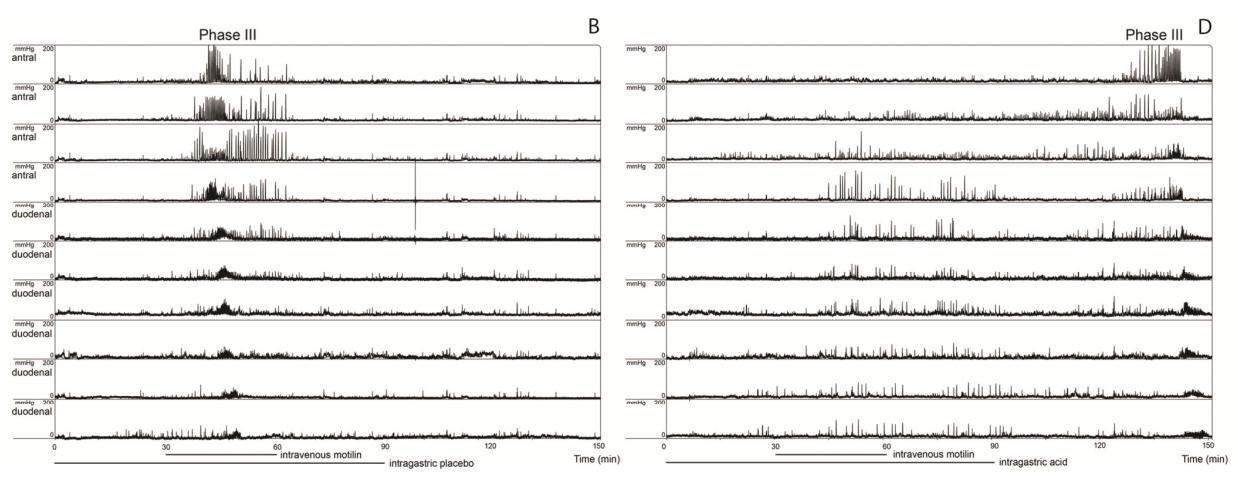

Figure 9.3 Manometric recording of antropyloroduodenal motility in one subject during intragastric infusion of saline and intravenous infusion of motilin (B) and intragastric infusion of acid and intragastric infusion of motilin (D). Intravenous infusion of motilin induced a phase III of antral origin and this effect was completely abolished by simultaneous intragastric infusion of acid.

The duration of phase I and phase III of the first MMC did not differ significantly between the four experiments (Table 9.1).

Antral and duodenal phase III characteristics are shown in Table 9.2. Mean amplitude, mean area under the contraction (AUC) and motility index (MI) did not differ significantly between the four experiments. However, the total number of phase III of antral origin was significantly $(p<0.05)$ higher during experiment $B$ compared to experiment A, 9 vs. 3 antral phase III respectively (Table 9.2).

In experiment $D$ the total number of phase III of antral origin was higher compared to experiment C, 6 vs. 3 antral phase III respectively (Table 9.2), although not significantly $(p=0.077)$.

Duodenal phase II characteristics of the first MMC such as mean amplitude, mean area under the contraction (AUC) and motility index (MI) did not differ significantly between the four experiments (Table 9.3). However, mean amplitude of the antral phase II of the first MMC was significantly $(p<0.05)$ lower during experiment $B, C$ and D compared to experiment A, 27.5 [20.5-34.4], 27.8 [21.0-34.6], 31.5 [24.2-38.7] vs. 42.2 [35.2-49.2] $\mathrm{mmHg}$ respectively (Table 9.3). Mean area under the contraction (AUC) was significantly $(\mathrm{p}<0.05)$ lower during experiment $B$ and $C$ compared to experiment A, 74.8 [49.4-100.3], 79.7 [54.9-104.4] vs. 123.9 [98.4-149.4] $\mathrm{mmHg} \cdot \mathrm{s}$ respectively (Table 9.3 ).

Table 9.4 shows the reoccurrence of a phase III during three subsequent periods in the experiment. As can be noticed the first phase III after the start of the experiment occurs during the first $60 \mathrm{~min}$ in experiment $B$ in all except one subject. On the other hand during experiment $C$ the first phase III occurs after $90 \mathrm{~min}$ in all subjects, i.e. after the time at which the intragastric acid infusion was stopped. 
Table 9.2 Characteristics of first phase III occurring after the start of each experiment

\begin{tabular}{|c|c|c|c|c|}
\hline & A & B & C & $\mathrm{D}$ \\
\hline \multicolumn{5}{|l|}{ Antrum } \\
\hline Frequency (contractions $\mathrm{min}^{-1}$ ) & $5.1[3.3-7.0]$ & $4.6[3.4-5.8]$ & $3.4[1.5-5.2]$ & $4.3[2.8-5.7]$ \\
\hline Mean amplitude (mmHg) & $49.9[31.8-68.0]$ & $70.7[57.0-84.4]$ & $61.7[43.1-80.2]$ & $55.3[39.9-70.6]$ \\
\hline $\begin{array}{l}\text { Mean area under contraction } \\
(\mathrm{mmHg} \bullet \mathrm{s})\end{array}$ & 150.8 [78.7-222.9] & 234.6 [181.4-287.8] & 213.4 [139.9-286.9] & $170.9[110.7-231.0]$ \\
\hline Motility index (mmHg•s) & 3964 [1369-6559] & 6470 [4348-8592] & 3915 [1237-6595] & 4101 [1779-6425] \\
\hline \multicolumn{5}{|l|}{ Duodenum } \\
\hline Antral origin/total & $3 / 9(33 \%)$ & $9 / 10(90 \%)^{*}$ & $3 / 10(30 \%)$ & $6 / 8(75 \%)$ \\
\hline Frequency (contractions $\mathrm{min}^{-1}$ ) & $10.4[9.6-11.2]$ & $10.8[10.0-11.7]$ & $11.2[10.4-12.0]$ & $10.8[10.0-11.7]$ \\
\hline Mean amplitude (mmHg) & $22.4[20.1-24.7]$ & $23.3[20.9-25.7]$ & $24.9[22.8-27.1]$ & $21.2[18.8-23.7]$ \\
\hline $\begin{array}{l}\text { Mean area under contraction } \\
(\mathrm{mmHg} \bullet \mathrm{s})\end{array}$ & $42.3[36.7-47.9]$ & $46.2[40.2-52.1]$ & $49.8[44.5-55.1]$ & $41.0[35.1-47.0]$ \\
\hline Motility index $(\mathrm{mmHg} \bullet \mathrm{s})$ & 1990 [1355-2624] & $2333[1660-3006]$ & 2172 [1570-2774] & 1750 [1076-2423] \\
\hline
\end{tabular}

Values are means $[95 \% \mathrm{Cl}$. $A=$ intragastric saline and intravenous saline infusion; $B=$ intragastric saline and intravenous motilin infusion; $C=$ intragastric acid and intravenous saline infusion; $D=$ intragastric acid and intravenous motilin infusion. ${ }^{*} \mathrm{p}<0.05$ compared to $\mathrm{A}$.

Table 9.3. Characteristics of first phase II occurring after the start of each experiment

\begin{tabular}{|c|c|c|c|c|}
\hline & A & $\mathrm{B}$ & C & $\mathrm{D}$ \\
\hline \multicolumn{5}{|l|}{ Antrum } \\
\hline Frequency (contractions $\mathrm{min}^{-1}$ ) & $1.4[0.9-1.9]$ & $1.3[0.8-1.9]$ & $1.5[1.0-2.0]$ & $1.2[0.6-1.7]$ \\
\hline Mean amplitude $(\mathrm{mmHg})$ & $42.2[35.2-49.2]$ & $27.5[20.5-34.4]^{*}$ & $27.8[21.0-34.6]^{*}$ & $31.5[24.2-38.7]^{*}$ \\
\hline Mean area under contraction (mmHg•s) & $123.9[98.4-149.4]$ & $74.8[49.4-100.3]^{*}$ & $79.7[54.9-104.4]^{*}$ & $90.0[63.7-116.4]$ \\
\hline Motility index (mmHg•s) & $5209[3385-7032]$ & $3248[1424-5071]$ & $3737[2006-5468]$ & 3358 [1424-5292] \\
\hline \multicolumn{5}{|l|}{ Duodenum } \\
\hline Frequency (contractions $\mathrm{min}^{-1}$ ) & $2.4[1.9-3.0]$ & $2.2[1.6-2.8]$ & $2.7[2.1-3.2]$ & $1.9[1.3-2.5]$ \\
\hline Mean amplitude $(\mathrm{mmHg})$ & $20.5[18.4-22.6]$ & $21.0[18.9-23.1]$ & $22.0[20.0-24.0]$ & $22.0[19.7-24.2]$ \\
\hline Mean area under contraction (mmHg•s) & $42.4[37.1-47.7]$ & $45.2[39.9-50.5]$ & $47.9[42.8-52.9]$ & $46.0[40.4-51.6]$ \\
\hline Motility index (mmHg•s) & $3450[2562-4338]$ & 3075 [2187-3962] & $3678[2834-4523]$ & 2854 [1915-3793] \\
\hline
\end{tabular}

Values are means $[95 \% \mathrm{Cl}$. $\mathrm{A}=$ intragastric saline and intravenous saline infusion; $\mathrm{B}=$ intragastric saline and intravenous motilin infusion; $C=$ intragastric acid and intravenous saline infusion; $D=$ intragastric acid and intravenous motilin infusion. ${ }^{*} \mathrm{p}<0.05$ compared to $\mathrm{A}$.

\section{Pyloric motility}

Pyloric motility data were analyzed for isolated pyloric pressure waves (IPPWs). The percentage of time, which showed a correct position of the pyloric sleeve over the pylorus, did not differ significantly between the four experiments: $84 \pm 11,80 \pm 14$, $95 \pm 4$ and $90 \pm 7 \%$ for experiment A-D respectively. 
The frequency of IPPWs during intragastric acid infusion (0-90 min) did not differ significantly from control: 16.3 [10.3-22.4] and 9.6 [3.7-15.7] per $15 \mathrm{~min}$ for experiment $C$ and $A$ respectively. During intravenous infusion of motilin (30-60 min) IPPW frequency was neither significantly different from control: 7.9 [-0.6-16.5] and 9.4 [0.9-17.9] per $15 \mathrm{~min}$ for experiment $B$ and $A$ respectively, nor significantly different between experiment $D$ and $B: 11.3$ [4.0-18.8] and 7.9 [-0.6-16.5] per $15 \mathrm{~min}$ respectively. After the end of intravenous motilin infusion (60-90 min) IPPW frequency did not differ significantly between experiments A-D. Overall the number of IPPWs during $15 \mathrm{~min}$ periods neither differed significantly between experiments A$D$, nor changed significantly in time during experiments A-D.

Table 9.4 Reoccurrence of phase III per time interval

\begin{tabular}{lcccc}
\hline Period & A & B & C & D \\
\hline $0-60$ min & $1 / 9(11 \%)$ & $9 / 10(90 \%)$ & $0 / 10(0 \%)$ & $3 / 8(37 \%)$ \\
$60-90 \mathrm{~min}$ & $3 / 9(33 \%)$ & $1 / 10(10 \%)$ & $0 / 10(0 \%)$ & $0 / 8(0 \%)$ \\
$90-240 \mathrm{~min}$ & $5 / 9(56 \%)$ & $0 / 10(0 \%)$ & $10 / 10(100 \%)$ & $5 / 8(63 \%)$ \\
\hline
\end{tabular}

Values are mean number/total (\%). $A=$ intragastric saline and intravenous saline infusion; $B=$ intragastric saline and intravenous motilin infusion; $C=$ intragastric acid and intravenous saline infusion; $D=$ intragastric acid and intravenous motilin infusion. During first period (0-60 min) combined intragastric and intravenous infusion. During second period (60-90 min) only intragastric infusion. Third period represents post-infusion period.

Table 9.5 Intragastric $\mathrm{pH}$ data pre- and post intragastric acid infusion

\begin{tabular}{lcccc}
\hline & $\mathrm{A}$ & $\mathrm{B}$ & $\mathrm{C}$ & $\mathrm{D}$ \\
\hline $0-90$ & $2.1[1.6-2.6]$ & $2.5[2.0-3.0]$ & $1.3[0.8-1.9]^{*} \dagger$ & $1.3[0.8-1.9]^{*} \dagger$ \\
$90-240$ & $1.8[1.1-2.4]$ & $1.8[1.2-2.5]$ & $1.8[1.2-2.5]$ & $1.6[1.0-2.3]$ \\
\hline
\end{tabular}

Values are means $[95 \% \mathrm{Cl}$. $\mathrm{A}=$ intragastric saline and intravenous saline infusion; $\mathrm{B}=$ intragastric saline and intravenous motilin infusion; $C=$ intragastric acid and intravenous saline infusion; $D=$ intragastric acid and intravenous motilin infusion. ${ }^{*} p<0.05$ compared to $A ; \uparrow p<0.05$ compared to $B$.

\section{Intragastric acidity}

During intragastric acid infusion mean intragastric $\mathrm{pH}$ for experiment $\mathrm{C}$ and $\mathrm{D}$ was significantly $(\mathrm{p}<0.05)$ lower compared to control and experiment B (Table 9.5). Mean intragastric $\mathrm{pH}$ after intragastric infusion (90-240 $\mathrm{min}$ ) did not differ between the four experiments (Figure 9.4).

\section{Plasma motilin levels}

Basal plasma motilin levels did not differ significantly between the four experiments: 78 [58-98], 77 [59-95], 68 [57-78] and 72 [60-84] pmol $\mathrm{I}^{-1}$ for experiment A-D 
respectively. Infusion of exogenous motilin resulted in significant increases within 15 min after the start of infusion ( $t=30 \mathrm{~min}$ ) to plasma motilin levels of 77 [64-90], 509 [461-558], 85 [68-102] and 516 [461-571] pmol I-1 for experiment A-D respectively. Within $60 \mathrm{~min}$ after the end of infusion plasma motilin levels had returned to basal levels (Figure 9.5).

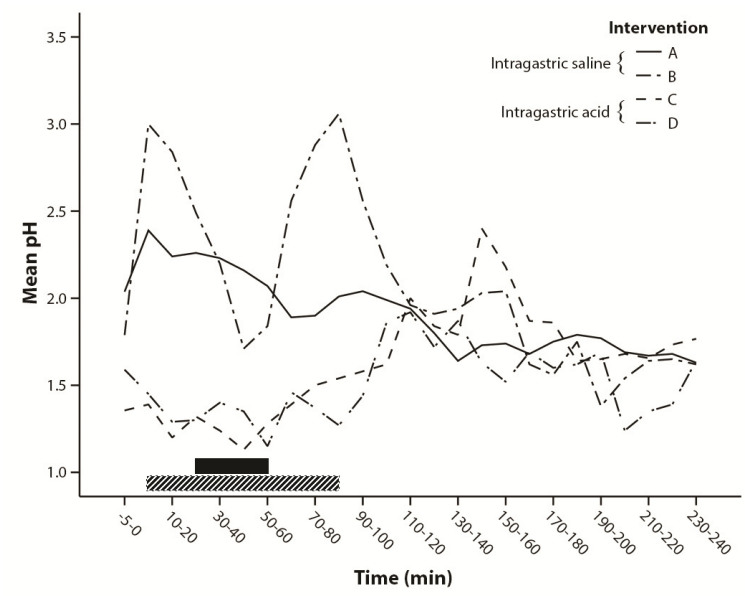

Figure 9.4 Mean intragastric $\mathrm{pH}$ in 10 healthy subjects during intragastric saline and intravenous saline infusion (Control, A), intragastric saline and intravenous motilin infusion (B), intragastric acid and intravenous saline infusion (C) and intragastric acid and intravenous motilin infusion (D). Filled bar represents intravenous saline or motilin infusion. Diagonal filled bar represents intragastric saline or acid infusion.

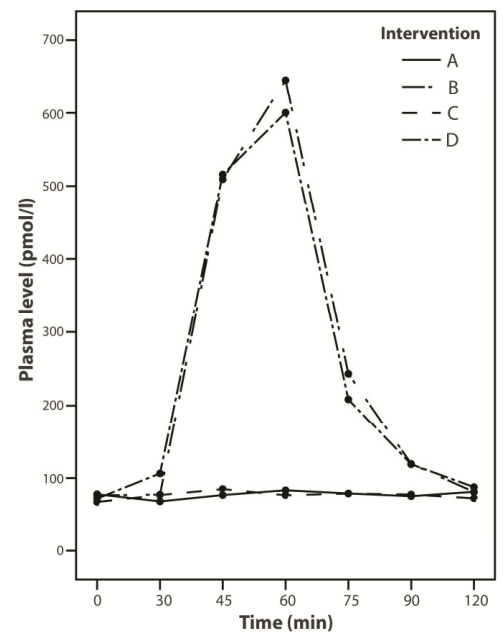

Figure 9.5 Mean motilin plasma levels in 10 healthy subjects during intragastric saline and intravenous 
saline infusion (Control, A), intragastric saline and intravenous motilin infusion (B), intragastric acid and intravenous saline infusion $(C)$ and intragastric acid and intravenous motilin infusion (D).

\section{Discussion}

We have shown in humans that the effect of exogenous motilin, i.e. the occurrence of a phase III of antral origin, is suppressed during intragastric acidification. These results indicate that intragastric acidification blocks the effect of motilin on interdigestive motility and are in line with previous findings in animal studies ${ }^{16,19}$. In addition, our data confirm that during exogenous motilin infusion at a dose of 4 pmol kg-1 $\mathrm{min}^{-1}$ for 30 min an antral phase III occurs. In previous studies, using motilin doses ranging from 2-16 pmol kg-1 $\mathrm{min}^{-1}$ for 20-60 min, the MMC was interrupted by the occurrence of an antral phase III $^{5,6,20}$.

Although during intragastric acidification no phase III occurred, the phase III reoccurrence time was not different between the control and intragastric acidification experiment. This may be due to the fact that the intragastric acidification period only lasted for $90 \mathrm{~min}$. Immediately after cessation of the intragastric acidification period the occurrence of a phase III was observed (Figure 9.1). An inhibitory effect of intragastric acidity on antral phase III occurrence has been well documented. Verkijk et al. $^{12}$ found delayed phase III occurrence during intravenous infusion of gastrin due to an increase in intragastric acidity. Bortolotti et al. ${ }^{4,15}$ found similar results in patients with increased gastric acid secretion. In these patients a decrease in phase III frequency and a prolonged MMC duration was observed. Our results show inhibition of phase III occurrence during the intragastric acidification period and occurrence of a phase III after the end of the intragastric acidification period.

Yamamoto et al. ${ }^{16}$ have extensively studied the effect of intragastric acidification on motilin-induced phase III in dogs. Intragastric acidification inhibited motilin-induced phase III and the authors suggested the presence of an unknown chemoreceptor mechanism sensitive to $\mathrm{pH}$ changes and influencing gastric motility through the vagus nerve. Direct duodenal acidification in dogs did not cause any significant change in the contractile response of the stomach to motilin indicating that the receptor mechanism is residing in the stomach. This receptor mechanism might reside in the gastric antrum as acidification after antrectomy does not inhibit the motilin-induced phase III activity ${ }^{21}$.

A candidate for this $\mathrm{pH}$ "sensing" receptor mechanism is the vanilloid (capsaicin) receptor subtype 1 (VR1). The VR1 receptor is activated by a variety of stimuli, including vanilloids (capsaicin, resiniferatoxin), acid (protons) and increases in temperature ${ }^{22}$. It has been located in the mucosa and myenteric plexus of the stomach ${ }^{23,24}$. Capsaicin-sensitive neurons are involved in regulation of 
gastrointestinal circulation, secretion, motility and nociception ${ }^{22}$. Several studies ${ }^{25-27}$ have shown relaxation of smooth muscle in the stomach due to activation of capsaicin-sensitive neurons to be associated with the release of NO. Relaxation of the stomach by capsaicin seems to occur through activation of capsaicin-sensitive neurons and/or through a direct effect on smooth muscle and seems dose dependent ${ }^{25,26,28}$. Intragastric administration of capsaicin in man decreased gastric electrical activity, inhibited volume waves in the proximal stomach and delayed gastric emptying, suggesting the involvement of VR1 receptors in gastric sensorimotor functions in $\operatorname{man}^{29,30}$.

In a recent study $\mathrm{Xu}$ et al..$^{31}$ suggested, based on the presence of motilin in neurons, that motilin acts not only as a hormone, but also as a neurotransmitter or neuromodulator. It had already been documented that motilin acts through neural pathways and increases the release of acetylcholine ${ }^{32-34}$. Atropine blocks the effect of motilin in the human antrum, suggesting the involvement of a muscarinic pathway, i.e. the parasympathetic nervous system, in motilin-induced motility ${ }^{34}$. However phase III contractions induced by a low concentration of a motilin-agonist were abolished by atropine, whereas high concentration motilin-agonist induced contractions were not $^{33}$. These studies show that motilin stimulates motility both through neural pathways and direct activation of smooth muscle cells and that the activation of these pathways is dose dependent.

A decrease in antral phase II contraction characteristics as represented by amplitude and area under the contraction curve was found during all interventions compared to control. These data suggest a decrease in antral contraction strength during intragastric acidification and confirm previous observations ${ }^{12}$. Furthermore a decrease in antral contraction characteristics is also seen during exogenous motilin infusion. This might result from the interruption of phase II, which normally shows an increase in antral phase II contraction strength towards the occurrence of phase III.

We conclude that in humans intragastric acidification inhibits the effect of motilin on antroduodenal motility, decreases the AUC of antral phase II contractions and delays the occurrence of phase III of the MMC. 


\section{References}

1. Vantrappen G, Janssens J, Hellemans J, Ghoos Y. The interdigestive motor complex of normal subjects and patients with bacterial overgrowth of the small intestine. J Clin Invest 1977;59:1158-66.

2. Polak JM, Pearse AG, Heath CM. Complete identification of endocrine cells in the gastrointestinal tract using semithin-thin sections to identify motilin cells in human and animal intestine. Gut 1975;16:225-9.

3. Vantrappen G, Janssens J, Peeters TL, Bloom SR, Christofides ND, Hellemans J. Motilin and the interdigestive migrating motor complex in man. Dig Dis Sci 1979;24:497-500.

4. Bormans V, Peeters TL, Janssens J, Pearce D, Vandeweerd M, Vantrappen G. In man, only activity fronts that originate in the stomach correlate with motilin peaks. Scand J Gastroenterol 1987;22: 781-4.

5. Luiking YC, Akkermans LM, Peeters TL, Cnossen PJ, Nieuwenhuijs VB, Vanberge -Henegouwen GP. Effects of motilin on human interdigestive gastrointestinal and gallbladder motility, and involvement of 5 HT3 receptors. Neurogastroenterol Motil 2002;14:151-9.

6. Kamerling IM, Van Haarst AD, Burggraaf J, Schoemaker HC, Biemond I, Jones R, Cohen AF, Masclee AA. Dose-related effects of motilin on proximal gastrointestinal motility. Aliment Pharmacol Ther 2002;16:129-35.

7. Luiking YC, Akkermans LM, van der Reijden AC, Peeters TL, van Berge-Henegouwen GP. Differential effects of motilin on interdigestive motility of the human gastric antrum, pylorus, small intestine and gallbladder. Neurogastroenterol Motil 2003;15:103-11.

8. Vantrappen GR, Peeters TL, Janssens J. The secretory component of the interdigestive migrating motor complex in man. Scand J Gastroenterol 1979;14:663-7.

9. Dalenback J, Mellander A, Olbe L, Sjovall H. Motility-related cyclic fluctuations of interdigestive gastric acid and bicarbonate secretion in man. A source of substantial variability in gastric secretion studies. Scand J Gastroenterol 1993;28:943-8.

10. Dalenback J, Fandriks L, Olbe L, Sjovall H. Mechanisms behind changes in gastric acid and bicarbonate outputs during the human interdigestive motility cycle. Am J Physiol 1996;270:G113-22.

11. Gielkens HA, Nieuwenhuizen A, Biemond I, Lamers CB, Masclee AA. Interdigestive antroduodenal motility and gastric acid secretion. Aliment Pharmacol Ther 1998;12:27-33.

12. Verkijk M, Gielkens HA, Lamers CB, Masclee AA. Effect of gastrin on antroduodenal motility: role of intraluminal acidity. Am J Physiol 1998;275:G1209-16.

13. Erckenbrecht JF, Caspari J, Wienbeck M. Pentagastrin induced motility pattern in the human upper gastrointestinal tract is reversed by proglumide. Gut 1984;25:953-6.

14. Bortolotti M, Brunelli F, Sarti P, Mari C, Miglioli M. Effect of omeprazole on interdigestive gastroduodenal motility of patients with ulcer-like dyspepsia. Hepato-Gastroenterol 1999;46:588-93.

15. Bortolotti M. Interdigestive gastroduodenal motility in duodenal ulcer: role of gastric acid hypersecretion. Am J Gastroenterol 1989;84:17-21.

16. Matsunaga Y, Yamamoto O, Ueki S, Haga N, Mizusawa F, Mizumoto A, Sano I, Itoh Z. Inhibition of phase III activity by acid in canine stomach. Regul Pept 1994;52:61-72.

17. Yamamoto O, Matsunaga Y, Haga N, Mizumoto A, Itoh Z. Inhibition of phase III activity by acidifying stomach in vagally denervated and innervated dogs with gastric pouches. Gastroenterology 1994;106:1533-41.

18. Ovesen L, Bendtsen F, Tage-Jensen U, Pedersen NT, Gram BR, Rune SJ. Intraluminal pH in the stomach, duodenum, and proximal jejunum in normal subjects and patients with exocrine pancreatic insufficiency. Gastroenterology 1986;90:958-62.

19. Hayashi N, Mizumoto A, Itoh Z. Inhibition of gastric acid secretion normalizes interdigestive motor activity in the stomach in dogs. Nihon Shokakibyo Gakkai Zasshi 1991;88:1168-76.

20. Luiking YC, Peeters TL, Stolk MF, Nieuwenhuijs VB, Portincasa P, Depoortere I, van Berge Henegouwen GP, Akkermans LM. Motilin induces gall bladder emptying and antral contractions in the fasted state in humans. Gut 1998;42:830-5.

21. Yamamoto O, Matsunaga Y, Haga N, Itoh Z. Vagovagal inhibition of motilin-induced phase III contractions by antral acidification in dog stomach. Am J Physiol 1994;267:G129-34. 
22. Holzer P. TRPV1 and the gut: from a tasty receptor for a painful vanilloid to a key player in hyperalgesia. Eur J Pharmacol 2004;500:231-41.

23. Ward SM, Bayguinov J, Won KJ, Grundy D, Berthoud HR. Distribution of the vanilloid receptor (VR1) in the gastrointestinal tract. J Comp Neurol 2003;465:121-35.

24. Nozawa Y, Nishihara K, Yamamoto A, Nakano M, Ajioka H, Matsuura N. Distribution and characterization of vanilloid receptors in the rat stomach. Neurosci Lett 2001;309:33-6.

25. Uno H, Arakawa T, Fukuda T, Higuchi K, Kobayashi K. Involvement of capsaicin-sensitive sensory nerves in gastric adaptive relaxation in isolated guinea-pig stomachs. Digestion 1997;58:232-9.

26. Sim JH, Kim YC, Kim SJ, Lee SJ, Suh SH, Jun JY, So I, Kim KW. Capsaicin inhibits the voltage-operated calcium channels intracellularly in the antral circular myocytes of guinea-pig stomach. Life Sci 2001;68:2347-60.

27. Lefebvre RA, De Beurme FA, Sas S. Relaxant effect of capsaicin in the rat gastric fundus. Eur J Pharmacol 1991;195:131-7.

28. Szallasi A, Blumberg PM. Vanilloid (Capsaicin) receptors and mechanisms. Pharmacol Rev 1999;51:159-212.

29. Gonzalez R, Dunkel R, Koletzko B, Schusdziarra V, Allescher HD. Effect of capsaicin-containing red pepper sauce suspension on upper gastrointestinal motility in healthy volunteers. Dig Dis Sci 1998;43:1165-71.

30. Lee KJ, Vos R, Tack J. Effects of capsaicin on the sensorimotor function of the proximal stomach in humans. Aliment Pharmacol Ther 2004;19:415-25.

31. Xu L, Depoortere I, Tomasetto C, Zandecki M, Tang M, Timmermans JP, Peeters TL. Evidence for the presence of motilin, ghrelin, and the motilin and ghrelin receptor in neurons of the myenteric plexus. Regul Pept 2005;124:119-25.

32. Mizumoto A, Sano I, Matsunaga Y, Yamamoto O, Itoh Z, Ohshima K. Mechanism of motilin-induced contractions in isolated perfused canine stomach. Gastroenterology 1993;105:425-32.

33. Coulie B, Tack J, Peeters T, Janssens J. Involvement of two different pathways in the motor effects of erythromycin on the gastric antrum in humans. Gut 1998;43:395-400.

34. Boivin M, Pinelo LR, St-Pierre S, Poitras P. Neural mediation of the motilin motor effect on the human antrum. Am J Physiol 1997;272:G71-6. 


\section{Chapter 10}

Summary and General discussion

J.J.L. Haans

A.A.M. Masclee 


\section{Background}

Gastric motor function consists of several aspects working in close interaction with each other to provide a well-dosed delivery of nutrients to the small intestine after meal intake. In response to ingestion of a meal the proximal stomach accommodates in order to provide capacity to store the meal. Hereafter the meal is distributed towards the more distal stomach for grinding to smaller particles and titrated delivery to the duodenum through relaxation of the pyloric muscle. Hence gastric motor function successively entails accommodation, tonic contractions and slow wave fundic contractions in the proximal stomach and phasic contractions in the distal stomach, altogether leading to gastric emptying.

Understanding the physiology of gastric motor function requires study of all these aspects. Up till now different techniques were needed to study these aspects separately. Gastric accommodation can be measured using the barostat technique and more recently also by SPECT and ultrasonography. Tonic contractions and slow wave fundic contractions are registered by the barostat technique. In order to measure phasic contractions in the stomach either water-perfused manometry and/or solid-state manometry can be employed. Gastric emptying and its parameters can be determined using either direct techniques, such as scintigraphy and/or ultrasonography, or indirect techniques such as stable isotope breath tests and/or acetaminophen blood test.

Most of these techniques are invasive and/or operator and condition dependent. In addition none of the above-mentioned techniques are able to determine all aspects of gastric motor function simultaneously or in a combined set up.

In this thesis, we have examined Magnetic Resonance Imaging (MRI) as a technique to study gastric motor function. We have compared other techniques such as barostat and stable isotope breath test with MRI. In addition we have compared gastric motor function measured by MRI in disease versus health and we have evaluated the effect of pharmacological interventions on gastric motor function both in health and disease.

In Chapter 2 we reviewed several aspects of gastroparesis, its prevalence, etiology, diagnosis and management. Determining the etiology of gastroparesis is relevant for adequate management. Underlying causes or disorders should be treated. Delayed gastric emptying should be quantified, preferably by a direct technique, such as scintigraphy or in research setting by MRI. The true prevalence of gastroparesis is unknown. It is assumed that up to $4 \%$ of the general population experiences symptoms of gastroparesis. Objectively determined $30-50 \%$ of patients with diabetes mellitus and $24-40 \%$ of patients with functional dyspepsia (FD) have delayed gastric emptying. Treatment options for gastroparesis are limited, most patients with mild 
disease will respond to dietary and life style measures, and prokinetics such as domperidone, metoclopramide and erythromycin. In patients with gastroparesis that do not respond to standard treatment options additional investigations are required in order to determine the aspects of gastric motor function that delay gastric emptying. Several techniques are available, however, in this thesis we have shown that MRI can determine all aspects of gastric motor function in a single visit. This might help to differentiate those patients that might benefit from intrapyloric botulinum toxin injection, feeding enterostomy, gastric pacing or more radical surgical interventions, like partial or total gastrectomy.

\section{Gastric accommodation}

Gastric accommodation is considered to be a vagally mediated reflex that occurs postprandial resulting in a reduction of tone, thus providing a reservoir for the meal. Impaired gastric accommodation is present in a considerable subset of patients with FD or following surgery. The barostat technique is used to study proximal gastric sensory and motor function, including gastric accommodation. Disadvantages of the barostat technique are the time consuming procedure and the invasive nature requiring oral intubation with intragastric positioning of a polyethylene bag. Questions have been raised about interference of the barostat with gastric physiology.

Therefore in the study described in Chapter 3, we evaluated gastric accommodation with MRI in the presence of a barostat bag and compared this with similar circumstances when such a bag was not present. Furthermore we evaluated the influence of such a bag on gastric motor function. The presence of a barostat bag influences gastric motor function, it overestimates gastric accommodation in response to a meal. In addition, initial intragastric contents volume, that is meal and secretory products, are influenced by the presence of the barostat bag. However, gastric emptying rate was not influenced by the presence of the barostat bag. Visualization of contraction patterns showed an irregular pattern in the presence of a barostat bag. Gastric barostat studies have provided further insight into the pathophysiology of functional dyspepsia (FD) and have been helpful in defining subgroups of patients with FD, for instance those with an impaired accommodation in response to a meal. Notwithstanding these observations, based on this study the true physiological background of gastric barostat studies should be reconsidered. Additional studies on the presence of an accommodation response under physiological circumstances in health and disease are required to provide more insight into the value of impaired accommodation in disease and it's clinical relevance. 
In Chapter 4 further validation of MRI was performed through in vitro and in vivo volume measurements. Polyethylene bags filled with known volumes were analyzed using MRI. Barostat determined volumes and MRI volume scans were compared in healthy subjects. In vitro analysis showed an excellent linear relationship $(r=0.995$, $\mathrm{p}<0.001)$. Although fasting gastric volume, postprandial gastric volume and relaxation volume measured by MRI were significantly larger compared to volumes measured with the barostat, volumes determined with both techniques showed excellent correlation. Our study has shown that MRI accurately measures volumes in the range of postprandial meal volumes. $\mathrm{MRI}$ is an accurate, non-invasive technique to measure stomach volumes and volume changes in response to a meal. Volume changes in response to a meal measured by MRI show a good correlation with those measured by the barostat device.

A vagovagal reflex pathway is involved in the accommodation reflex with nitric oxide (NO) as an important neurotransmitter. Previous barostat studies have shown an increase in postprandial gastric accommodation in response to sildenafil, a selective phosphodiesterase type 5-inhibitor (PDE-5), known to affect this vagovagal reflex pathway. In Chapter 5 we studied the effect of sildenafil on gastric motor function. We have shown that MRI, as a non-invasive technique, enables determination of pharmacologically induced changes in gastric emptying, relaxation and receptiveness. Moreover, we demonstrated that sildenafil augmented proximal gastric relaxation and influenced intragastric meal distribution with increased proximal meal receptiveness thus delaying the onset of early gastric emptying. Further evaluation of the MRI technique is warranted, especially with respect to the pathophysiological concept of impaired gastric accommodation/relaxation, before the non-invasive MRI technique can be applied for assessment of patients with FD and management decisions in clinical settings.

Functional dyspepsia (FD) is a gastrointestinal disorder defined as the presence of symptoms originating from the gastroduodenal region, in the absence of any organic, systemic, or metabolic disease, likely to explain the symptoms. More recently a FD subtype classification into postprandial distress syndrome and epigastric pain syndrome has been proposed. Several pathophysiological mechanisms have been identified in FD such as delayed gastric emptying, abnormal antroduodenal motility, hypersensitivity to gastric distension, altered duodenal sensitivity to acid or nutrients and impaired gastric accommodation. Impaired accommodation is associated with symptoms of early satiety in FD. Gastric accommodation can be measured using barostat equipment. Previous barostat studies have provided evidence for impaired accommodation in up to $40 \%$ of FD patients. Unfortunately the barostat is an invasive technique limiting its application in daily practice. In chapter 6 we studied early postprandial gastric volume changes in health and disease (FD) using MRI. Volume changes in response to a meal were 
studied up to 30 min. postprandial. Proximal relaxation and proximal distribution of contents were considered abnormal (impaired relaxation or reduced receptiveness respectively) in FD when values were below the $5^{\text {th }}$ percentile for controls. We observed impaired relaxation and reduced proximal receptiveness in 19\% of FD patients. This is different from previous observations made. In our opinion these differences are related to technical differences between MRI and the other techniques, the applied stimulus, either in the form of meal size or due to the presence of a barostat bag, and our study population, that was recruited from a nontertiary center. Part of these observations are supported by data from a previous study by Fruehauf et al. (Chapter 6, reference 16) utilizing MRI and showing a more pronounced difference in volume responses between controls and FD for a high volume liquid meal $(800 \mathrm{ml})$ compared to a low volume liquid meal $(200 \mathrm{ml})$. Our study has shown that MRI is a suitable non-invasive technique that allows detailed measurement of early postprandial changes in gastric volume, and intragastric meal distribution. Moreover MRI is able to differentiate a subgroup of patients with FD from controls based on early changes in gastric volumes and intragastric meal distribution, having impaired proximal relaxation and reduced proximal receptiveness for contents.

\section{Gastric emptying}

Reliable measurement of gastric emptying is essential for diagnosis and treatment of patients suspected of disorders that either delay or accelerate gastric emptying. MRI has been validated previously to measure gastric emptying of both liquid and solid meals. In the past two decades MRI has been used for evaluation of gastric emptying almost exclusively in the research setting. Gastric emptying has been evaluated using MRI in health and disease, after surgical or pharmacological interventions, to study intragastric distribution and meal layering and to analyze gastric motility, i.e. antral contractions. Indirect stable isotope breath test is frequently applied to determine parameters of gastric emptying but needs validation against direct imaging techniques, preferably during simultaneous recording. In Chapter 7 we studied the reliability of our in-house made interactive software tool for the analysis of MRI determined volumes. We used MRI to determine accuracy of the stable isotope breath test technique for gastric emptying of solids and liquids. Furthermore we compared different mathematical models currently used to determine and correct gastric emptying parameters in stable isotope breath test analysis to gastric emptying parameters determined by MRI. Our in-house made interactive software tool showed an excellent reliability of volume analysis with high inter-observer agreement and intra-observer reproducibility. We demonstrated that correlation between the direct MRI technique and the indirect stable isotope breath test is better for gastric emptying of liquids than for gastric emptying of solids. Moreover, 
mathematical correction of stable isotope breath test data did not improve the outcome of gastric emptying parameters.

\section{Gastric motor function}

Somatostatin is a cyclic tetradecapeptide that is widely distributed throughout the nervous system and the gastrointestinal tract. Outcomes of studies on the effect of somatostatin on gastric emptying in humans have been contrasting, showing either acceleration or delay in gastric emptying. In healthy subjects somatostatin reduces perception to mechanical and chemical stimuli in the upper gastrointestinal tract and may therefore have potential in the treatment of FD. Data on the effect of somatostatin on gastric emptying in FD are lacking. In Chapter 8 we used a single technique, MRI, to study the effect of somatostatin on early gastric motor function that is gastric volume changes, gastric emptying of liquids and contractions. We observed a reduction in gastric volume induced by somatostatin that resulted from changes in gastric contents. Early gastric emptying was significantly accelerated by somatostatin in both healthy volunteers and patients with FD. However, contraction frequency did not differ, suggesting that somatostatin does not influence gastric motility. Although somatostatin accelerated gastric emptying in FD patients, somatostatin did not affect postprandial symptoms such as nausea, fullness or epigastric tension. Using MRI, as a single technique, we have shown that somatostatin reduces postprandial gastric volumes in both health and FD, through earlier initiation and acceleration of gastric emptying without quantitatively affecting gastric motility. We did not observe a reduction in postprandial symptoms in patients with FD.

Interdigestive antroduodenal motility is characterized by a cyclic motor pattern. The so-called migrating motor complex (MMC) consists of three distinct phases: phase $I$ is a pattern of motor quiescence, phase II a pattern of irregular single contractions and phase III a pattern of intensive rhythmic contractions. Motilin, a 22-amino acid gastrointestinal peptide released from enterochromaffin cells in the upper part of the small intestine, plays an important role in the occurrence of a phase III of antral origin. Gastric acid secretion is also variable during the three phases of the MMC. Gastric acid secretion is low during phase I and early phase II. It increases during late phase II and reaches a maximum during phase III of the MMC. In has been shown that intraluminal acidity affects interdigestive motility as shown by a suppression of the antral phase III. In chapter 9 we studied the effect of gastric acidification on motilininduced interdigestive antropyloroduodenal motility. We have shown that reoccurrence of phase III was earlier during intragastric saline and intravenous motilin infusion compared to control (intragastric saline and intravenous saline). This effect was completely abolished during intragastric acid and intravenous motilin 
infusion. We established that intragastric acidification inhibits the effect of motilin on antroduodenal motility and delays the occurrence of a phase III of the MMC in humans.

In conclusion, the studies described in this thesis have provided additional insight into the complex process of gastric motility and the function of gastric emptying. However, it is obvious that many questions remain unanswered and new questions have arisen. Magnetic Resonance Imaging is a promising technique for evaluating gastric motor function in a non-invasive manner. Reproducibility, validity, user friendliness and ease in data analysis are important conditions prior to reaching clinical application. 
Samenvatting en Algemene discussie

J.J.L. Haans A.A.M. Masclee 


\section{Achtergrond}

De postprandiale maagmotiliteit betreft een samenspel van verschillende aspecten die na een maaltijd leiden tot een gedoseerde afgifte van voedingsstoffen naar het duodenum. De proximale maag accommodeert in reactie op de inname van een maaltijd om ruimte te bieden voor de tijdelijke opslag van deze maaltijd. Hierna wordt de maaltijd verplaatst naar de distale maag om vermalen te worden tot kleinere partikels en gecontroleerd getitreerd te worden naar het duodenum via relaxatie van de pylorus of maaguitgang. Hiermee bestaat postprandiale maagmotiliteit uit achtereenvolgens accommodatie, tonische contracties in de proximale maag en fasische contracties in de distale maag, samen leidend tot maaglediging.

in de fysiologie van postprandiale maagmotiliteit vereist studie van al deze aspecten. Tot nu toe was het weliswaar mogelijk deze aspecten te bestuderen, maar alleen separaat en met verschillende technieken. Accommodatie kan gemeten worden met de barostat techniek en meer recentelijk ook middels SPECT en echografie. Tonische contracties worden geregistreerd met behulp van de barostat techniek. Om fasische contracties in de maag te meten kan water-geperfundeerde manometrie en/of solid-state manometrie worden toegepast. Maaglediging en haar parameters kunnen worden bepaald door middel van directe technieken, zoals scintigrafie en/of echografie, of middels indirecte technieken zoals de stabiele isotoop ademtest en/of de paracetamol bloedtest. De meeste van deze technieken zijn invasief en/of operator en conditie afhankelijk. Bovendien kan geen van bovengenoemde technieken alle aspecten van maagmotiliteit gelijktijdig of in een gecombineerde setup meten.

In dit proefschrift hebben we onderzocht of Magnetic Resonance Imaging (MRI) ingezet kan worden om de maagmotiliteit te bestuderen. We hebben andere technieken zoals barostat en stabiele isotoop ademtest vergeleken met MRI. Daarnaast hebben we de maagmotiliteit bestudeerd met behulp van MRI bij patiënten en gezonde vrijwilligers, en de effecten bekeken van farmacologische interventies op de maagmotiliteit.

In Hoofdstuk 2 hebben we de verschillende aspecten van gastroparese belicht, waaronder prevalentie, etiologie, diagnostiek en behandeling. Het vaststellen van de oorzaak voor gastroparese is van belang voor een adequate behandeling. Initieel moeten onderliggende oorzaken of aandoeningen worden geïdentificeerd en behandeld. Vertraagde maaglediging moet worden geobjectiveerd, bij voorkeur door een directe techniek, zoals scintigrafie of in een experimentele setting middels MRI. De werkelijke prevalentie van gastroparese is onbekend, aangenomen wordt dat tot $4 \%$ van de bevolking symptomen ervaren, die passen bij een gastro- 
parese. Geobjectiveerd heeft $30-50 \%$ van de patiënten met diabetes mellitus en 24-40\% van de patiënten met functionele dyspepsie (FD) een vertraagde maaglediging. De behandelingsopties voor gastroparese zijn beperkt. De meeste patiënten met een milde ziekte reageren op dieet- en leefstijl maatregelen, eventueel aangevuld door pro-kinetica zoals domperidon, metoclopramide en erythromycine. Bij patiënten met gastroparese die niet reageren op de standaard behandelingsopties is aanvullende diagnostiek gewenst om de verschillende aspecten van de maagmotiliteit in kaart te brengen die bij kunnen dragen aan een vertraagde maaglediging. Meerdere technieken zijn hiervoor beschikbaar. In dit proefschrift hebben wij laten zien dat middels MRI al deze aspecten met één onderzoek en bezoek in kaart gebracht kunnen worden. Dit kan helpen om patiënten te differentiëren die mogelijk meer baat kunnen hebben bij intra-pylorische botuline toxine injecties, het aanleggen van een enterostomie, maag-pacing of meer radicale chirurgische ingrepen, zoals een partiële of volledige gastrectomie.

\section{Maagaccommodatie}

Maagaccommodatie is een door de nervus vagus gemedieerde reflex, die leidt tot een verlaagde tonus van de proximale maag, waarmee de opslagcapaciteit van de maag wordt vergroot. Verminderde maagaccommodatie is aanwezig in een aanzienlijke subgroep van patiënten met FD, maar wordt ook gezien na operaties. De barostat techniek wordt gebruikt om sensorische en motorische functies van de maag te meten, inclusief maagaccommodatie. Nadelen van de barostat techniek zijn de tijdrovende procedure en het invasieve karakter, waarbij middels orale intubatie een ballon van polyethyleen in de maag gepositioneerd moet worden. De invloed van de barostat op de "fysiologische" respons van de maag staat ter discussie.

In de studie beschreven in hoofdstuk 3 , hebben we de maagaccommodatie met MRI in de aanwezigheid van een barostat ballon geëvalueerd en vergeleken met gelijkwaardige omstandigheden waarbij een dergelijke ballon niet aanwezig was. Daarnaast hebben we de invloed van een dergelijke ballon op de maagmotiliteit bestudeerd. De aanwezigheid van een barostat ballon had invloed op de maagmotiliteit en gaf een overschatting van de maagaccommodatie in reactie op een maaltijd. Bovendien wordt het intragastrische volume, dat bestaat uit maaltijd en secretieproducten, beïnvloed door de aanwezigheid van de barostat ballon. Maagledigingssnelheid werd niet beïnvloed door de aanwezigheid van de barostat ballon. Visualisatie van de contractie patronen liet een onregelmatiger patroon zien in aanwezigheid van een barostat ballon. Barostat studies hebben geleid tot beter inzicht in de pathofysiologie van functionele dyspepsie (FD) en het definiëren van subgroepen van patiënten met FD, bijvoorbeeld met een verminderde accommodatie respons op een maaltijd. Ondanks deze waarnemingen, 
zou op basis van deze studie de werkelijke fysiologische achtergrond van eerdere barostat studies heroverwogen moeten worden. Aanvullend onderzoek naar de aanwezigheid van een accommodatie reactie onder meer fysiologische omstandigheden bij gezondheid en ziekte zijn nodig om inzicht te geven in de waarde van een verminderde accommodatie en haar klinische relevantie.

In Hoofdstuk 4 hebben wij de MRI techniek verder gevalideerd door in vitro en in vivo volume bepalingen. Polyethyleen zakken werden gevuld met een bekend volume en geanalyseerd met behulp van MRI. Volumes bepaald met de barostat en MRI werden vergeleken bij gezonde personen. De in vitro analyse toonde een uitstekende lineaire relatie $(r=0,995, p<0,001)$. Hoewel nuchtere, postprandiale en accommodatie volumes gemeten met MRI significant groter waren in vergelijking met volumes gemeten met de barostat, bleken de volumes een uitstekende correlatie te hebben. Dit onderzoek heeft laten zien dat met behulp van MRI volumes in het bereik van postprandiale maaltijd volumes nauwkeurig kunnen worden gemeten. Dit maakt MRI een nauwkeurige, niet-invasieve techniek om maagvolumes en volumeveranderingen te meten na een maaltijd. Volumeveranderingen in reactie op een maaltijd gemeten met MRI vertonen een goede correlatie met die gemeten met de barostat.

Een vagovagale reflex is betrokken bij de accommodatie respons, waarbij stikstofmonoxide (NO) als neurotransmitter een belangrijke rol speelt. Eerdere barostat studies hebben aangetoond dat sildenafil, een selectieve fosfodiësterase type 5-remmer (PDE-5), via beïnvloeding van deze vagovagale reflex, een stimulerend effect heeft op de postprandiale accommodatie respons. In hoofdstuk 5 bestudeerden we het effect van sildenafil op de maagmotiliteit. We hebben aangetoond dat MRI farmacologisch geïnduceerde veranderingen in de maaglediging, relaxatie en ontvankelijkheid voor een maaltijd kan vaststellen. Bovendien hebben we aangetoond dat sildenafil een meer uitgesproken relaxatie van de proximale maag induceert en de maaltijddistributie beïnvloedt door een toegenomen ontvankelijkheid voor een maaltijd van de proximale maag. Hierdoor wordt het begin van de vroege maaglediging vertraagd. Verdere evaluatie van de MRI-techniek is noodzakelijk, vooral in relatie tot het pathofysiologische concept van een verminderde maag accommodatie/relaxatie, alvorens de niet-invasieve MRItechniek kan worden toegepast voor evaluatie van subtypen FD patiënten en selectie van therapie in de klinische setting.

Functionele dyspepsie (FD) is een gastro-intestinale conditie, die gedefinieerd wordt als de aanwezigheid van symptomen in de maagstreek, zonder dat er sprake is van organische, systemische of metabole ziekten, die de symptomen zouden kunnen verklaren. Recentelijk heeft er een indeling plaatsgevonden, die onderscheid maakt tussen twee typen: het postprandiale distress syndroom en het epigastrische pijn 
syndroom. Verschillende pathofysiologische mechanismen zijn geïdentificeerd in FD, waaronder vertraagde maaglediging, abnormale antroduodenale motiliteit, overgevoeligheid voor distensie van de maag, veranderde gevoeligheid van het duodenum voor zuur of voedingsstoffen en een verstoorde accommodatie. Verminderde accommodatie wordt met name in verband gebracht met symptomen van vroege verzadiging in FD. Accommodatie kan worden gemeten met behulp van de barostat. Eerdere barostat studies hebben aangetoond dat verminderde accommodatie in ongeveer $40 \%$ van de FD patiënten een pathofysiologische rol speelt. Helaas is de barostat een invasieve techniek, waardoor de toepassing ervan in de dagelijkse praktijk beperkt is. In hoofdstuk 6 onderzochten we vroege postprandiale maagvolume veranderingen in gezondheid en ziekte (FD) met behulp van MRI. We bestudeerden volumeveranderingen in de $1^{\mathrm{e}} 30$ minuten na maaltijdinname. Proximale relaxatie en proximale ontvankelijkheid voor een maaltijd werden als abnormaal beschouwd (respectievelijk verminderde relaxatie en afgenomen ontvankelijkheid) in FD als de waarden onder de $5^{\mathrm{e}}$ percentiel voor controles waren. We zagen verminderde relaxatie en afgenomen ontvankelijkheid in bijna $20 \%$ van de FD patiënten. Dit wijkt af van de eerder genoemde waarnemingen. Wij zijn van mening dat deze verschillen veroorzaakt worden door technische verschillen tussen $\mathrm{MRI}$ en andere technieken, door verschillen in de toegediende stimulus, door de vorm en het volume van de maaltijd, door de aanwezigheid van een barostat ballon, en door de samenstelling van de studie populatie, waarbij onze populatie niet afkomstig was van een tertiair centrum. Een deel van deze waarnemingen wordt ondersteund door gegevens uit een eerdere studie van Fruehauf et al. (Hoofdstuk 6, referentie 16), waarbij middels MRI een meer uitgesproken verschil in volume veranderingen werd geobserveerd tussen controles en FD patiënten voor een hoog volume vloeibare maaltijd $(800 \mathrm{ml})$ vergeleken met een laag volume vloeibare maaltijd $(200 \mathrm{ml})$. Onze studie heeft aangetoond dat MRI een geschikte, niet-invasieve techniek is, die gedetailleerde meting van de vroege postprandiale veranderingen in het maagvolume en de maaltijd distributie toelaat. Bovendien is MRI in staat om een subgroep van patiënten met FD te onderscheiden van gezonden op basis van de vroegtijdige veranderingen in maagvolumes en maaltijd distributie, waarbij een verminderde proximale relaxatie en een afgenomen ontvankelijkheid voor een maaltijd wordt gezien.

\section{Maaglediging}

Betrouwbare meting van de maaglediging is essentieel voor de diagnose en behandeling van patiënten verdacht van aandoeningen die de maaglediging vertragen of versnellen. MRI is in voorgaande onderzoeken gevalideerd voor de meting van maaglediging van zowel vloeibare als vaste maaltijden. In de afgelopen twee decennia is MRI bijna uitsluitend gebruikt voor de evaluatie van de 
maaglediging in experimentele c.q. onderzoek setting. Maaglediging is geëvalueerd met behulp van MRI bij gezondheid en ziekte, na chirurgische of farmacologische interventies, om de maaltijd distributie te bestuderen en om antrale contracties te analyseren. De indirecte stabiele isotoop ademtest wordt veelvuldig toegepast om de parameters van de maaglediging te bepalen, maar validatie hiervan dient verricht te worden ten opzichte van directe beeldvormende technieken, bij voorkeur simultaan. In hoofdstuk 7 hebben we de betrouwbaarheid van onze interactieve software voor de analyse van MRI volumes bepaald. We gebruikten MRI om de accuratesse van de stabiele isotoop ademtest voor de maaglediging van vloeistoffen en vaste stoffen vast te stellen. Daarnaast vergeleken we verschillende wiskundige modellen die momenteel worden gebruikt om de parameters van maaglediging te bepalen en te corrigeren in de stabiele isotoop ademtest analyse met de maaglediging parameters bepaald via MRI. Onze interactieve software liet een uitstekende betrouwbaarheid van de volume-analyse zien met een hoge interobserver overeenkomst en intra-observer reproduceerbaarheid. We hebben aangetoond dat de correlatie tussen de directe MRI-techniek en de indirecte stabiele isotoop ademtest beter is voor de maaglediging van vloeistoffen dan voor de maaglediging van vaste stoffen. Bovendien gaf wiskundige correctie van stabiele isotoop ademtest analyse geen verbetering van de uitkomsten van de maaglediging parameters.

\section{Maagmotiliteit}

Somatostatine is een cyclische tetradecapeptide dat wijd verspreid aanwezig is, zowel in het zenuwstelsel als in het maag-darmkanaal. De resultaten van studies over het effect van somatostatine op de maaglediging bij de mens zijn wisselend, variërend van versnelling tot vertraging van de maaglediging. In gezonde vrijwilligers vermindert somatostatine de gevoeligheid voor mechanische en chemische stimuli in het bovenste maagdarmkanaal en zou daarom mogelijk een rol kunnen spelen bij de behandeling van FD. Gegevens over het effect van somatostatine op maaglediging in FD ontbreken. In hoofdstuk 8 hebben we gebruik gemaakt van MRI om het effect van somatostatine op de vroege maagmotiliteit, in de vorm van maagvolume veranderingen, maaglediging van vloeistoffen en contracties, simultaan te bestuderen. We zagen een daling in het maagvolume, die veroorzaakt werd door veranderingen in de maaginhoud onder invloed van somatostatine. De vroege fase van maaglediging werd aanzienlijk versneld door somatostatine, zowel bij gezonde vrijwilligers als bij FD patiënten. We zagen geen veranderingen in contractie frequentie, waarmee gesuggereerd wordt dat somatostatine geen invloed heeft op de maagmotiliteit. Hoewel somatostatine de maaglediging versnelde in FD patiënten, heeft somatostatine geen invloed op postprandiale symptomen zoals misselijkheid, een vol gevoel of epigastrische 
spanning. Middels MRI hebben we aangetoond dat somatostatine de postprandiale maagvolumes doet afnemen in zowel gezonden als patiënten met $F D$, door een eerdere initiatie en versnelling van de maaglediging zonder hierbij de contracties kwantitatief te beïnvloeden. We zagen geen vermindering van de postprandiale symptomen bij patiënten met FD.

Interdigestieve antroduodenale motiliteit wordt gekenmerkt door een cyclisch patroon. Het zogenaamde migrerende motor complex (MMC) bestaat uit drie verschillende fasen: fase I is een patroon van motorische rust, fase II een patroon van onregelmatige contracties en fase III een patroon van intensieve ritmische contracties. Motiline, een 22-aminozuur peptide, geproduceerd door enterochromaffine cellen in het bovenste deel van de dunne darm, speelt een belangrijke rol bij het optreden van een fase III van antrale origine. Ook de maagzuursecretie verandert tijdens de drie fasen van het MMC. Maagzuursecretie is laag tijdens fase I en de vroege fase II. Het neemt toe tijdens de late fase II en bereikt een maximum tijdens de fase III van het MMC. Eerder werd aangetoond dat de intraluminale zuurgraad de interdigestieve motiliteit beïnvloedt zoals blijkt uit de onderdrukking van antrale fase III activiteit. In hoofdstuk 9 hebben we het effect van acidificatie op de motiline-geïnduceerde interdigestieve antropyloroduodenale motiliteit bestudeerd. We hebben aangetoond dat het opnieuw optreden van een fase III eerder plaatsvindt tijdens het infunderen van een zoutoplossing in de maag en motiline intraveneus dan tijdens het inlopen van een zoutzuuroplossing in de maag en placebo intraveneus. Het effect van intraveneus motiline werd volledig teniet gedaan door het inlopen van een zure oplossing in de maag. We hebben hiermee vastgesteld dat verzuring van de maag het effect van motiline op de antroduodenale motiliteit onderdrukt en het ontstaan van een fase III vertraagt.

Concluderend hebben de door ons uitgevoerde studies het inzicht in het complexe proces van maagmotiliteit en de functie van maaglediging deels doen toenemen, waarbij onmiddellijk duidelijk is dat nog vele vragen onbeantwoord zijn en er even zoveel nieuwe vragen zijn ontstaan. Magnetic Resonance Imaging is een veelbelovende techniek om maagfunctie te meten op non-invasieve wijze. Reproduceerbaarheid, goede vergelijking met andere technieken, gebruikersvriendelijkheid en gemak in data analyse zijn voorwaarden vooraleer tot klinische toepassingen te kunnen komen. 
Dankwoord 


\section{Dankwoord}

Eindelijk is het klaar. Zonder de hulp van de vele mensen die ik in de afgelopen jaren tegen ben gekomen was het nooit zover gekomen. Ik wil iedereen bedanken die in meer of mindere mate betrokken is geweest bij de totstandkoming van dit proefschrift. Een aantal hiervan wil ik in het bijzonder noemen.

Allereerst wil ik alle gezonde vrijwilligers en patiënten bedanken die hebben deelgenomen aan de verschillende studies beschreven in dit proefschrift. Zonder hun inbreng was de totstandkoming van dit proefschrift überhaupt niet mogelijk geweest.

Prof. dr. A.A.M. Masclee, Ad, ik heb veel aan je te danken. Het eindeloze vertrouwen en de steun die je me in de afgelopen jaren hebt gegeven hebben mij gebracht waar ik nu ben. Dat ik uiteindelijk geen maag-, darm- en leverarts word, is een heel bewuste en goed overdachte keuze geweest. Ik hoop dat je hier vrede mee hebt. Je bent gedreven, diplomatiek, maar ook vergeetachtig (soms ook in mijn voordeel uitpakkend) en wispelturig. Een deel van deze eigenschappen is mij bekend, al heb ik me jouw diplomatieke kwaliteiten nooit aan kunnen leren. Ik wil je danken voor de vrijheid die je me gegeven hebt in de jaren dat ik onderzoek bij je heb mogen doen. Ik zal ons conflict aan het einde van mijn eerste jaar onder jouw hoede nooit vergeten. Een open gesprek, waarin ook onvriendelijke woorden zijn gevallen, maar dat uiteindelijk geleid heeft tot een doorbraak in onze samenwerking en wederzijds respect; na regen komt zonneschijn.

Prof. dr. A. de Roos, Albert, dank voor de mogelijkheden die je me gaf om binnen de afdeling Radiologie onderzoek te doen. Het was ongelooflijk hoeveel steun ik van je afdeling kreeg zonder dat daar een financiële compensatie tegenover stond. Ik heb dit altijd beschouwd als de ware academische instelling, maar realiseer me ook dat dit in de huidige bedrijfsvoering steeds moeilijker wordt. Ik hoop dat je je realiseert dat zonder jouw "gastvrijheid" het werk beschreven in dit proefschrift waarschijnlijk nooit tot stand gekomen was.

Collega dr. P.W.J. Maljaars, Jeroen, wat was ik blij toen je het besluit had genomen om mee te gaan naar Maastricht, Limburg, één van de locaties waarvan ik tijdens mijn studententijd nog zei dat ik er nog niet dood gevonden wilde worden (wat waarschijnlijk wel het geval gaat zijn). De teleurstelling was dan ook groot toen je de beslissing nam je opleiding tot maag-, darm- en leverarts voort te zetten in het bruisende, jachtige en zo directe deel van Nederland; de Randstad of meer specifiek het mooie Leiden. Dank voor alle fijne momenten op onze kamer in het Leids Universitair Medisch Centrum en later de Universiteit Maastricht; onze gezamenlijke 
waardering voor die roze website (GeenStijl, toen nog acceptabel), je mooie verhalen over vele vrienden, de talloze biertjes en de gevolgen daarvan.

Professor dr. P.H.C. Eilers, Paul, wat heb ik genoten van onze uren samen achter een computer of een bureautafel met koffie en thee, starend naar curves gecreëerd in software waar velen nog nooit van gehoord hebben. Hiermee had ik de mogelijkheid om mijn grootste hobby en mijn liefde voor bètavakken (waarvoor ik achteraf beter had kunnen kiezen; mam, je kent me toch het best) mee te nemen in mijn werk. Vele uren (ja Jeroen, toch maar weer een andere analyse) heb ik doorgebracht met het aanpassen van syntaxen en scripts om data werkbaar te maken. Zonder je hulp en enthousiasme was dat waarschijnlijk nooit gelukt.

Dr. J. Doornbos, Joost, bedankt voor je (technische) ondersteuning in de afgelopen jaren. Je hebt altijd ruim de tijd genomen voor uitleg, toelichting en experimenten. De rust die je hierbij uitstraalt is een verademing.

De leden van de beoordelingscommissie dank ik voor hun bereidheid het proefschrift kritisch te lezen en te beoordelen.

Uiteraard wil ik alle medeauteurs danken voor hun correcties en adviezen.

Alle stafleden, artsen, (functie)verpleegkundigen, secretariële medewerkers en overige medewerkers van de afdeling maag-, darm- en leverziekten van zowel het Leids Universitair Medisch Centrum als het Maastricht Universitair Medisch Centrum wil ik bedanken voor hun behulpzaamheid in de afgelopen jaren.

Alle laboranten van de afdeling radiologie van het Leids Universitair Medisch Centrum wil ik danken voor hun hulp bij het aanleren van de praktische vaardigheden noodzakelijk voor het bedienen van een MRI scanner, zodat er op een veilige manier fraaie plaatjes gemaakt konden worden.

Een aantal (oud)medewerkers van het LKEB wil ik in het bijzonder noemen: Hans, Faiza, Roald en Rob. Bedankt voor de tijd die jullie hebben gestoken in het aanpassen van de software die gebruikt is voor de studies beschreven in dit proefschrift.

Veel hulp heb ik in de afgelopen jaren gehad van geneeskunde studenten die met name bij de praktische uitvoering van de studies een belangrijke rol hebben gespeeld: Chun Yu, Dionne, Hanneke, Noortje, Peter en Paul.

De vele (arts)onderzoekers met wie ik in de afgelopen jaren heb mogen samenwerken in Leiden (Andrea, Eduard, Ingrid, Patrick, Pieter, Thomas en Wouter) en Maastricht (Annemieke, Andrea, Carolina, Daniel, Daisy, Eveline, Freddy, Karen, 
Henrike, Samefko en Steven). Gezelligheid, vliegreizen, hotelverblijven en zo nu en dan wetenschappelijke input.

Mijn ouders, lieve mam en pap, wil ik bedanken voor hun onvoorwaardelijke steun. Jullie hebben de basis gelegd voor mijn persoonlijkheid die mij ver heeft gebracht, maar mij ook nog regelmatig tegenwerkt. Ik hou ontzettend veel van jullie en hoop dat we nog kunnen genieten van de tijd die ons samen rest.

Mirjam, je bent nu al 10 jaar met me samen en dat is al een ongelooflijke prestatie. Ik hoop dat er nog vele decennia volgen samen met Tijme en Veere. Je hebt me voluit gesteund in de moeilijke keuze die ik dit jaar gemaakt heb. Zonder die steun was dit eenvoudigweg niet mogelijk geweest. Ik denk dat ik namens ons beiden spreek als ik zeg dat het goed is dat het proefschrift afgerond is. Ik hou van je en je bent de enige in mijn leven bij wie ik zonder zorgen helemaal mezelf kan zijn. 
Curriculum vitae 


\section{Curriculum vitae}

Jeoffrey Josephus Leonardus Haans werd geboren op 13 december 1973 te Goirle. In 1992 behaalde hij het VWO diploma aan het Theresia Lyceum te Tilburg. In datzelfde jaar begon hij met de opleiding geneeskunde aan de Katholieke Universiteit Leuven. In 1993 zette hij de opleiding geneeskunde voort aan de Universiteit Leiden, waar hij in 2003 het artsexamen behaalde. Aansluitend startte hij als arts-onderzoeker bij de afdeling maag-, darm- en leverziekten van het Leids Universitair Medisch Centrum het promotie-traject (promotores: prof. dr. A.A.M. Masclee en prof. dr. A. de Roos) dat uiteindelijk zou leiden tot dit proefschrift. In 2006 werd de overstap gemaakt naar het Maastricht Universitair Medisch Centrum, waar de auteur verantwoordelijk was voor de modernisering van de functieafdeling maag-, darm- en leverziekten. In december 2007 startte hij in het kader van de opleiding tot maag-, darm- en leverarts, met de vooropleiding interne geneeskunde in het Maastricht Universitair Medisch Centrum (opleider: prof. dr. C.D.A. Stehouwer). In december 2009 startte hij met de vervolgopleiding maag-, darm- en leverziekten in het Atrium Medisch

Centrum Parkstad (opleider: dr. J. Goedhard). Vanaf april 2011 werd de opleiding gecontinueerd in het Maastricht Universitair Medisch Centrum (opleider: prof. dr. A.A.M. Masclee). In april 2012 besloot hij de opleiding tot maag-, darm- en leverarts voortijdig te beëindigen. In september 2012 zal hij beginnen met de opleiding Technische Informatica aan de Technische Universiteit Eindhoven. Hij heeft sinds 2001 een relatie met Mirjam Willemsen, zij hebben samen twee kinderen: Tijme en Veere. 
List of publications 


\section{List of publications}

Haans JJL, Masclee AAM. Intragastric acidification inhibits motilin-induced phase III activity in humans. Neurogastroenterology and motility 2006;18:637-46.

Haans JJL, Masclee AAM. MRI of the stomach in neurogastroenterology. Neurogastroenterology and motility 2006;18:1041.

de Zwart IM, Haans JJL, Verbeek P, Eilers PHC, de Roos A, Masclee AAM. Gastric accommodation and motility are influenced by the barostat device: Assessment with Magnetic Resonance Imaging. American Journal of Physiology Gastrointestinal and Liver Physiology 2007;292:G208-G14.

Haans JJL, Masclee AAM. Review article: The diagnosis and management of gastroparesis. Alimentary pharmacology \& therapeutics 2007;26 Suppl 2:37-46.

Haans JJL, de Zwart IM, Eilers PHC, Reiber JH, Doornbos J, de Roos A, Masclee AAM. Gastric volume changes in response to a meal: Validation of Magnetic Resonance Imaging versus the barostat. Journal of magnetic resonance imaging: JMRI 2011;34:685-90. 
